February 2005 - NREL/TP-710-37678

\title{
DOE/NREL Inner Mongolia PV/Wind Hybrid Systems Pilot Project: A Post-Installation Assessment
}

\author{
K.K. Stroup
}

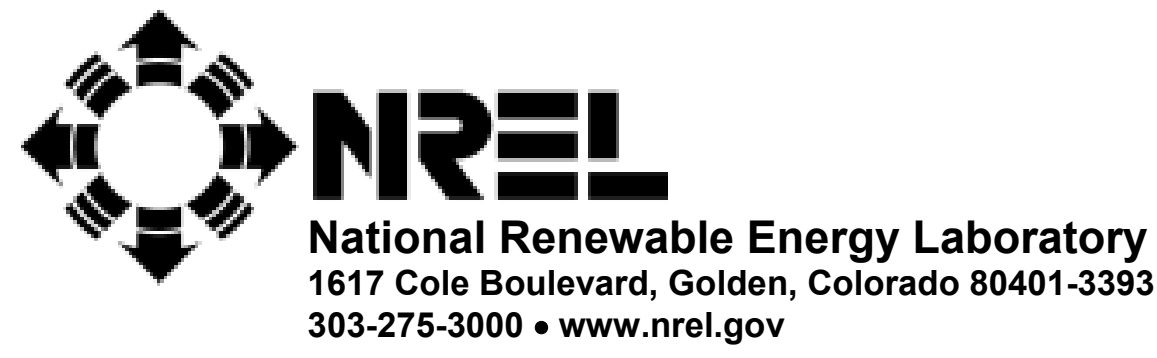

Operated for the U.S. Department of Energy Office of Energy Efficiency and Renewable Energy by Midwest Research Institute • Battelle 
February 2005 • NREL/TP-710-37678

\section{DOE/NREL Inner Mongolia PV/Wind Hybrid Systems Pilot Project: A Post-Installation Assessment}

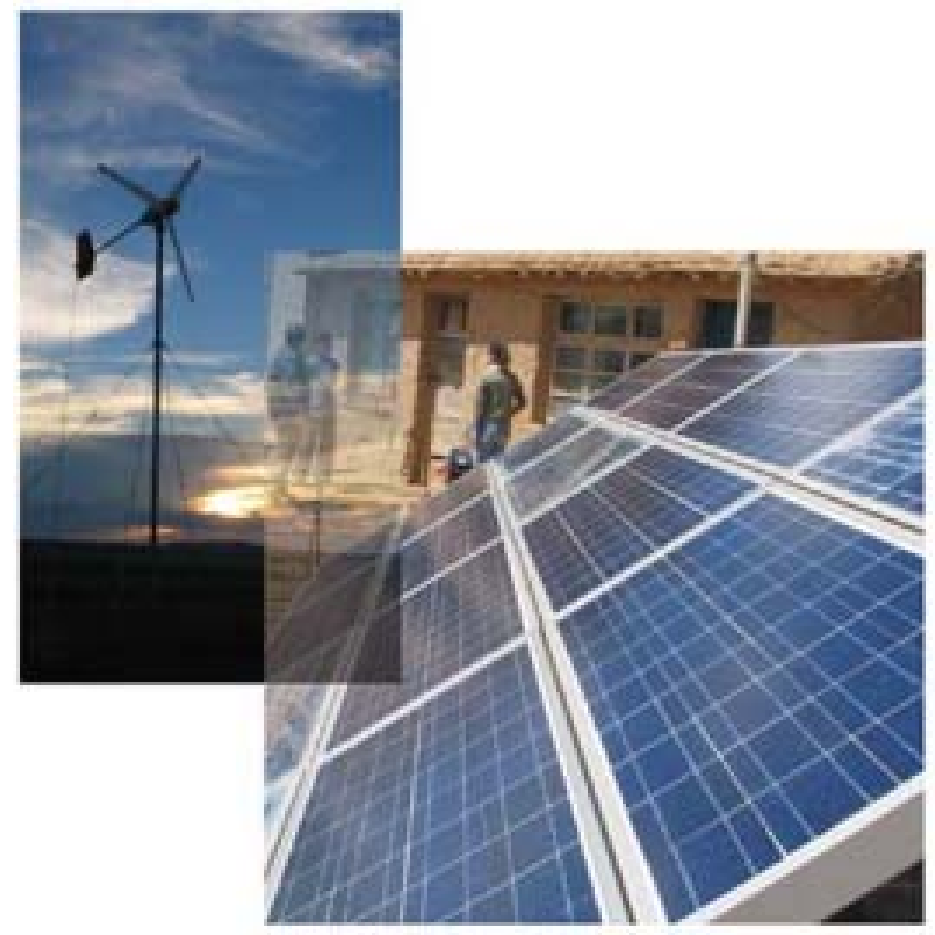

\section{K.K. Stroup}

Prepared under Task No. IGIN.5300
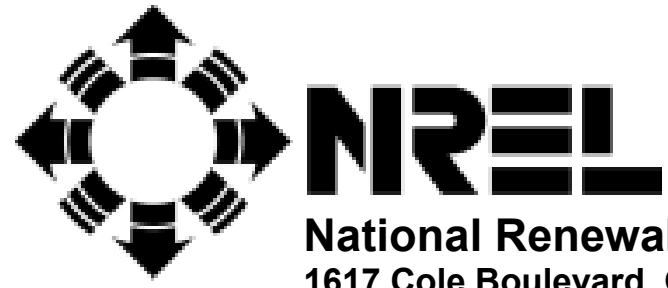

National Renewable Energy Laboratory 1617 Cole Boulevard, Golden, Colorado 80401-3393 303-275-3000 • www.nrel.gov

Operated for the U.S. Department of Energy Office of Energy Efficiency and Renewable Energy by Midwest Research Institute • Battelle Contract No. DE-AC36-99-GO10337 


\section{NOTICE}

This report was prepared as an account of work sponsored by an agency of the United States government. Neither the United States government nor any agency thereof, nor any of their employees, makes any warranty, express or implied, or assumes any legal liability or responsibility for the accuracy, completeness, or usefulness of any information, apparatus, product, or process disclosed, or represents that its use would not infringe privately owned rights. Reference herein to any specific commercial product, process, or service by trade name, trademark, manufacturer, or otherwise does not necessarily constitute or imply its endorsement, recommendation, or favoring by the United States government or any agency thereof. The views and opinions of authors expressed herein do not necessarily state or reflect those of the United States government or any agency thereof.

Available electronically at http://www.osti.gov/bridge

Available for a processing fee to U.S. Department of Energy and its contractors, in paper, from:

U.S. Department of Energy

Office of Scientific and Technical Information

P.O. Box 62

Oak Ridge, TN 37831-0062

phone: 865.576.8401

fax: 865.576.5728

email: mailto:reports@adonis.osti.gov

Available for sale to the public, in paper, from:

U.S. Department of Commerce

National Technical Information Service

5285 Port Royal Road

Springfield, VA 22161

phone: 800.553 .6847

fax: 703.605.6900

email: orders@ntis.fedworld.gov

online ordering: http://www.ntis.gov/ordering.htm 


\section{Preface}

I, Kristin K. Stroup, am both the sole author of this report and the Principal Investigator (PI) of the research that it details. Throughout the report, I refer to myself as the PI, if at all. However, I am responsible for all fieldwork and interpretation - the study protocol, the interview questions, and all data collection, including the interviews and field notes.

Nonetheless, I am profoundly indebted to many people for facilitating this work. Field research, no matter the sort, is never a one-person operation. The expertise of colleagues at NREL and diverse authorities in renewable energy and international project development - both in the U.S. and in China - provides the cadence to and inspiration for this work. The assistance of local experts in Inner Mongolia was crucial to daily research operations. None of the work would have been possible, however, without the cooperation of the people of the Inner Mongolian grasslands, on whom this report is focused and to whom it is dedicated.

\section{Acknowledgements}

I am indebted to the following people for their support and guidance throughout the research and writing process: Jean Ku and Debra Lew of NREL; Charlie Dou of Beijing Bergey Windpower; Frank Laird and Sally Hamilton of the Graduate School of International Studies, University of Denver.

For their instrumental support during field research, I am deeply thankful to Liu Zhizhang, Dao $\mathrm{Ri} \mathrm{Na}$, Ming Jie, and Ma Tao of the Inner Mongolia Polytechnic University in Hohhot; Li Xiuguo of the Chinese Academy of Sciences; Zheng Rui of Huade New Technology Company in Hohhot; Yang Yi and Mr. Dong of the SiXu Brightness Program Company in Saihantala; Gao Xiuhe and Mr. Siqin of the Dongwu MOST; Wang Sangui, Chinese Academy of Agricultural Sciences; Pang Shu Qin, Hohhot MOST; Lucy Jing of Beijing Bergey Windpower.

For reading and improving the final version of the report, I am especially grateful to Barbara Farhar and Paul Gilman of NREL; William Wallace of the UNDP/GEF Renewable Energy Project in Beijing; John Byrne of the Center for Energy and Environmental Policy, University of Delaware; Bo Shen of the Delaware Division of the Public Advocate.

Of especial importance, I acknowledge the people of Inner Mongolia for their kindness in inviting me into their homes and allowing me a glimpse of their lives.

Finally, I thank NREL's International Program team for their friendship and support during my time at NREL. 


\section{Executive Summary}

\section{Background}

The U.S. Department of Energy (DOE) and its National Renewable Energy Laboratory (NREL) have been involved in China's sustainable development and energy diversification objectives since 1994. DOE formally entered into an agreement with the Chinese Ministry of Science and Technology (MOST) in February 1995. The Protocol for Cooperation in the Fields of Energy Efficiency and Renewable Energy Technology Development and Utilization supports the advancement of sustainable development and renewable energy and energy efficient technologies in order to help meet China's environmental and rural electrification goals. Under Annex I of the Protocol (rural energy development), the Inner Mongolia Household PV/Wind Hybrid Systems Pilot Project was developed to demonstrate the technical and economic effectiveness of off-grid renewable energy technologies for China's rural populations.

Rural electrification initiatives in China are increasingly focused on off-grid and mini-grid applications, since much of the country's rural population is characterized by a dispersed settlement pattern or is located far from an urban grid; renewable energy technologies, such as those that utilize the sun and wind, have proved more economical and practical than traditional solutions like diesel-powered generator and battery sets (gen-sets). Off-grid electricity generally serves only one load, such as a household or rural restaurant, while a mini-grid system serves a remote village; a grid system generates power for an entire region. The electricity needs of China's rural population are relatively low and are thus well served by off- or mini-grid renewable energy systems. In rural Inner Mongolia, the primary use of household electricity is for appliances such as lights, televisions, and refrigerators; and for communication via satellite telephone.

The objective of the Inner Mongolia Pilot Project was to disseminate wind-solar hybrid systems ${ }^{1}$ to a rural and remote population in order to demonstrate their performance advantages over wind-only systems or diesel-powered gen-sets, and thus leverage future installations of such systems in the province. Over 400 single-household wind-solar hybrid systems were installed in six counties of Inner Mongolia between 1996 and 2001. Since that time, as many as 8,000 additional single-household hybrid systems have been installed as a result of the Pilot Project, which served to demonstrate that hybrid systems are indeed practically and technically well suited to meet the needs of the population. However, demonstrating that the renewable energybased hybrid power system is technically feasible is only part of the value of a pilot project. Understanding how the technology fits in with the socioeconomic context of a rural community is critical to ensuring the sustainability of rural energy projects. Toward this end, the underlying objective of the pilot project was to raise the quality of life of the project population. It is concern for the latter that motivated this post-installation study.

\footnotetext{
${ }^{1}$ A hybrid power system is one that combines two or more energy conversion devices (in this case, a PV panel and wind turbine) or two or more fuels for the same device, that when integrated, overcome limitations inherent in either. For a diagram, see Figure 1, page 11).
} 


\section{Objective}

Electrification by off-grid renewable energy systems constitutes an area of analysis that has been little explored in detail. The general objective of this study was therefore to contribute a broader understanding of the impacts to be expected from stand-alone household-scale renewable energy systems in the rural context. Specifically, the study had three objectives: (1) to assess the overall project outcome; (2) to evaluate the technical performance of the systems; (3) to document the social and economic effects of the project. The study was formulated on the premise that the long-term benefits of access to an improved energy source (one that provides high quality lighting and near 24-hour power) outweigh the initial cost; specifically, such access should facilitate higher human development in terms of self-empowerment and freedom from poverty; an improved quality of life; and higher levels of income, education, health, and productivity.

\section{Methods}

Fieldwork was conducted during the month of August 2004 in three counties of central Inner Mongolia: Suniteyou, Dongwuzhumuqin, and Siziwang. The method of investigation was the qualitative in-depth focused interview - an unstructured interview which allows for a holistic understanding of the respondent's viewpoint and situation while eliciting specific information. Interviews were conducted among 109 respondents in 37 households that employed hybrid windsolar household systems for electricity, the majority of which (84\%) were installed under the Pilot Project. The household interview sample was purposively selected from the 404 households that received Pilot Project systems between 1996 and 2001; however, six families were included from non-DOE projects and these represented the population of about 8,000 households using hybrid systems in the province today. Interview topics fell into four categories: the hybrid system, household demographics, daily activities, and quality of life (standard of living, education, productivity, and subjective wellbeing). Interviews were also conducted with Central and provincial Government officials and technicians who were involved in project planning, installation and maintenance of the systems.

\section{Results}

Almost half (49\%) of the systems surveyed were in good condition, fully operational after three to eight years (depending on date of installation). About a third (35\%) experienced periodic failures, and $16 \%$ were in poor condition. Main issues included poor manufacturing quality of the inverter and inadequate end-user education. Detailed information on system configuration and performance is available on pages $42-7$.

Overall, the hybrid system was found to have a significant effect on daily routine of the household, owing to the convenience provided by modern appliances such as the washing machine and electric cooking fan (a small appliance that "fans" and maintains the oven fire-a task previously accomplished by hand). Information regarding appliance ownership and daily activities is found on pages 48-51 and 55-7, respectively. Social effects were largely concentrated on television viewing by all members of the household, which provided indirect productive use applications and also led to an increased incentive for educational achievement on the part of the youth. 
A productive use is defined as any activity that leads, directly or indirectly, to generation of income. Examples of direct productive uses include refrigeration of dairy products for sale and irrigation systems for agricultural development; indirect productive uses can be found in activities that build on non-financial assets, such as education, which lead to higher returns in financial capital. This study will present findings that indicate TV viewing provides opportunities for learning and may also increase the desire of youth to achieve academically, in order to gain access to the outside world. In this way, TV may indirectly build the human capital of grassland residents. In fact, the enrollment in colleges, universities and professional schools in Inner Mongolia increased 224\% between 1995 and 2002. Though this statistic applies to the entire province and is the result of many factors both urban and rural, this report will show that electricity use and educational achievement are positively correlated.

The satellite telephone has also served as an indirect productive use and is an important factor in the improved quality of life of study respondents - it has increased the ease of business transactions and facilitates more social interaction within the grassland community. Direct productive use potential among this population is limited by the nature of the pastoral economy, as income is garnered by sale of wool and meat; herdsmen find that accomplishing shearing and slaughtering tasks are most efficiently done by hand. However, indirect applications - such as when television programs inform herdsmen of market prices for wool, enabling them to determine the optimum time to sell—remain significant, especially in regard to access to information and communication. Details are available on pages 51-55.

\section{Conclusion}

Though off-grid renewable energy technologies allow for simultaneous achievement of sustainable development ${ }^{2}$ and environmental responsibility objectives, lack of post-installation support severely limits the sustainability of projects. The assessment detailed in this report allows for valuable lessons learned, especially in regard to project oversight and long-term planning. In particular, to guarantee the sustainability of rural electrification projects, it is imperative that a mechanism for project ownership be established to assign accountability for system upkeep. In addition, strategies for end-user education should be improved. Further, there is a need for improvement in regard to the manufacturing quality of Chinese power system components - the inverter and controller. Finally, the objectives of renewable energy development must include a holistic view of long-term impacts, especially in regard to accurately understanding the needs of the target population.

This study points to the need for qualitative research in the renewable energy literatureexpressing the social and environmental factors that are not easily quantified or placed neatly into a formula. The true indicator of success for development projects, even if they begin as technical endeavors, is whether and how the project functions within the society, long after the planners have packed up and gone home. Ultimately, the Inner Mongolia Pilot Project has achieved its objective; as this report will show, the rural population has benefited in many respects from the use of renewable energy technologies. Indeed, renewable energy has become an integral part of the grassland landscape.

\footnotetext{
${ }^{2}$ A widely held definition of sustainable development is economic growth that meets the needs of the present without compromising the ability of future generations to meet their own needs.
} 


\section{Abbreviations and acronyms}

$\begin{array}{ll}\text { Ah } & \text { Amp hour(s) } \\ \text { AC } & \text { Alternating Current } \\ \text { CAS } & \text { Chinese Academy of Sciences } \\ \text { CEEP } & \text { Center for Energy and Environmental Policy, University of Delaware } \\ \text { DC } & \text { Direct Current } \\ \text { DOE } & \text { United States Department of Energy } \\ \text { GDP } & \text { Gross Domestic Product } \\ \text { GW } & \text { Gigawatt(s) } \\ \text { HDI } & \text { Human Development Index } \\ \text { IMAR } & \text { Inner Mongolia Autonomous Region (referred to simply as Inner Mongolia) } \\ \text { IMPU } & \text { Inner Mongolia Polytechnic University } \\ \text { kW } & \text { Kilowatt(s) } \\ \text { kWh } & \text { Kilowatt hour(s) } \\ \text { MOA } & \text { Ministry of Agriculture of the People's Republic of China } \\ \text { MOST } & \text { Ministry of Science and Technology of the People's Republic of China } \\ \text { m/s } & \text { Meters per second } \\ \text { MW } & \text { Megawatt(s) } \\ \text { NDRC } & \text { National Development and Reform Commission } \\ \text { NPC } & \text { National People's Congress, People's Republic of China } \\ \text { NREL } & \text { National Renewable Energy Laboratory } \\ \text { PI } & \text { Principal Investigator (Kristin Stroup) } \\ \text { PPP } & \text { Purchasing Power Parity } \\ \text { PV } & \text { Photovoltaic } \\ \text { SDPC } & \text { State Development and Planning Commission } \\ \text { SHS } & \text { Solar Home System(s) } \\ \text { SUV } & \text { Sport Utility Vehicle } \\ \text { TV } & \text { Television } \\ \text { UN } & \text { United Nations } \\ \text { UNDP } & \text { United Nations Development Program } \\ \text { V } & \text { Volt(s) } \\ \text { W } & \text { Watt(s) } \\ \text { Wh } & \text { Watt hour(s) } \\ & \end{array}$




\section{Table of Contents}

INTRODUCTION

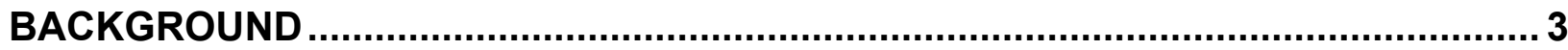

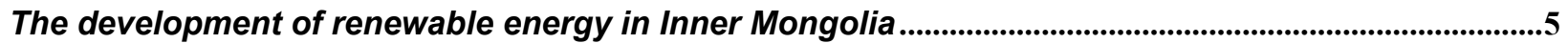

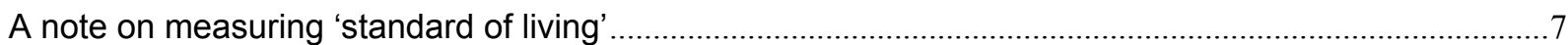

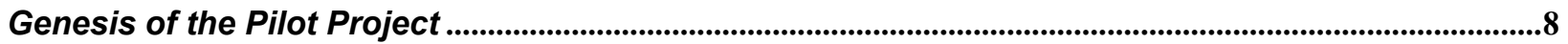

Figure 1. Configuration of a single-household hybrid renewable energy system. ......................................11

The role of the Chinese government

The case for renewable energy in China: a brief overview..................................................................................13

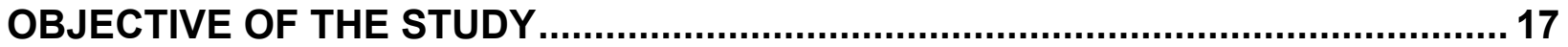

A REVIEW OF THE LITERATURE.................................................................... 19

The socioeconomic effects of rural electrification: overview.........................................................................19

Measuring human development and 'quality of life' .................................................................................25

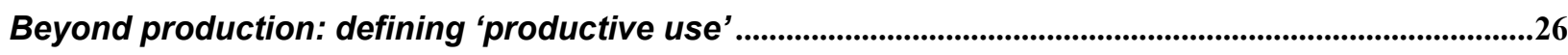

The role of television and broadcast media ..............................................................................................................28

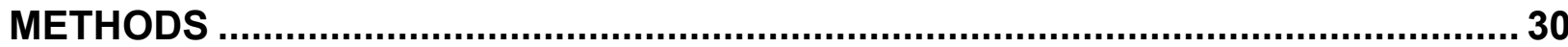

Figure 2. Map of central Inner Mongolia Autonomous Region........................................................... 31

Table 1. Distribution of households surveyed; projects under which systems were supplied. ........32

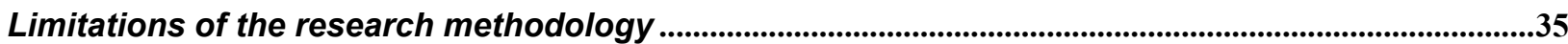

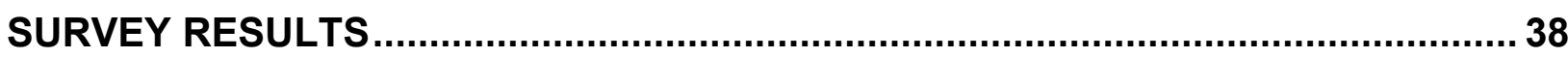

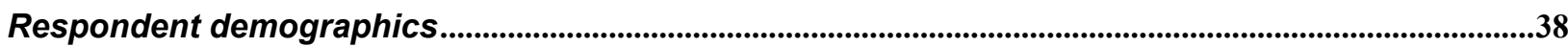

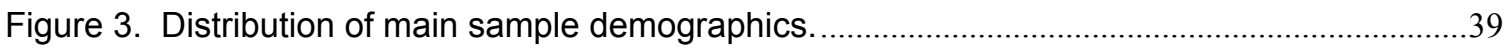

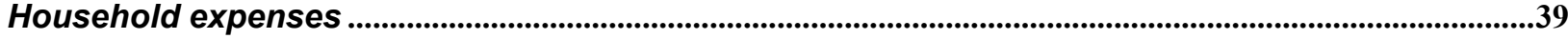

Table 2. Main expenses/use of disposable income cited by families. ...............................................40

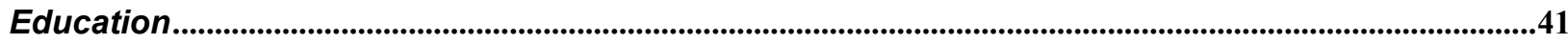

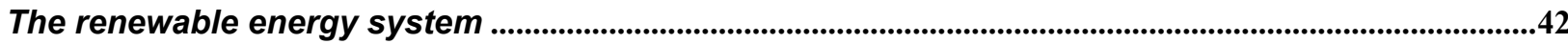

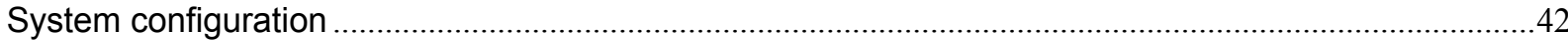

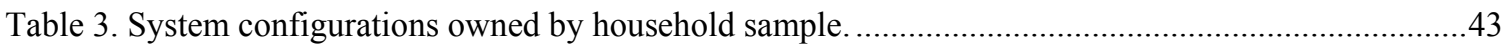

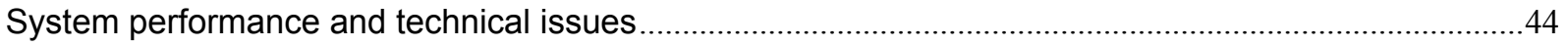

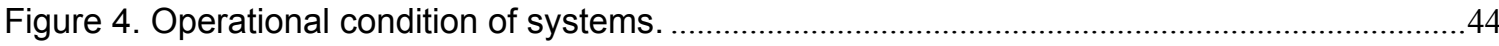

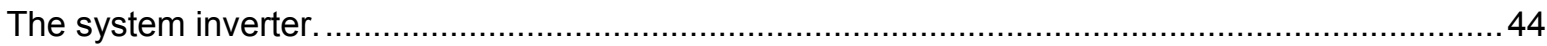

Table 4. Main problems households cited for poor system performance or failure...........................4

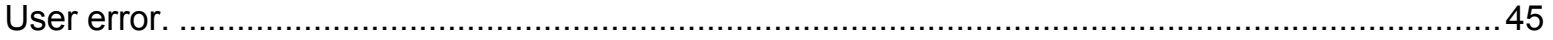

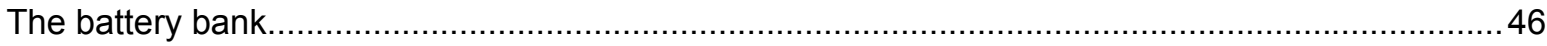

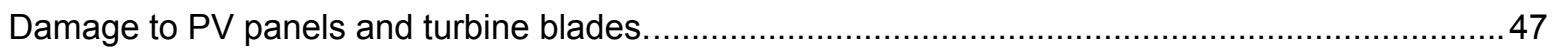

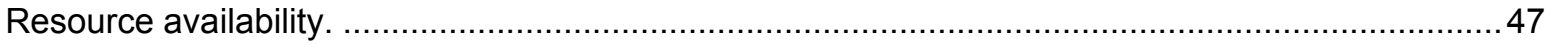




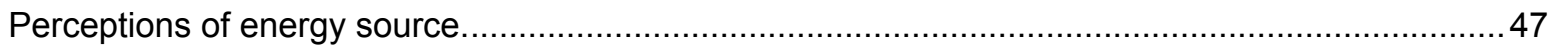

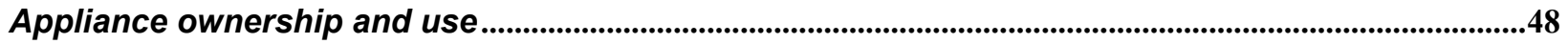

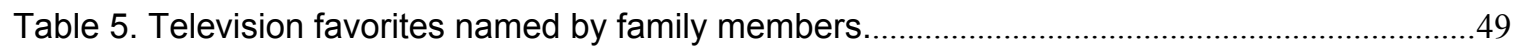

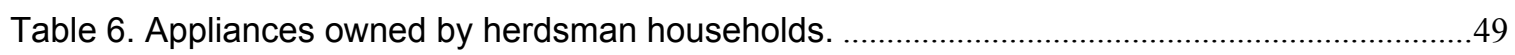

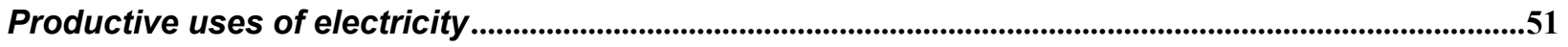

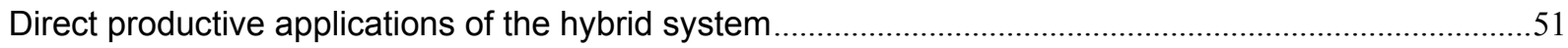

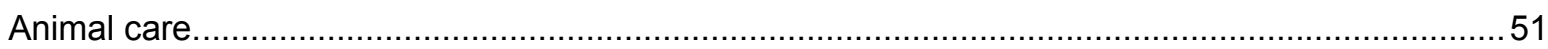

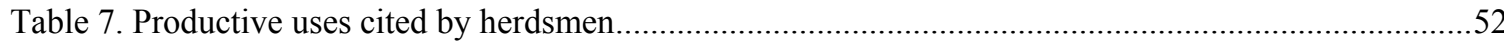

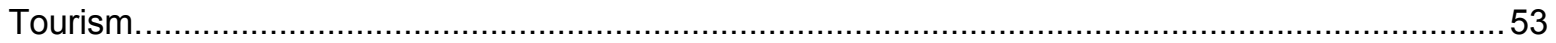

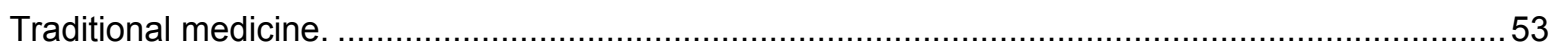

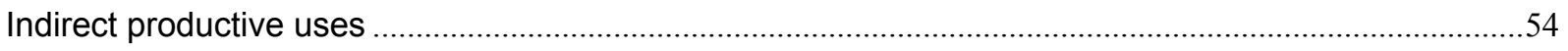

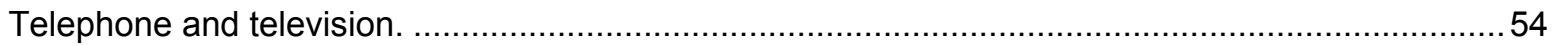

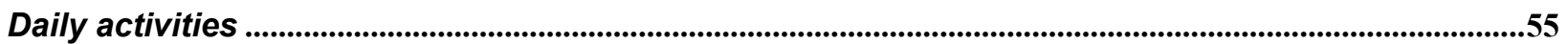

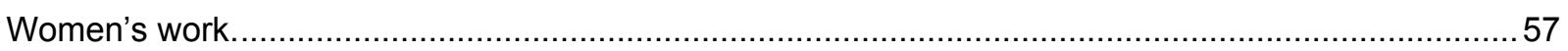

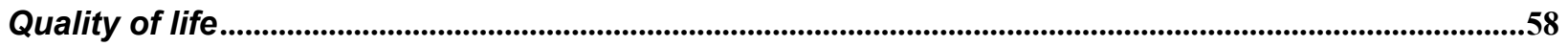

Electrification's impacts on the individual and society: A personal look...................................................60

Perception of renewable energy system maintenance costs ...................................................................67

Table 8. Average retail price of main appliances owned by households. ........................................68

Table 9. Average price of Chinese-manufactured hybrid system components................................68

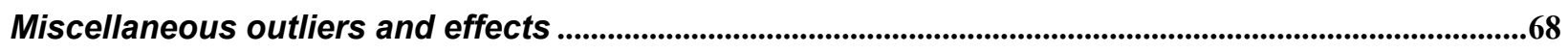

An unelectrified village: Xingmingxiang.................................................................................................................69

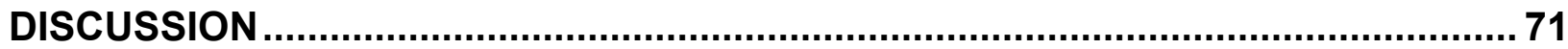

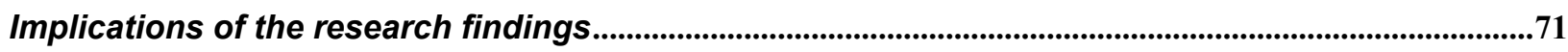

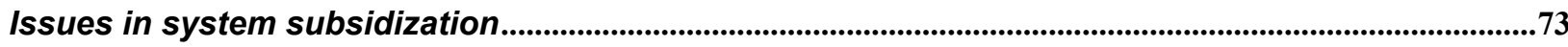

Table 10. System subsidy amounts as reported by herdsmen. ....................................................74

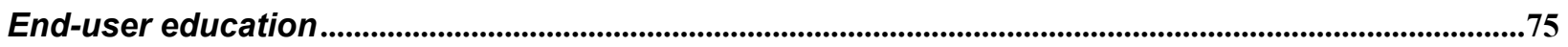

Issues in management of project funding and oversight ......................................................................................76

Recommendations for further study ................................................................................................................................77

The future of renewable energy for pastoral applications ......................................................................80

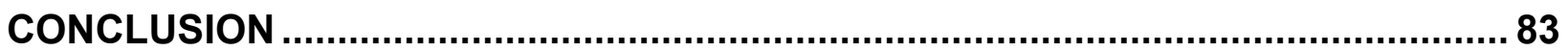

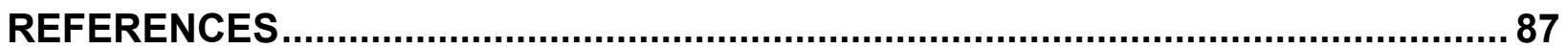

APPENDIX A. HOUSEHOLD INTERVIEW QUESTIONS........................................ 92

APPENDIX B. USER MANUAL_CHINESE VERSION ......................................... 94

APPENDIX C. USER MANUAL_ENGLISH TRANSLATION ................................. 108 


\section{Introduction}

Environmental responsibility and sustainable development ${ }^{3}$ have gained in currency over the last quarter century. Worldwide, there is growing awareness of the consequences of climate disturbance and the tenuous future of fossil fuel utilization. It too often seems, however, that an inherent conflict exists between the need for economic growth and the imperative of resource conservation. In a world where 21 percent of the population lives in extreme poverty-less than US\$1 a day (World Bank 2004)_economic growth naturally takes precedence.

Renewable energy offers a rare exception to the growth-conservation paradox, and can be located at the nexus of sustainable development and environmental responsibility. Renewable energy offers a means of providing people with electricity at little or no expense to the environment, and by definition is that which comes from resources that are naturally occurring and inexhaustible, such as the wind and sun. Access to energy also facilitates the provision of basic goods and services, such as healthcare, education, water, and sanitation. Increasingly, development strategies around the world combine the use of renewable energy technologies with objectives of poverty alleviation to raise the wellbeing of the world's poor, especially those in rural areas.

Approximately 40 percent of the population in developing countries does not have access to electricity (Martinot et al 2002); this translates to a quarter of the world population. In rural areas worldwide, the need is even more acute - about 70\% are unelectrified. The majority of this unelectrified population is found in rural areas of South Asia, East Asia, and Africa. Those without access to electricity lack the ability to refrigerate medicine and food, pursue productive activities after sundown (such as studying or producing income-generating crafts), and ultimately, rise out of poverty. The combination of poverty and an environmentally compromised resource base results in a vicious cycle that is often overlooked by traditional development policies. With renewable energy, electrification and poverty alleviation are seen as two sides of the same coin.

Biomass is the energy source most relied upon by the world's rural poor-in some developing countries, as much as 90\% of the energy supply comes from biomass (Martinot et al 2002). Globally, more than half of the world's households use wood, untreated coal, crop byproducts, or animal waste to cook and heat the home, which results in high levels of indoor pollutants as well as outdoor air pollutants. The World Bank estimates that $4 \%$ of the global burden of disease comes from indoor air pollution, with women and children at highest risk. Deforestation is another result of the reliance on wood for energy, and can lead to soil erosion and desertification, silting of lakes and rivers, reduced precipitation, and increased atmospheric $\mathrm{CO}_{2}$ concentration. Growing evidence suggests that the costs of using "traditional" energy sources, be they biomass or fossil fuels, are significant.

\footnotetext{
${ }^{3}$ A widely held definition of sustainable development is economic growth that meets the needs of the present generation without compromising the ability of future generations to meet their own needs.
} 
Rural electrification based on grid extension is often impractical. Rural areas of developing countries are characterized by a low population density or dispersed settlement pattern, and small-scale agricultural or pastoral industry. Running power lines over long distances and between isolated households is costly, especially when the main electrical grid of the nearest urban area is relatively distant to begin with. The cost of extension cannot reasonably be borne by the rural population - even the tariff paid by urban residential customers for grid service, which is government-subsidized, is often beyond the means of the rural poor.

Further, the electricity needs of such rural populations are relatively low. Satisfying basic needs includes home and community lighting, and communication tools for access to information through radio, telephone, and television. Less basic but nevertheless important needs include refrigeration for meat, produce, and medicine, and access to other commodities that facilitate decreased labor input, such as water pumps or washing machines. Commercial applications, where the market exists, still represent a relatively light load and are found in the form of retail stores, cottage industry, and small-scale agricultural tools. It is often most practical to supply energy to rural areas using mini-grid systems designed for a relatively small load or singlehousehold off-grid systems for remote households with a lower load still. Such configurations can be provided much more economically and practically than grid extension. Studies have shown that using renewable energy for mini-grid and off-grid systems is more economical still than using diesel or gasoline-powered gen-sets (Byrne et al 1996, 2001).

Economic growth and human development are interconnected and yet distinct processes; electrification by off-grid renewable energy represents only a step on the path. But it is an important one, and it can be achieved at a lower cost—economically and environmentally - than access to traditional fuels and grid connection. This report documents the course of one such project in the Inner Mongolia Autonomous Region (IMAR - hereafter referred to as Inner Mongolia) of China, which utilized hybrid wind-solar systems to electrify rural households between 1996 and 2001. The study is based on household survey work completed during August 2004 that included a technical review, project assessment, and documentation of demographic, economic, and quality of life variables. The analysis will shed light on the post-installation performance of household-scale renewable energy systems in the rural context. In addition, it will address the intersection of rural electrification and modernization - the ways in which economic, political, and environmental forces have shaped and continue to influence the daily reality of a rural society. 


\section{Background}

The Inner Mongolia Autonomous Region ${ }^{4}$ is located along China's northern border with Mongolia. It is traversed by the Yellow River and a good portion of the Gobi Desert, and is situated in the temperate monsoon climatic region, which is characterized by an arid and semiarid grassland ecosystem. Most of Inner and Outer Mongolia sits around 1,000 meters above sea level, and with low average rainfall, it is poorly suited for agriculture. Its total area covers $1,183,000$ square kilometers, which equals approximately one-eighth of China's entire land area (see Figure 2 inset, page 31); its population in 2002 numbered 23,785,900 people, less than 2\% of China's total. Slightly more than $60 \%$ of the province's population lives in rural areas, and grassland covers about 73\% (IMARBS 2003). Much of this area is sparsely populated, with households located at an average distance of two to five kilometers from one another, and almost all of the grassland area is used for animal grazing and supporting the pastoral lifestyle. The climate is characterized by warm, dry summers and very cold and dry winters. Winds in the province can be fierce and are steady from fall to spring (ecologically, Inner Mongolia is similar to the Great Plains of the United States), presenting an excellent opportunity for wind power development.

Though the province is named for the ethnic Mongolians who, by way of Genghis Khan, have a long history of influence in China, in reality Mongolians make up a tiny minority of the province. In 2002 ethnic Mongolians comprised only 17\% of Inner Mongolia; other minority nationalities 4\%, and Mandarin Han Chinese (the majority nationality of China) 79\%. Ethnic Mongolians are characterized by nomadic or semi-nomadic pastoralism dating back to antiquity. Today, they are characterized by settled pastoralism. Pastoralism is here defined as an economic practice of depending on the products of domestic animals, adapted to the ecology and scarce resource base of the grasslands. Nomadic pastoralism might be considered a sort of natural resource management system; however, as this report will indicate, today's settled variation is taxing the resource base of the grasslands. In any case, the most common definition of pastoralism in the development literature focuses on economics and states that pastoral production systems are those in which at least half of a household's income comes from livestock or livestock-related activities, and more than $15 \%$ of a household's food consists of milk or milk products produced by the household. Historically, pastoralism might be understood both as a mode of production and a mode of perception, for the role of livestock in the pastoral lifestyle is as much symbolic as practical (Swift 1998).

For purposes of simplicity, throughout this report ethnic Mongolian pastoralists of China will be referred to as herdsmen. Though use of 'herdsman' or 'herdsmen' would seem to refer only to male figures, the term is inclusive of each member of ethnic Mongolian pastoral society. The use of the term is chosen over an ethnic signifier because, as Khazanov has written, "pastoralism

\footnotetext{
${ }^{4}$ Autonomous Regions are provincial-level divisions distinguished by a designated ethnic minority; they have a chairman instead of a governor, and the chairman must be of the ethnic minority. They are not autonomous from the Central government as the name suggests. There are 55 distinct ethnic groups in China, and five Autonomous Regions. The Inner Mongolia Autonomous Region was established in 1947, the first of China's five such Regions, as a cooperation between Mongol communists and the Chinese Communist Party. At the time, Mongolians made up only $15 \%$ of the provincial population, compared to an $84 \%$ Han majority (IMARBS 2003). See Sneath 2000 or Bulag 2002 for an ethnic and political history of the province.
} 
is not only a way of making a living; it is also a way of living, dear to those who practice it" (Williams 1996, 665).

By virtue of the pastoral occupation, Inner Mongolian herdsmen earn a better living than most other rural residents of China (IMARBS 2003). This is due to the fact that sale of wool, and especially cashmere, is a much more profitable business than agricultural production. Indeed, half of the world's cashmere production comes from China and Inner Mongolia. Compared to China's western provinces (typically considered the country's most underdeveloped), Inner Mongolia is economically one of the best situated. For example, only 3.6\% of Inner Mongolia's population is without electricity, compared to $52.8 \%$ of Tibet (AEC 2002). However, Inner Mongolia's rural residents are still poor by Chinese standards.

Inner Mongolia consists of 12 major divisions: nine prefecture-level cities and three leagues. The nine prefecture-level cities are governed by the province; the leagues have greater autonomy under their own administrative government. Both prefecture-level cities and leagues are composed of counties, cities, towns, and farm- and/or pastureland. Prefecture-level cities and leagues comprise the second level of the administrative structure, under the province but above counties. The county level, third down, includes counties and banners; counties are found mainly in Han Chinese areas (there are 17) and banners in ethnic Mongolian areas (there are 52 banners). Each banner is further subdivided into sumus, which are equivalent to the Han county subdivision of township (xiang, in Chinese).

The areas of Inner Mongolia in which most herdsmen live fall under the league, banner, and sumu structure. Each banner, consisting of several sumus, has a town at its administrative center. Each sumu also has a central area consisting of at least an elementary school, a post office, health clinic, and government buildings. Most herdsman families live in brick houses in the pastureland surrounding the sumu centers, marry within the sumu, and remain within this territory. In most areas, each household pays a tax and pasture fee to the sumu's local government. Though the Communist Party retains control of the media, educational system, and provincial government, it is officially separate from the league- and county-level governments (Sneath 2000).

Most herdsmen live within a 1,000-2,000 square kilometer radius around the sumu center. Those who live at the far margins of this surrounding area can be quite removed from the goods and services provided at the center. Though road building has been a key part of China's recent modernization and poverty alleviation programs in rural areas, the vast majority of Inner Mongolian households are not reachable by paved roads; though there are often dirt roads or worn paths, sometimes driving across the pastureland and skirting fences is the only way to reach a household. Much of the province is characterized by an extremely flat and monotonous landscape, making it very difficult to navigate in the absence of roads and local knowledge. In fact, some areas of the grassland are so remote from sumu centers that few government officials know the location of the households there.

Though ethnic Mongolians were traditionally nomadic, sedentarization of Inner Mongolia began soon after Mao Zedong's establishment of the People's Republic in 1949-following the Russian model, the Chinese state began to collectivize the population of Inner Mongolia (as well as the 
rest of China) and sought to transform the nomadic culture to the Chinese model of modernity. Mao's agenda, including the Great Leap Forward and the Cultural Revolution, persisted until 1978, when Deng Xiaoping gained power and decollectivization (land reform) began. Land was divided up and legally contracted to individual families under ownership of the state. It was this establishment of assigned property that secured the settlement of the pastoral population (Sneath 2000).

The local government remains in control of pastoral life in several ways. The Chinese Rangeland Law of 1985 stipulates that all grazing land is state property and that the local government maintains control over its use and assigns it to individuals. Permission of the local government must be secured before even dead trees can be cut down, and households will retain their land only as long as they fulfill certain obligations and obey various regulations. In addition, households must obtain a residence permit to move, as Chinese residence policy ties people to the place they were born. Almost all of the pasture and agricultural land has been allocated to individual households or groups of households; there are very few common lands (Sneath 2000).

Other policies have been put in place to halt the destruction of the grassland resource. In recent years, the local government has imposed a limit on the number of livestock that can be grazed on each $m u$ of grassland (according to local officials, the government allows one sheep per each 42 $m u$ of land in most areas, which is equal to about 2.3 hectares or 6.9 acres (Yang, personal interview, 2004); however, some herdsmen stated the limit was different-one sheep per $30 \mathrm{mu}$ ). In addition, the local government has fenced off portions of the grassland for emergencies such as severe drought; livestock is prohibited from grazing in these areas, which means that the permissible pastureland is more heavily abused.

\section{The development of renewable energy in Inner Mongolia}

Because Inner Mongolia is primarily rural, with households dispersed far from urban centers and often at great distance from one another, extending the electrical grid to individual households was never an option. Thus experts and officials in China and Inner Mongolia took note when Western countries began to research and utilize renewable energy in the 1970s. Chinese research groups established laboratories in Inner Mongolia and later, a mechanical factory, which began to manufacture 50-watt and 100-watt wind turbines, setting up demonstrations in urban areas. The government took interest and began pilot projects to test wind turbines on local herdsmen. The herdsmen who were involved in these pilot projects were more than enthusiastic; the word spread rapidly, and because many families immediately bought DC-powered ${ }^{5} \mathrm{TVs}$, the demand for wind turbines was immense. In 1980, the Inner Mongolia branch of the Central government department known today as the Ministry of Science and Technology (MOST; formerly named the State Science and Technology Commission) declared renewable energy a priority, and set

\footnotetext{
${ }^{5}$ Small wind machines, PV panels, generators, and batteries produce electricity in direct-current (DC) form, which cannot be used to power most household appliances. Alternating-current (AC) electricity is better for supplying electricity than DC, primarily because the voltages can be transformed. Inverters take the DC power supplied by a storage battery bank and electronically convert it to $\mathrm{AC}$ power for use in household appliances. In China, very few appliances (only small black and white TVs, radios, and low-voltage lights) are readily available that run on DC power, which makes use of the inverter necessary in household power systems.
} 
about putting programs and policies into place that would focus on technological development, pricing, technician training, and government support. In 1986, the provincial government began offering subsidies to herdsmen who wanted to buy a renewable (usually wind) energy system. The standard subsidy at the time was 200 Yuan per each 100 watts of capacity, or $10 \%$ of the typical system cost. With this incentive, distribution of turbines moved from small- to largescale. During the mid-1980s, small solar panels (20-50 watts) also began to be used, but to a much lesser extent (Gao, personal interview, 2004).

Government subsidies covered only a portion of the cost of renewable energy systems (10\%), and depended on the size of the system. If families could not afford to pay the majority of the cost, they were unable to obtain even a small system. Thus, from the beginning, electrification of rural Inner Mongolian households depended on financial ability more than government support. Nonetheless, by the 1990s, in pastoral areas like that surrounding Dongwu (see Figure 2 , page 31$)$, the vast majority of herdsman households $(80 \%)$ were utilizing household-scale renewable energy, mostly wind systems (Gao, personal interview, 2004). Though other counties lagged behind this number, it is widely held that by the time of project implementation, 140,000 small-scale renewable energy systems were in use throughout the province (however, the number does not account for systems retired over time). Most systems were of only 100 watts and provided basic lighting and power for small black and white TVs, but more than one-fourth of households enjoyed this service - at the time, there were about 440,000 households living in rural pastoral areas of the province. However, wind energy did not prove entirely satisfactory during summer months, when wind speed and consistency is much lower and is insufficient to power many appliances. Further, the type of battery used with small wind systems was not equipped for long periods of discharge, which shortens battery life significantly (Lew 2001).

By the 1990s, many families were beginning to feel that wind-only (or the occasional solar-only) systems were insufficient (Gao, personal interview, 2004); China was transitioning to a market economy and many new commodities were becoming popular while herdsman houses were becoming larger and more modern. By the 1990s, almost all herdsmen had built standard houses of mud and straw, and used gers (yurts, from the Russian-a domeshaped latticed wooden frame and felt covering that can be collapsed down easily for transport - pictured at right)

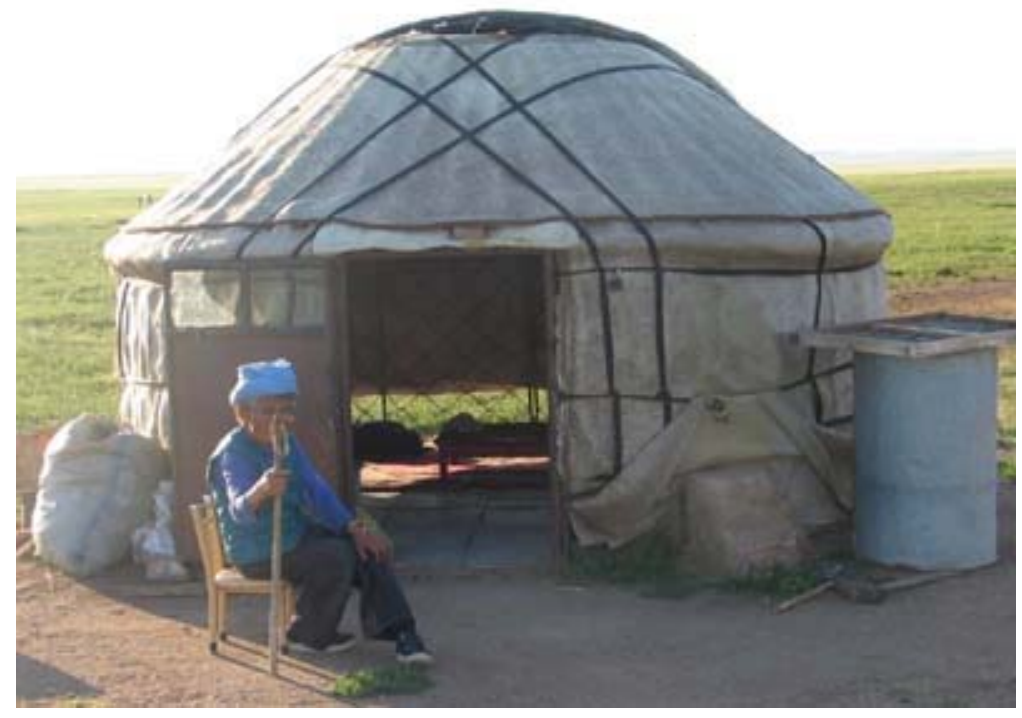
only in summer because they were cooler. By the millennium, the base standard of living had increased further, and many herdsmen have now built dwellings of brick with tiled floors, woodpaneled living rooms, and glass partitions. In these multi-room houses, families need five to six lights, and desire larger color TVs, washing machines, refrigerators, and entertainment consoles that may even include karaoke machines. Refrigerators have become especially important, for 
the distance some families live from the market means that access to fresh produce is sporadic. Still considered somewhat of a dietary outlier, fresh fruit in particular is highly valued by most families. Hybrid systems provide the solution to these basic needs, in addition to more power and reliability.

China's rapid transformation mirrored that of the herdsmen. For many years of China's modern era (1949-present), though they were no longer nomadic, herdsmen continued to live in gers; diesel fuel was considered a luxury, so most lived without electricity. Daily activities for the men consisted of herding the livestock, retrieving water for the household and livestock, maintaining animal enclosures, and shearing and slaughtering livestock. Women's activities included childcare, food and clothing preparation, milking the livestock, and maintaining the household. The primary diet consisted of meat (mainly mutton) and dairy products (fresh milk, butter, and dried curd), which they produced for themselves. Wheat products, such as noodles and fried dough twists, were included when available (Xu and Wang 1999). Slaughtered meat and fresh milk had to be consumed quickly or dried, to avoid wasting by spoiling. Typically, the household would rise at dawn and complete work by dusk. Though candles and the rare kerosene lantern were used on occasion, the evening meal was usually eaten before nightfall and bedtime followed soon after. Thus, the introduction of electricity to this lifestyle made for great changes in the standard of living - the structure of household work, diet, and entertainment.

\section{A note on measuring 'standard of living'}

It bears mentioning that a 'standard of living' can be highly subjective and thus ambiguous. Many economists rely on comparative per capita GDP to come up with a standard for comparison. The GDPs of different countries are converted to U.S. dollars but are standardized by adjusting for inflation and exchange rates and then valuing the currency on the "basket of goods" it will buy in its country of origin. This valuation is called purchasing power parity (PPP). Where the gap between the wealthiest and poorest is extreme, however, per capita GDP even in PPP can be misleading. For example, per capita GDP in 2001 US\$PPP in Shanghai was 18,634 , compared to $\$ 1,443$ in Guizhou, a southern province; yet China's overall per capita GDP in US\$PPP was 4,020 (UNDP China 2002).

Another way of comparing standards of living is using the Engel's coefficient, which is the standard used by the United Nations Food and Agriculture Organization. The Engel's coefficient measures the proportion of income that is spent on food and is based on the premise that as income increases, the proportion spent on food decreases; a lower figure reflects a higher standard of living. According to this measure, the standard of living of Inner Mongolian herdsmen has indeed improved. In 2002, they spent $34.1 \%$ of income on food, compared to $48.1 \%$ in 1995 (IMARBS 2003). By comparison, Beijing's Engel's coefficient for 2002 was $33.8 \%$, and western countries average about 20\% (China Daily 2003). It is important to note, however, that this measure is misleading in the case of pastoral populations. Inner Mongolian herdsmen produce the majority of the food they consume (meat and dairy products); that in 1995 they spent nearly half of their income on the small amount of grain and fresh produce they purchase would indeed indicate that they had relatively little disposable income. However, comparing the percentage spent by herdsmen with that of urban residents is indeed misleading, since urban residents must purchase all of the food they consume. In essence, neither method of 
quantifying a standard of living is wholly satisfactory-for this reason, qualitative valuations will be used in this report.

\section{Genesis of the Pilot Project}

The U.S. Department of Energy (DOE) and its National Renewable Energy Laboratory (NREL) have been involved in China's sustainable development and energy diversification objectives since 1994. DOE formally entered into an agreement with the Chinese Ministry of Science and Technology (MOST) in February 1995. The Protocol for Cooperation in the Fields of Energy Efficiency and Renewable Energy Technology Development and Utilization supports the advancement of sustainable development and renewable energy and energy efficient technologies in order to help meet China's environmental and rural electrification goals. Under Annex I of the Protocol (rural energy development), the Inner Mongolia Household PV/Wind Hybrid Systems Pilot Project was developed to demonstrate the technical and economic effectiveness of off-grid renewable energy technologies for China's rural populations. Of the projects under consideration at the time, installing hybrid wind-solar systems in rural Inner Mongolian households was determined to be the most cost-effective option and easiest to implement because of being an off-grid application; it met an existing need, and provided a good marketing opportunity for renewable energy.

The aim of the Inner Mongolia Pilot Project was to disseminate wind-solar-battery hybrid household systems to herdsmen in order to demonstrate the performance advantages of these systems over wind-only systems or traditional gen-sets, and thus leverage future installations of such systems in the province. However, the fundamental goal was to effect a higher standard of living for the project population. The idea for the Pilot Project came into being as early as 1993 and was a result of prior work on assessing the potential for renewable energy in China, done at the Center for Energy and Environmental Policy (CEEP) of the University of Delaware and at the Chinese Academy of Sciences (CAS) in Beijing. The U.S. Department of Energy consulted with China's State Development and Planning Commission (since renamed the National Development and Reform Commission), the Ministry of Science and Technology (MOST), the State Economic and Trade Commission (eliminated in Government restructuring in 2003), the Ministry of Agriculture (MOA), the Ministry of Electric Power (separated into various units during Government restructuring of the power sector in the late 1990s), and various members of China's state-owned utility corporations in forming the 1995 Protocol. The signing of the Protocol was instrumental in bringing the Pilot Project to fruition, as it provided a mechanism through which the project's goals could be met.

The lead U.S. coordinator and project leader for the Pilot Project under the DOE/MOST Protocol was William Wallace at NREL; Li Xiuguo at CAS was the key Chinese domestic advisor and logistical coordinator for the project. John Byrne and associates at CEEP led the key analysis for the U.S. side that served to establish technical system options and define project objectives. The project was implemented by MOST through Lin Li at the Inner Mongolia Science and Technology Branch in Hohhot. Liu Zhizhang of the Inner Mongolia Polytechnic University (IMPU) provided engineering and design support for Chinese system components as well as strategic support for the project. 
A key objective of the project was to create a good demonstration for the utilization of renewable energy, and an off-grid project seemed the most likely to succeed in this regard. On-grid and urban-based projects were deemed too risky in terms of investment and policy support. Because there were so many unelectrified rural households at the time, this project would also present the best marketing strategy. At the time, the Chinese government demonstrated an increasing interest in the utilization of wind and solar power for rural electrification.

Experts at CEEP, NREL, and CAS (hereafter referred to as the 'implementation team') conducted surveys and an extensive analysis of the average household load along with a resource assessment, and the research team assessed a range of system options designed to match the income levels of households: in the 150-200-watt low range; 250-350-watt medium range, and 400-500-watt high range. The high range provided sufficient energy to equate roughly to a developed country electrified home in terms of the modest energy efficient loads that could be supported (radio, color television, washing machine, freezer, etc.), but not heating or cooking loads.

The analysis took place within four counties of Inner Mongolia (three of which were the areas of focus for the present study). Estimation of household load and socioeconomic indicators was based on a survey of 41 herdsman households that relied on PV-only or wind-only systems; 40 that relied on gasoline or diesel gen-sets; and 40 that possessed no electricity. Most of these families consumed 300 Watt-hours (Wh) to $600 \mathrm{Wh}$ per day for lighting and radios or small black and white televisions. The introduction of a refrigerator brought daily consumption up to levels of 1.2 kilowatt-hours $(\mathrm{kWh})$ to $1.6 \mathrm{kWh}$, which are not supported by the popular domestic small wind turbines. Thus, with the projected increased energy demand, hybrids, larger wind turbines, or gen-sets would be required.

The resource assessment revealed that Inner Mongolia boasts the best wind resources in the entire country, and sufficient solar insolation is available to provide power $82 \%$ of the year $(\mathrm{Li}$, personal interview, 2004). Because these resources are complementary (wind is strongest during the winter when sun is weakest; sun is strongest during the summer, when wind is weakest), hybrid systems were found to meet the region's increasing energy demand at competitive and relatively stable costs - wind and wind-solar configurations are the least-cost options in comparison to conventional diesel gen-sets (Byrne et al 1998). In addition, the choice of the hybrid system and its design presented a solution to the major difficulties that had faced the 140,000 users of wind-only systems up until that point: short battery life due to long periods of discharge, and low output during summer months.

The implementation team decided on a minimum system size of 400-500 watts. The decision took into consideration not only the efficacy of wind-solar hybrid systems compared to traditional diesel gen-sets, but the financial ability and willingness to pay of the households. They found that hybrids carried the same levelized cost whether of small or larger capacity. However, field-testing revealed that the limited lifetime of domestic batteries increased the levelized system costs (includes equipment, balance of system, and operation and maintenance costs over the period of evaluation plus discounted costs of the system lifetime) by $14 \%$ to $108 \%$. Thus, adequately training herdsmen in system maintenance was anticipated to be extremely important (Byrne et al 1996; 1998). 
This early analysis work (Byrne et al 1996) demonstrated the viability of the wind-solar hybrid household system for the pastoral application and served to establish the design principles for the project, as well as to inform practical decisions as to where and how the project should be sited. Because China had begun transitioning to a market economy in the early 1990s, the implementation team decided that the systems should be provided to higher-income herdsman families based on the principles of demand and willingness to pay. In addition, targeting households that were part of the growing economy allowed for the possibility of establishing a national standard for off-grid household systems. Had the systems been designed for lowincome and low-demand households, the standard would have become outdated in a few years. Because Inner Mongolian herdsmen are better off than most of rural China, they represented the best population for the project.

Use of the wind-solar hybrid system was key to the project, since it solved the problems encountered in the wind-only systems already popular in the province. The implementation team found that herdsmen were interested in higher capacity renewable energy systems not only to meet daily household needs but also for productive activities such as water pumping and the use of electric shearers on sheep (Byrne et al 1998). This implied that electrification would serve a dual function of economic development and improved quality of life, and such justification sealed the deal for a larger-capacity system.

Families had to meet certain criteria to receive a hybrid system. The decision to design a highercapacity system in anticipation of herdsmen's long-term needs was controversial, as the estimated cost of the system was 10,000 Yuan (about US\$1200.00) including installation and two-year warranty — such an amount is beyond the means of most herdsmen. By concentrating on the top income level in the rural population (top 15\%), however, the implementation team felt that the project would have a better chance to be implemented on a sustainable basis, and the system owners would subsequently serve as pioneers to stimulate interest in the systems throughout the rural society. Also, at the time of project implementation, wool prices were up and many herdsmen were doing well financially; it was expected that their economic condition would continue to improve. Thus, the main criterion for families was that they be willing and able to pay for the system up front in cash, minus a government subsidy (structured as a price discount). This meant that the majority of project families fell within the middle- to upper-class range. In many aspects, this decision turned out to be well informed. Three to eight years (depending on date of installation) after the first systems were installed, herdsmen today desire even higher capacity. However, there are still families for whom hybrid systems remain out of financial reach.

The other main criterion for choosing project families was their location. It was important that they be located close to county or sumu centers where installation and maintenance service people were available, and where they were relatively close to a main road. The implementation team considered this important for two reasons: first, the relatively low level of education among herdsmen suggested that success of user education and training would be limited and therefore the need for maintenance frequent; second, the closer households were to a main road, the more easily they could be accessed by visiting government officials to demonstrate project success. 


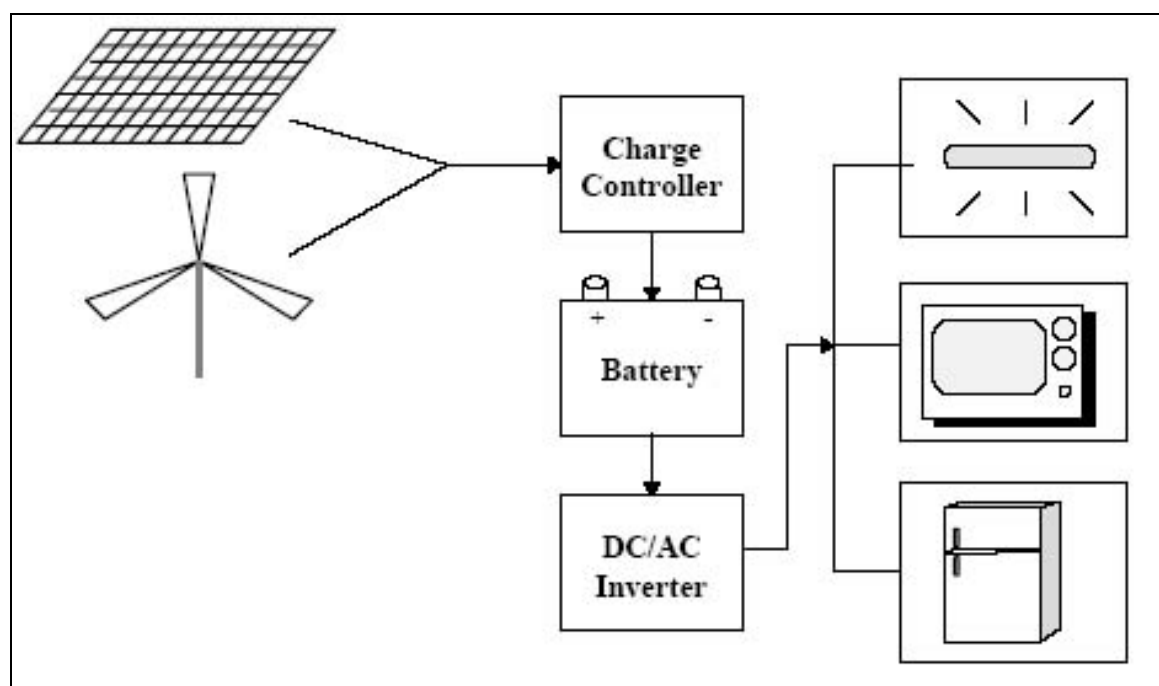

Figure 1. Configuration of a single-household hybrid renewable energy system. Source: Byrne et al 2001.

Standard system configuration consisted of a 300-watt wind turbine, a 100-200-watt PV panel, and a 500-600-watt inverter. The U.S. DOE provided U.S.-manufactured solar panels from Solarex and Siemens for use in the systems, and the Chinese-made inverters and batteries were tested at NREL's Golden laboratory, since the components were different from anything else then available on the Chinese market. Both Chinese and U.S. engineers contributed to the testing phase, and the systems performed well. The Chinese government agreed to provide a 3000-Yuan (US\$362.00) subsidy for each family installing a hybrid system, and also put up the capital for training installation and service teams. Originally, the project leaders intended to install 200 systems as part of the project. Because local demand was so great, 404 systems were installed in six different counties or banners of the province, between 1996 and 2001 (Li, personal interview, 2004).

\section{The role of the Chinese government}

The People's Republic of China was established in 1949 by Chairman Mao Zedong and was so named for the ideal that all power belongs to the people. In the government structure established under the People's Republic, the National People's Congress (NPC) retains the highest authority and is led by the Chinese Communist Party. China remains a socialist country in many respects - its economy is still governed largely by central planning as opposed to market mechanisms, and the political structure is also highly centralized and regulatory. All major economic and social welfare activities are carried out at the national level, and the country's development initiatives are generated and must be approved by the NPC. Though the Government retains considerable authority over economic development issues, this situation is rapidly changing, given recent Government restructuring and a strong emphasis on market-based economic reforms. Today, China's commercial sector is thriving and it has become a major force in the world economy. The strong interest in developing new technologies - both in the public and private sector-has proved beneficial for the advancement of renewable energy.

Much of the responsibility for formulating development programs, especially in regard to rural electrification and renewable energy utilization, falls to the newly renamed National 
Development and Reform Commission (NDRC; previously named the State Development and Planning Commission). The NDRC, a department of the State Council, is primarily responsible for regulation and planning of the economy, and for China's sustainable development strategy, which includes economic, social welfare, and environmental directives. Funding for China's renewable energy programs comes from the central government but is overseen primarily by the NDRC, MOST, and the MOA, with interests in several other government agencies.

Resource availability and marketing potential were important criteria in choosing the Pilot Project's location, but the key qualification was local government support. Inner Mongolia promised the best foundation in this regard as well. It is a near-universal truth that to accomplish any task, large or small, one must have a strong relationship with the people at the bottom levels of the authoritative structure, not just at the top. However, this is nowhere more true than in a centrally-planned government. In Chinese, guanxi means relationship; for Chinese government programs, guanxi constitutes a foundation. This is well illustrated by the Pilot Project, for which local government has provided a necessary base from the very beginning.

The Pilot Project, and indeed the history of renewable energy development in Inner Mongolia, was based on a model of decentralized power supply - in other words, off-grid electricity represents a form of distributed generation which the Chinese government has no means of regulating. Until the late 1990s, China's electricity supply and regulation were governed entirely by the central state; though the country is presently reforming its electricity industry to allow for price competition within the utility market, at the time of project implementation distributed generation conflicted with the model of central planning. Thus, support of the local government was especially crucial, since there was no paradigm for central oversight. In effect, off-grid electrification represented a bottom-up model of power supply, in contrast to the top-down structure of the Chinese state. As will be borne out in the Discussion section of this report (page 71), this paradigmatic change created some project challenges.

Within Inner Mongolia, the six counties that were chosen to receive hybrid systems not only represented areas of high demand for renewable energy systems but most importantly, enjoyed strong local government support. The provincial governments of China are the next step down from the central government, but local county or banner governments play a crucial role in the field. Each sumu has its own government administration as well, and it was the local MOST offices in these county and sumu centers that became the hub of installation and maintenance activities for the project. This arrangement was practical, since local MOST offices had been involved in demonstration and dissemination of renewable energy systems since the early 1980s (though known previous to 1998 as the State Science and Technology Commission).

After the initial analysis and capacity-building phase was complete, MOST undertook training of a local Chinese service team which would serve the entire province in order to guarantee standardized quality. The training and service team was operated through the rural renewable energy business infrastructure that already existed in the province. The team was comprised of technicians from four different counties, and was sub-divided into an installation team, a commercial/sales team, and a maintenance team. For the latter team, Pilot Project leaders considered it important that the technicians be locally based and entirely separate from the installation team. This local component eventually took over all responsibilities of the project, and today provides crucial technical maintenance and part replacement support for the herdsmen. 
In fact, only a handful of people in each county are knowledgeable about the systems, and it became clear to this study's Principal Investigator (PI) that these people are today quite familiar with most hybrid system-using herdsman households. The strength of this service infrastructure established for the Pilot Project can be credited with sustaining the project in many aspects.

When evaluating any government program it is important to understand the structure of influence through which projects are undertaken. The Inner Mongolia hybrid household project began as an idea of CEEP, developed into an agreement between the Chinese government and U.S. DOE/NREL, and today is maintained by local MOST officials and renewable energy experts in Inner Mongolia. As will be seen, the project has helped to further the development of renewable energy in the province; the Chinese government used the Project as a "demonstration" to justify its later Brightness Program, a government-funded effort to electrify 23 million people by 2010 using household- and village-scale renewable energy systems ( $\mathrm{Li}$, personal interview, 2004) (see page 15 for Program information). However, the Pilot Project represented a departure from China's historical development strategy because of the innovation of distributed generation.

At the time of the Pilot Project's planning, provincial MOST officials envisioned a second or follow-on phase of rural electrification for Inner Mongolia, one part of which would focus on village-scale electrification and the other on more remote single-household systems. This latter part aimed to use the Pilot Project as a springboard for the utilization of wind-solar systems, and would be a project of the Chinese government. The goal was to electrify 25,000 additional households by the year 2000 and 80,000 more between 2000 and 2010 using renewable energy systems. At the time of the PI's investigation in August 2004, approximately 70,000 pastoral households in the province remained without sufficient electricity (100 watts capacity or less, comparable to the household situation described on page 63 ), which equals about $16 \%$ of the total province population. Nonetheless, renewable energy companies in the province sell between 4000 and 5000 wind turbines every year. And, as previously mentioned, $96.4 \%$ of the entire province (including both urban cities and grassland areas) is now electrified.

\section{The case for renewable energy in China: a brief overview}

China is the world's fourth-largest country in land area, with the world's largest population at nearly 1.3 billion; in 2003, China ranked as the second-largest world economy after the U.S. Owing to its gradual transition to a market economy, in just the last 25 years China's GDP has quadrupled (CIA 2004). However, the difference between the country's eastern cities and its underdeveloped provinces in the west and south is marked. The transition to a socialist commodity economy has led to widening welfare gaps in many respects: urban-rural, coastalinterior, and class- and ethnicity-based. In addition, the pursuit of unrestrained development during the last few decades has led to unprecedented destruction and degradation of the environment, which poses a real threat to the sustainability of the effort and China's future. The main environmental problems facing the country today are widespread deforestation, air pollution and water contamination, excessive losses of arable land, and a drastic decline in biodiversity.

However, such trends are not unique to China or developing countries - indeed, the United States and Europe underwent similar transitions during industrialization. In fact, such transitions are an inherent part of modernization: "In general, the attitudes of people who have just emerged 
from long years of privation to the threshold of life promising a bit more freedom and a little more prosperity are not conducive to conservation, savings, and the eschewing of immediate consumption; just the opposite is likely to be true, putting further accelerated pressure on the environment. Indeed, here is a perfect illustration of a key ecological concept well known as the tragedy of the commons, or killing the goose that lays the golden egg" (Smil 2004, 144). Indeed, the "tragedy of the commons" is applicable to the global environmental situation today. Originally formulated by Garrett Hardin (1968), the "tragedy" is the outcome of economic thinking that is rational and individualistic, bent on maximizing gains but applied to commonly held resources. The individual's gain is his/hers alone, but the depletion of non-renewable resources is felt by all.

This is one way of contextualizing the increased international scrutiny of China's modernization process. Since the 1972 United Nations Conference on the Human Environment, the conceptualization of the environment as a global commons has increasingly taken hold. During the last decade, China has come under international political pressure to lower its greenhouse gas emissions and pursue sustainable development policies. The upcoming 2008 Olympic Games in Beijing has served to bring attention to the air quality in China's major cities; and growing evidence has suggested that environmental irresponsibility carries heavy economic and human health costs. That said, the country's environmental, social and economic predicaments represent versions of the problems that face every nation.

China was the world's second-largest consumer of petroleum in 2003, and this trend is expected to continue. However, China's energy consumption depends primarily on coal, and China is the world's largest consumer and producer of the fuel. Unfortunately, the coal and the technology used are low-grade and highly polluting. In addition, China now ranks as the second-largest emitter of carbon dioxide in the world. Further, projections in energy demand show it will experience the largest growth in carbon dioxide emissions between now and 2020 (EIA 2004). Comparatively, China's per capita energy consumption and carbon emissions fall far below the world average. However, the World Health Organization estimates that of the ten most polluted cities in the world, seven can be found in China; sulfur dioxide and soot from coal combustion are major air pollutants, and acid rain falls on 30\% of China's land area. In addition to human health concerns from air pollution, China's citizens face water shortages and pollution, deforestation, soil desertification, and loss of agricultural productivity - since 1949, one-fifth of the country's agricultural land has been lost as a result of erosion and economic development (CIA 2004).

In 1997, the Chinese government undertook a comprehensive cost-benefit analysis of pollution control and abatement, in partnership with the World Bank. The study (Johnson et al 1997) found that the costs of pollution at 1997 business-as-usual levels equaled US\$54 billion per year, or $8 \%$ of China's GDP - in the form of premature death, sickness, and damage to productive resources. Air particulate and sulfur levels in China's major cities are among the highest in the world, and exceed World Health Organization standards by two to five times. Health and productivity losses (medical costs, crop damage, and reduced work-years from health damages) were estimated at $\$ 20$ billion per year - the single largest environmental cost in China. Exposure to lead is also a main cause for concern. The study found that in Chinese children, a consistent correlation existed between lead exposure and deficits in intelligence, neurobehavioral development, and physical growth. In strictly economic terms, the prospect of lowered 
productivity for an entire generation of workers - from pollution-related costs in human healthis significant.

In addition, the study estimated the costs of water pollution due to inadequate sanitation, disease, eutrophication of lakes and aquatic ecosystems, and damage to agricultural areas at $\$ 4$ billion per year. Finally, estimated crop and forest losses from acid rain were $\$ 5$ billion per year. Add to this scenario projected global climate change effects - Chinese research has suggested that an increased concentration of greenhouse gases will lower rice, wheat, and cotton production, and a sea-level rise of just one meter could flood an area of China the size of Portugal, displacing 67 million people - and the social and economic costs borne not only by China but by the global theatre are huge (Johnson el al 1997). However, recent research shows that there are substantial opportunities in China to develop a renewable energy infrastructure as well as provide electricity to its rural populations, while adhering to the international call for sustainable development (Zhou and Byrne 2002).

The development of renewable energy technologies has appeared on the Chinese political agenda since the early 1990s, when policies in support of such development were included in the Eighth Five-Year Plan. However, the Chinese government has provided subsidies for renewable energy since the 1950s, when hydropower in rural areas was part of a water conservation program. In the 1980s the government began providing loans and grants in addition to subsidies, and since the 1990s, tax reduction, exemption policies, preferential pricing, credit guarantees, and other support vehicles have come into use (Zhang et al 1998).

Like much of the developed and developing world, China's participation in the 1992 United Nations Conference on Environment and Development in Rio de Janeiro (a.k.a. the Earth Summit) established its commitment to environmental responsibility. At the Summit, world leaders signed the Framework Convention on Climate Change and adopted Agenda 21, a comprehensive plan for achieving sustainable development in the 21 st century. Each participating country was encouraged to create its own Agenda 21; China completed its version in 1994 (CA21 1994). In 1995, the Chinese government formulated its Electric Power Act, which was the first law to discuss energy policy. The Ninth Five-Year Plan (1996-2000) developed further guidelines for including renewable energy resources in the country's power infrastructure. Most recently, the Chinese government has drafted a new law that will address the major roadblocks in the country's renewable energy development strategy - the high costs of renewable technologies, lack of infrastructure, and national manufacturing capacity. The Renewable Energy Law focuses on synthesizing basic principles of the market economy with the political objectives of energy security. It is expected to be the most ambitious such law to date, and is expected to be passed by end-2005. ${ }^{6}$

Though renewable energy policy in China has historically lacked the necessary support mechanisms for large-scale development, there has been notable progress in small-scale wind power and photovoltaic (PV) utilization, especially in rural electrification initiatives. To this end, two key programs were introduced in the Ninth Five-Year Plan. The first is the national

\footnotetext{
${ }^{6}$ See the fact sheet Renewable Energy Policy in China: Overview at http://www.nrel.gov/docs/fy04osti/35786.pdf and other information available at http://www.nrel.gov/international/china for more information on the role of law in China's development of renewable energy.
} 
Brightness Program, which is based on an international effort initiated at the 1996 World Solar Peak Conference in Zimbabwe to bring electricity to rural and impoverished areas. The program is funded by grants from the Chinese central government, local governments, and foreign sources, with the possibility of additional costs being covered by consumers. Its goal is to provide electricity for 23 million people using household- and village-scale PV, wind, and $\mathrm{PV} /$ wind hybrid systems, with a target completion date of 2010 - ideally, the program will provide 100 watts of capacity per person. Program tasks include identifying financing schemes and a training program, so that local operators will be able to maintain village and household systems independently. So far, a total capacity of $165.4 \mathrm{~kW}$ of wind and approximately 10.3 MW of PV have been installed in Inner Mongolia, Tibet, and Gansu provinces.

Most recently, the Chinese Government has initiated its National Township Electrification Program (Song Dian Dao Xiang or "Sending Electricity to Townships"), which builds on the success of the Brightness Program. Through this initiative, the government has already electrified 1065 townships, supplying power to more than one million people. The majority of townships are electrified with PV-only mini-grid systems, and a few with PV/wind hybrid systems (688 use PV-only or PV/wind); 388 townships are electrified using small mini-grid hydropower systems. ${ }^{7}$ Overall, the program has installed $20 \mathrm{MW}$ of PV and $840 \mathrm{~kW}$ of wind power during a two-year period. It is the world's largest renewable energy-based rural electrification programs, and is also the most rapid in terms of implementation. In addition, a second phase of the project, known as the Song Dian Dao Cun Program ("Sending Electricity to Natural Villages"), is being considered for the period 2005-2010 and would electrify the remaining 29,000 natural villages in China's rural areas, using not only village power systems but also hybrid household systems. Currently, the government is in the process of drafting guidelines for tariffs and system ownership; importantly, local provincial agencies will also be established to operate training centers and support institutional development ( $\mathrm{Ku}$ et al 2003).

Studies have shown that China's wind power potential is as high as 1,600 GW-more than eight times China's current electricity capacity (Zhou and Byrne 2002). Wind power potential is highest in China's northern and western provinces - above 200 watts per square meter (Liu (Y) 2004). In fact, average wind speeds in many areas of Inner Mongolia are in excess of 6 meters per second (m/s) for more than 3,000 hours per year (Byrne et al 2001). To put this in perspective, small wind turbines require a minimum of only $3.5 \mathrm{~m} / \mathrm{s}$; wind power is proportional to the cube of the wind speed.

Moreover, the potential for solar power is equally promising. Most parts of the country receive high levels of solar insolation - $66 \%$ of the country's land area takes in more than 2200 solar hour equivalents per year ( $\mathrm{Li} 2002)$. Thus, China is particularly well-situated to develop its renewable energy capabilities in the face of encroaching environmental costs related to fossil fuel utilization.

\footnotetext{
${ }^{7}$ These figures are current as of end-January 2005 and are derived from a presentation given by Ma Shenghong, Vice Director of the Beijing Jikedian Renewable Energy Development Center, during the Renewables 2005 Conference in Bonn, Germany in June 2004.
} 


\section{Objective of the study}

The Inner Mongolia Household PV/Wind Hybrid Systems Pilot Project began conceptually in 1993, but most installations occurred between 1999 and 2000. Though generally understood to be a success by all persons involved in implementation and execution of the project, it had not been revisited in any depth since its completion. While an evaluation of the project in cooperation with local Inner Mongolian authorities had been planned, no budget for evaluation had been set aside at the time of project implementation.

The need for this type of post-project follow-up is two-fold: First, when there is interest in designing a replication project elsewhere, a post-installation assessment affords the opportunity to do so from a 'lesson-learned' and informed perspective. Second, by highlighting successful projects and charting their progress, the potential for promoting future commitment to such projects is enhanced. Thus, the primary objective of this study was to revisit the Pilot Project systems in order to glean a general 'lessons learned' in light of the sustainability of future such projects.

The secondary objective was to evaluate the technical performance of the hybrid systems themselves. Specifically, the technical review sought to determine which system components had been replaced, and if problems had been encountered, why they had occurred. The aim was also to determine whether the system configuration and its components were technically sound, and whether herdsmen had been adequately trained in system maintenance. Perhaps most important, this portion of the survey sought to ascertain whether the systems continued to meet the needs of the herdsmen, or if the needs documented in the pre-project study had changed over time.

The third objective was to assess the societal and economic impacts of the project. Since most herdsman households in Inner Mongolia have had some experience with electricity since the late 1970s, what this objective seeks to evaluate is the effects that come from having sufficient electrical power for modern appliances such as color TVs, refrigerators, and washing machines, for close to 24 hours a day year-round. In other words, the overriding question asked by this objective was how the multifaceted processes of modernization converge with electrification. Before herdsmen acquired hybrid systems of 450-500 watts and sometimes more, wind turbines provided them with 100 watts of DC power on which a small black and white TV and lowwattage light bulbs would operate. They fashioned crude cables to pick up the two provincial television channels available to them, but these only aired for a few hours each evening. Further, because wind is not strong all year-round, electricity to power TVs and lights was sometimes entirely unavailable during summer months when the batteries could not store enough energy to power appliances.

With the introduction of the hybrid system, which includes an inverter and charge controller for converting DC to AC electricity, herdsmen were able to purchase modern appliances like the ones used in urban areas and enjoy them year-round. Satellite dishes accompanied the new and larger color televisions, and with the newfound options provided by as many as 30 channels with international programming - from Chinese music television to American movies - the window to the outside world was suddenly wide open. Based on what the PI has observed in other parts of the developing world, the socioeconomic effects of the Pilot Project are perhaps of greatest 
consequence - the introduction of television and other modern appliances initiates inevitable changes in daily behavior, standard of living, and even future aspirations.

Overall, the objective of the study was to contribute a broader understanding of the impacts to be expected from off-grid single-household renewable energy systems in the rural context. In addition, a crucial component of the analysis included evaluating the sustainability of such projects. There is a small but valuable collection of literature which has evaluated the use of offgrid renewable energy in the Inner Mongolian herdsman household from an economic and quantitative cost-benefit perspective (Byrne et al 1996, 1998, 2001; Richter 1997, 1999). This study does not attempt to expound on that literature. Instead, the objective here is assess the effects of off-grid electrification from a qualitative perspective - to get at the meaning and the context of the project as it is understood by those who have lived it: the end-users of the systems, and the maintenance personnel. 


\section{A review of the literature}

\section{The socioeconomic effects of rural electrification: overview}

There is an important distinction to be made between electrification by off-grid systems and electrification by grid extension, as there is between electrification by fossil fuel-powered generators and renewable energy systems. Electrification by off-grid renewable energy systems, the subject of the current study, constitutes an area of analysis that has been little explored in detail. Though by no means extensive, there is a sufficient body of literature that deals with the socioeconomic effects of rural electrification, but in all but a very few cases, it looks at electrification by grid connection to conventional power plants. However, this literature remains relevant to the study at hand, as it provides a theoretical basis of understanding. Highlights from the literature discussed here lend support to this study's premise that the long-term benefits of access to an improved energy source outweigh the initial cost; specifically, such access facilitates higher human development; an improved quality of life; and higher levels of income, education, health, and productivity.

In the early 1980s, as the energy crisis waned and the Third World debt crisis waxed, a brief public debate ensued in the developed world regarding the social merits of electrification. Many then held (and some still do today) that development initiatives focused on health, clean water, and education were more urgent and that extending electricity to rural areas was often a moot point as long as rural communities remained in abject poverty (Barnes 1988). In other words, what good is a light socket if one cannot afford a bulb? However, the two main international aid and development organizations - the United Nations and the World Bank - have both found access to electricity to be an essential part of socioeconomic development and economic growth (Goldemberg 1995; Reiche 2000). In fact, it is practically impossible to improve health, access to sanitation or education in the absence of an efficient energy source. Of course, where electrification initiatives are undertaken in the absence of a larger development strategy, the former argument has merit. A holistic strategy is one that seeks to expand on all aspects of capital or streams of benefit. Though investment in an energy infrastructure often requires a higher initial capital commitment than investment in educational, sanitary, or healthcare facilities or employment-generating activities, modernization and continued improvement of such goods and services depend on electricity. Examples include lighting for public buildings, water purifiers, indoor plumbing, and medical equipment.

The first study to evaluate the importance of energy to socioeconomic development was published in 1976, and subsequent studies conducted by the World Bank and the World Energy Council found that a rise in per capita energy use corresponds to increased life expectancy and lowered infant mortality, illiteracy, and fertility rates. Though low energy use is not itself an indicator of poverty, access to electricity improves the provision of all basic human needs: access to jobs, food, healthcare, education, shelter, and adequate sanitation. For sure, there are areas of the world in which remote communities live full and productive lives without electricity, but these represent rare and increasingly tenuous circumstances. In addition, though food and shelter are not in themselves dependent on energy, inefficient energy use - such as relying on scarce firewood or dirty coal - constitutes an obstacle to achieving an acceptable standard of living in which freedom from poverty and disease are human rights. In addition, the rural poor pay a higher price (in health, time spent laboring, and the natural environment) for energy than their 
urban counterparts. Promoting energy-efficient technologies is an attempt to supply the same amount of energy using a lessened quantity of resources (Goldemberg 1995).

Given the significant development in energy-efficient and renewable energy technologies worldwide, developing countries have an opportunity to "leapfrog" over the stages developed countries have undergone on the development path and move directly to the most prudent options (Goldemberg 1995; Cecelski 1995). Popular opinion seems to hold that the poor and underdeveloped nations are being unfairly pressured to adopt energy conservation at the expense of development. However, encouraging behavioral and technological change toward energy conservation has not been found to inhibit economic growth or reduce societal wellbeing. Instead, it is more likely that "the most ubiquitous inequity has been the inability of those who will be directly affected by technologies to inform themselves of what is going on, and to organize politically around universally shared inequities that affect life processes" (Nader 1995).

Extending the main electrical grid to remote or low-demand areas can be a costly and impractical approach. Off-grid electrification — whether by household-scale or mini-grid village systemsoften offers a lower cost option while encouraging local capacity-building for rural energyservice companies. Innovation in off-grid services can also influence national energy policy. The World Bank has found that in some cases, as a result of rural off-grid projects, governments have been forced to recognize and incorporate renewable energy into electrification planning. This leads to consideration of new pricing and policy support mechanisms, and well as heightened consumer awareness and capacity building (Reiche 2000).

Numerous studies have evaluated the effects of rural electrification on the social and economic life of developing countries, and several lessons have become clear. First, the impact of electricity is dependent on its end-use and on the quantity of people served. Second, and as noted above, electrification must be part of a broader development strategy in order to be successful. The opportunity costs of electrification must not include forgone investment in other poverty alleviation strategies such as healthcare or education. Third, the long-term result of electrification should be increased social equity. Fourth, the benefits of electrification must outweigh the costs, and any cost-benefit analysis should include a quantitative valuation of societal and environmental impacts. ${ }^{8}$ Finally, the effects of electrification initiatives must be considered over the long term to account for lasting trends, for only long-term benefits provide true justification for such initiatives (Barnes 1988).

Saunders el al (1978) conducted a study in Costa Rica and Colombia that sought to evaluate the social and economic consequences of electrification. The main independent variable of the study was use or non-use of electricity, in order to reveal the impact of electrification programs. Data collection included demographic information (head of household information, sex, age, and education of family members), exposure to mass media (radio, television, newspapers, and magazines), agricultural and/or business activities, a measure of residents' level of living (pertains to how household functions are performed rather than material possessions or economic status), and a measure of residents' sense of social wellbeing or contentment. The authors found that the level of living variable was most consistently associated in a positive manner with

\footnotetext{
${ }^{8}$ Barnes (2002), discussed on page 22 of this report, provides a comprehensive explanation of why this should be done in relation to electrification projects, and how it is accomplished.
} 
electricity use, as was mass media exposure. However, as with the chicken and the egg, the authors had to allow for the possibility that electricity users were predisposed to seek a higher level of living, perhaps owing to their exposure to mass media, which led to their use of electricity, rather than the other way around. As they note, "unidirectional causality between two variables to the exclusion of all others is virtually unknown in the social sciences" (159). Despite their reservations about causality, the authors recommended that policy decisions be based on the suggested correlation between electrification and higher levels of education and income.

Barnes (1988) conducted a study of rural electrification initiatives in India, Colombia, and Indonesia. Based on extensive research of both electrified and unelectrified households from upper to lower income within a range of ecological variation, Barnes evaluated the impact of electrification on industry, agriculture, productivity, quality of life, demographic variables, and migration. Barnes maintains that the most important long-term contribution to be gleaned from electrification involves gains in productive uses and income- and employment-creating opportunities. In India electrification may have been an important cause of agricultural innovation (for example, new mechanized tools), leading to increased crop yields; electrical water pumps also raised the productivity of electrified areas. In all three countries, electrification positively affected the development of small-scale industries and commerce (dependent, of course, on access to markets and credit, as well as literacy). Barnes also cautions that though electrification appeared to spur economic development, the absolute level was still relatively low.

Not surprisingly, Barnes found that electrification had a significant impact on appliance ownership, especially televisions. Though electric lighting replaced the use of kerosene or candles, electricity had little impact on the use of biomass for cooking, however. He concludes that income, education, and appliance ownership all contribute to a higher rural quality of life and represent a pattern that should be expected in other developing countries. Living patterns were also affected. In Colombia, Barnes observed that households had changed their daily activities to watch TV in the evening. This lessened or eliminated their time spent on activities that figured prominently in pre-electrification life, such as socializing, listening to a batterypowered radio, or adult reading (by lantern light); however, the amount of time children spent reading and/or studying increased substantially. He also found that because of TV viewing, the amount of housework performed by women in the evening had declined. Barnes concluded that quality of life, determined by eliciting the subjective perception of respondents, was positively correlated with electrification, even when controlling for income and level of education.

Barnes' findings on migration effects were mixed. As he points out, out-migration from rural communities usually occurs for reasons of employment or education, and can be seasonal or permanent. In India, electrification was positively correlated with permanent out-migration (for employment or "other" reasons, including government service), even after other variables were controlled for in the statistical analysis. (Though Barnes does not suggest it, "other" reasons may include the desire for a better way of life, caused in part by access to information and the possibilities newly experienced.) However, electrification was not associated with seasonal migration (it decreased), as electrification improved the agricultural activities in the region of study. In Colombia, a strong correlation between electrification and migration was not confirmed. He found that electrification and literacy or level of education are strongly 
correlated, although the relationship is complementary, since more highly educated adults are likely to use electric lighting to read or study with their children. However, the variables remain associated when income and local school variables are controlled for.

Barnes mentions studies conducted in the mid-1970s in Colombia and the Philippines which found that electricity use by rural communities raised incomes and education levels. He cautions, however, that it is difficult to determine whether these associations are causes or effects of electrification. Higher income households will already tend to be more highly educated, and are better situated to afford electricity.

As Barnes points out, electrification of rural areas lessens the rural-urban divide; therefore, it encourages a government investment in infrastructure, since over-crowding in urban areas is a significant problem for many developing countries; development of rural areas leads to a better quality of life for both rural and urban residents. Theoretically, this investment has spill-over effects, as people will be more willing to remain in rural areas, thus reducing rural-urban migration. It may also ease the difficulty of attracting doctors and other professionals to serve rural areas. However, he cautions that electrification may serve to worsen rural inequality in the short term, as poorer households adopt electricity at a lower rate than their wealthy counterparts. The caveat is that even poor households who adopt electricity and use it to power one light bulb benefit greatly in comparison to unelectrified households (in terms of improving reading and studying conditions which serve to develop human capital), and over the long term, as projects mature and their reach becomes greater, the income gap narrows.

In a more recent study of rural electrification in the Philippines, Barnes, on behalf of the World Bank (2002), assigns quantitative values to socioeconomic benefits of electrification that were previously considered unquantifiable. He finds that the total benefit of electrifying a typical, previously unelectrified, household equals US\$81-150 per month, depending on the number of wage earners in the household. This amount includes valuations of less expensive and expanded use of lighting, radio, and television (all of which are correlated positively with education); higher returns from education on income; time savings on household chores; and improved productivity of home businesses, whether already in existence or created after electrification. These findings support the theory that the long-term benefits of electrification outweigh the initial cost even in strictly economic terms. This is important since the capital cost of rural electrification projects is often the stumbling block for developing country planners and international donor agencies. Both the breadth of the analysis and its results are an important addition to the literature.

In another study, the World Bank has found that rural electrification (both on- and off-grid) effects poverty alleviation in the following ways: better living standards are achieved through improved amenities and services; the negative impact of compromised energy sources on human health and the environment is reduced; employment is increased, both via the supply of energy and demand effects (growth of industry and productive uses); educational achievement is bolstered for children through higher quality lighting and thus increased study time; incomegenerating work and social activities are both available to adults during the evening; communication and access to information empowers marginalized populations; time gained through decreased reliance on biomass leads to individual and community development; and 
residential and public lighting increases safety, especially for women and children (Reiche 2000).

An analysis of the socioeconomic effects of conversion from 3-hour per day power to 24-hour power yielded similar results (Boer 2000). Based on a survey of households in San Juanico, a fishing village in Baja, Mexico, and interviews with local residents and officials, the author found that 24-hour power contributed beneficially to local businesses, social services, and domestic quality of life. In addition, 24-hour power improved the economics of the village as its residents no longer had to rely on costly private generators. However, the economic improvements were only moderate. Boer found that individual behavior modification was fairly significant, as newly acquired electric appliances shortened the time spent on household chores. The increase in time spent in front of the TV was not found to be a benefit to schoolchildren, but home education was not significantly affected. One finding that counters much of the literature — which associates electrification almost solely with out-migration - is that inmigration occurred as a result of electrification, while out-migration was not directly related. Though this finding was tentative, it appeared that electrification would lead to a rapid development of the seaside town, including an influx of tourism. Overall, Boer concluded that stronger infrastructure (namely, administrative oversight, education, and communication) is required to increase the potential benefits of 24-hour power. For it is certainly true that electricity "does nothing on its own. Rural people and businesses must first acquire and use electric appliances to realize its benefits. This requires an adequate institutional framework including the availability of credit, the existence of enterprise building programs, and access to markets" (2).

It would seem that certain socioeconomic effects may thus be expected in the study of rural electrification initiatives. The question remains, however, as to whether there are any differences in off-grid electrification projects compared to grid-connected ones, or in projects that utilize renewable energy in comparison to those that rely on fossil fuels. Again, very few studies have investigated these different approaches. Wamukonya and Davis (2001) evaluated a rural electrification program in Namibia that relied on both grid-connected fossil fuel and off-grid solar technologies. The study investigated the program's effects on households' energy consumption patterns, wellbeing, and perception of electricity. Only $10 \%$ of rural households in Namibia are electrified at present, due largely to the dispersed settlement pattern of rural areas and the costs of electrification. However, a recent program has sought to counter this problem by installing solar home systems (SHS) instead of extending the grid. The authors interviewed almost 400 households that included unelectrified, grid-electrified and solar-electrified samples. They found that solar-electrified households had the highest monthly energy expenditure, mostly because of monthly payments for the system (grid-extension carries very low end-user cost), which will change once repayment is accomplished. However, high expenditure was also a result of the use of appliances like irons, refrigerators, and TVs. Because households receiving the SHS had to meet a minimum income requirement, unlike newly grid-connected users, income and appliance ownership are understandably skewed.

The authors found that households continued to use a range of traditional fuels even after electrification. Candles were still used to a high extent, because of service interruptions and the lack of light bulbs for each room of the house. Paraffin and wood decreased in both grid and offgrid electrified households, but continued to a notable extent-wood continued to be used for 
cooking, as electrical stoves and the energy needed to power them are considered expensive. Households using SHS did not possess sufficient electricity for electrical stoves. Thus deforestation and environmental degradation continued.

The authors also found that electrification by grid or SHS improved household welfare almost exclusively because of electric lighting. The ability to study in the evenings was the most important change. The day was also extended to include time for reading, watching TV, socializing, or finishing chores. Though it is difficult to measure the effects of electrification on health, the authors found that households reported their health had improved since gaining electricity. Finally, electrification did not have a significant impact either on migration or on income-generating activities. The latter finding may be explained by the fact that very few home-based income-generating activities utilized electricity. In fact, most home businesses were found in unelectrified households.

Socioeconomic effects varied little between grid-connected and SHS users, and controlling for the other factors, such as the higher base income of solar-electrified households and occupations of the inhabitants, made differentiating between impacts difficult. However, only $12 \%$ of SHS users reported technical problems, which were usually owing to the battery and were resolved within one day. Among grid-connected households, 45\% reported technical problems that required an average of eight days to correct. SHS users reported dissatisfaction with the level of energy supplied, however, and would have preferred the capacity to support more appliances. In addition, SHS users who were not part of the government program expressed dissatisfaction with the system performance, mostly because they were not adequately trained and misunderstood the system's capability. However, all solar users reported that electrification had improved their lives, while less $(90 \%)$ grid users reported the same opinion. The authors concluded that once schools, health clinics and other community centers are included in electrification schemes in solar-powered areas, there will be little reason to recommend grid-connection over solar power. In the most remote areas, SHS offer the lowest-cost solution over the long term.

Another comparison of off-grid renewable energy technologies and grid connection is briefly discussed in the context of Maphephetheni, a rural community of South Africa. Green and Zwebe (2004) interviewed six female heads of household who were serviced both by the electrical grid and by SHS. All households thus had experience with and opinions of both sources of energy. In this community, access to electricity in general had not changed much about users' daily life, however. Most families still used paraffin to cook; only a few had begun using electric refrigerators in place of gas-powered ones. All considered electricity extremely precious and were loathe to use electrical appliances for any but the most necessary activities. Of the six women, only one preferred grid-connected electricity to the SHS, and in her case, the SHS had ceased to work. Three women preferred the SHS to the grid, and two were indifferent. The main reason for preference of the SHS was financial-electricity from the SHS was free but the rated cost of the grid was considered expensive. Similar to the Namibia study, the women also noted that the grid experienced many problems. During storms, it would not work, and repairs took up to a week to resolve.

Unfortunately, the two studies that evaluate off-grid renewable energy versus grid connection suggest no compelling differences between the two approaches. A possible exception exists in terms of empowerment — renewable energy users have more control over their decentralized 
energy sources, and are not dependent on the local authorities for resolution of power issues as are grid users. This distinction will prove of note in the upcoming analysis.

In sum, the studies expounded upon here represent only a portion of the existing literature linking electrification with social and economic development. Nevertheless, they provide convincing evidence of a range of benefits to be expected from rural electrification initiatives. The upcoming analysis is based on the theoretical underpinnings established in this literature.

\section{Measuring human development and 'quality of life'}

According to the United Nations' (UN) Human Development Index (HDI), the key ingredients of human wellbeing are a long and healthy life (measured by life expectancy at birth), knowledge (measured by adult literacy and enrollment in primary, secondary, and tertiary school), and a decent standard of living (measured by per capita GDP in purchasing power parity [PPP]) (UNDP 2004). According to the UN's China Index, the average Inner Mongolian enjoys a life expectancy at birth of 69.05 for males and 72.51 for females; a literacy rate of $88.4 \%$; and $99.4 \%$ enrollment in primary school, $93.8 \%$ in secondary, and $27.3 \%$ in tertiary school. Finally, GDP per capita for the average Inner Mongolian is 6463 Yuan per year (about US\$780.00; in U.S. PPP, though, this amount is only 3222 Yuan or US\$389.00). Overall, of China's 31 provinces, Inner Mongolia ranks 21st in human development - there is great disparity between the HDI of Shanghai and Inner Mongolia, as there is between Inner Mongolia and Tibet, which sits last (UNDP China 2002). Compared internationally, China falls into the category of 'medium human development,' which it shares with countries like Bosnia, Colombia, Iran, and Bangladesh (UNDP 2004).

Certainly, a long and healthy life, knowledge, and a decent standard of living are key components of a satisfactory existence. However, human development and wellbeing depend on additional qualities that are harder to measure. Mahbub ul Haq, who pioneered the concept for and developed the UNDP Human Development Reports, believed that human development is most accurately measured by the degree of one's freedom:

The basic purpose of development is to enlarge people's choices. In principle, these choices can be infinite and can change over time. People often value achievements that do not show up at all, or not immediately, in income or growth figures: greater access to knowledge, better nutrition and health services, more secure livelihoods, security against crime and physical violence, satisfying leisure hours, political and cultural freedoms and sense of participation in community activities. The objective of development is to create an enabling environment for people to enjoy long, healthy and creative lives. ${ }^{9}$

Thus, a better way of defining quality of life might be a full and productive life in which opportunities are available for self-development, freedom from poverty and disease, and the pursuit of happiness - however one conceives of it (see also Sen 1999). Any measure of quality of life must include abstract as well as material considerations.

\footnotetext{
${ }^{9}$ Quote available at http://hdr.undp.org/hd; refer to this site for further information on human development and the UNDP's Human Development Reports.
} 
One's judgment of one's quality of life is, first, relative; second, it is dependent on societal values. First, consider the quality of life of a person born with Cystic fibrosis in a comfortable suburb of the United States. Then consider a person of perfect health born in the slums of Rio de Janeiro. One must struggle with a life-threatening disease, and the other with crippling poverty. Whose quality of life is higher? Each might consider the other to be better off if they were asked to compare.

Second, one's quality of life is shaped by one's societal expectations and background. For example, people living in western countries might place more value on personal accomplishment and income, whereas those living in socialist countries might emphasize community or equality. Quality of life depends on internal standards that include not only fulfillment of basic needs and pleasure but also ethical norms. Studies in East Asia have shown that self-esteem and autonomy are not correlated significantly with quality of life; subjective wellbeing is a reflection of the societal frame of reference. In some areas of the world, cultural or ethical values and a concern for the "big picture"- such as in areas where civil war has become the daily norm — affect quality of life much more than subjective life circumstances do (Diener et al 2000).

Findings in support of the correlation between electrification and improved quality of life have already been presented (Barnes 1998; Barnes el al 2002; Boer 2000; Goldemberg et al 1995; Reiche et al 2000; Saunders et al 1978; Van Campen et al 2000; Wamukonya and Davis 2001), and a literature search reveals no studies that have found a lowered quality of life to result from electrification. Of course quality of life is intrinsically bound up in the other effects of electrification investigated in this report, such as labor-saving appliances, entertainment, and education, not to mention factors not related to electrification, such as environmental sustainability.

\section{Beyond production: defining 'productive use'}

A term that carries heavy currency in the development and rural electrification literature is 'productive use.' A productive use is generally understood to be an activity that leads, directly or indirectly, to generation of income. A common opinion regarding productive uses is exemplified by the following statement:

Although electricity provides improvements in the quality of life through lighting, entertainment, and increased conveniences, it is the productive uses of this electricity that increase incomes and provide development benefits to rural areas. As incomes increase, rural populations are better able to afford greater levels of energy service, which can allow even greater use of renewable energy. The major emerging productive uses of renewable energy are for agriculture, small industry, commercial services, and social services like drinking water, education, and health care (Martinot et al 2002, 319).

Other examples of direct productive uses include improved livestock care through water pumps, incubators, electric fences, or veterinary clinics; refrigeration of milk products or beer for retail; small handicrafts; tourism; Internet and communication services.

Time and labor savings, garnered by use of washing and sewing machines and/or other appliances, are also considered productive uses (Van Campen et al 2000). There has been documentation of women in Inner Mongolia using washing machines to separate butter from 
milk, and herdsmen utilizing weather forecasts to better manage grazing and shearing and prepare for drought (Richter 1999) - this too is considered a productive use. More efficient use of renewable energy instead of kerosene saves household income for other uses, and this may be counted as productive as well.

As the forthcoming analysis will show, the range of productive uses is wide, and for the purpose of this study, a 'productive use' will be considered one that enhances productivity in a general sense, including activities that have the potential to generate higher human development in addition to income. In other words, a productive use is one that builds capital, which refers to certain assets - whether physical (made by people, such as financial assets); natural (created by nature, such as fertile soil); human (the capacity for productive activity that utilizes the other forms of capital, such as education); or social (collective empowerment that increases a society's potential, such as grass-roots social movements) - that produce flows of income or streams of benefit (Uphoff and Wijayaratna 2000).

'Social capital' is a fairly new concept and a brief explanation is warranted here. Social capital has three main components: it refers to networks and connections among people and between groups of people; shared values, ideas, and objectives; and trust. In other words, it is the collective form of human capital. If human capital is the stock one individual contributes to the productivity or betterment of his/her society, then social capital is the stock created when human beings together pool their collective effort to achieve a goal. The key is the 'collective' dimension, for collectivity implies all three of the above components - people coming together in a cooperative way must share some idea or value which brought them to one another, and in order for that cooperation to build cohesion and develop into social capital, a measure of trust must be present.

A good case study of social capital in development projects is found in Uphoff and Wijayaratna (2000), which describes an irrigation project involving rice farmers in Sri Lanka that was rife with disagreement and unrest, owing to extreme water scarcity during dry seasons, and the fact that the system was shared by rival ethnic groups - one upstream, and one downstream. The project involved facilitation of farmer organization by outside agents, which helped farmers to form a sort of cooperative. Faced with the prospect of no harvest due to water shortage, the upstream and downstream users began to cooperate in the interest of their common livelihood. During the 1997 dry season, after they were told by local authorities that there was not enough water in the reservoir to grow a rice crop, the farmers achieved through their organization a better-than-average harvest by efficient and equitable distribution. At first informal, the farmer's group led to larger canal organizations; these organizations were further extended to area councils, which achieved a powerful voice in the local government. The case illustrates that though the outside organizers were the initial catalyst for change, both economic and social success was achieved through the shared values and cooperative nature of the participants - as the authors state, "people need to create their own social capital" (p. 1885).

Though it is conceivable that social capital or community solidarity might lead to electrification - a group begins a movement for change and either lobbies local government, for instance, or raises the financial capital for community improvement - but at present there is no literature that describes an electrification project resulting in the formation of social capital. However, the term remains applicable here since this report will suggest the potential for social 
capital in the herdsman community. The overall premise is that improved access to electricity will lead to new productive activities in both direct and indirect ways, some of which may only become evident in the future.

\section{The role of television and broadcast media}

In the rural electrification literature, a widely accepted observation holds that access to broadcast media facilitates valuable access to information (which may lead to education and empowerment) and entertainment (which increases quality of life). Among development strategists, access to information is generally considered essential to human and economic development because it reduces uncertainty by lessening unknowns, and aids in problem-solving abilities when unfamiliar situations arise: "one cannot have knowledge unless one gets information. ...information equips a person with power, the power to choose and to act in an informed manner. It empowers people towards actions that can transform lives, and allows for a great sense of independence" (Jiyane and Ocholla 2004, 3). In addition, access to information is considered critical in capacity building, which includes self-actualization or empowerment. Often, the income and infrastructure gaps that exist between the rural poor and the urban elite are widened and partially caused by an information gap (Leach 2001). This could also be considered an empowerment gap. Building upon information availability, whether in the form of indigenous radio, access to state-run TV programming, or community organization and outreach, is a crucial part of rural development.

Knowledge can be an instrument of power in an individual but it can become a source of mobilization in a network or community. Social capital is created when members of a community come together and build common goals, and access to information facilitates this process. In western society a commonly held idea is that television presents a way of disengaging from reality, possibly to the detriment of the viewer's development - one need only look at the volume of literature that suggests a link between violence among western youth and television viewing. However, some studies have suggested that in newly developed or developing societies, television provides a forum for discussion - the stories and foreign lifestyles shown on TV provide an opportunity to experiment and evaluate new situations with more variety of choice. Take for a hypothetical situation a young girl of one rural family who begins to act strangely, exhibiting extreme mood swings that begin to disrupt her life and her schoolwork. The girl's peers shun her and her teachers punish her distracted behavior with bad grades, believing she is simply trying to attract attention. However, having recently watched a television program in which a family grapples with a child's psychological disorder, her parents take her to the local medical clinic and begin the process of understanding and recovery.

It is therefore erroneous to conceive of watching TV as a passive process. Instead, "what people watch is mediated by and at the same time helps illuminate developments in their lives" (Mankekar 1993, 553). TV is powerful not only because people can learn from it, but also because sometimes it provides the best way to discuss what is happening to people individually without violating rules of social etiquette. For, "far from being innate, many emotions are themselves produced by the social practices that television's narratives mediate and, indeed, sometimes create" (Mankekar 555). For example, a conversation about the character in a popular serial who defied his father's wishes for the family business by going to business school, might indeed spark a conversation among the viewing family that represents the beginnings of 
renegotiation of social norms. Perhaps a herdsman family's eldest son wishes to attend university in Beijing and pursue a career as a photographer, leaving his grassland ancestry behind. The herdsman's family or community may have had little experience with breaking tradition before, but the experiences available for consumption on TV ease the process of coping with change. However, people also resist what TV tries to sell them; "resistance' and 'compliance' are not mutually exclusive categories, and the role of television in the constitution of viewers' subjectivities cannot be conceived in terms of just one or the other" (Mankekar 556).

Indeed, the truly profound impact of television is that it opens up space for new ideas to form. There is a vast collection of literature on the effects of television on urban populations, especially the youth. However, very little has been written about TV's impacts on rural populations and on societies in transition. A rare exception is found in Johnson (2000), who documents television's role in social change in rural India. Johnson finds that the introduction of television leads to a reordering of daily household routines to make time for viewing of specific television programs; a change in colloquial speech to incorporate the dominant languages seen on television, one of which is English; and a rise in individualistic and consumer behavior. In addition, television viewing by women effects a slight adjustment in gendered perception, as women begin to consider the possibility of choosing a self-identity that exists outside traditional Hindu ideology. As one elderly villager tells Johnson, TV is the most significant thing ever to happen to the village.

A brief narrative by Blacker (2002) also discusses how the introduction of TV changes rural and marginalized people's self-identity. The author notes that the introduction of TVs in Eastern Europe caused people to compare themselves to the western ideals shown on TV and conclude that they were primitive or inferior. Identification with these ideals, combined with contact with advertising — now the backbone of TV even in socialist countries like China-eventually led people to become self-identified consumers, desiring products they formerly had no use for.

Television and its promotion of domestic popular culture are not the only variables influencing culture or identity change; commodity ownership, increased access to commercial markets, and rising income are also contributors, and it is often difficult to separate the chicken from the egg. Nevertheless, one aspect of this study's focus on television is the expectation that it facilitates a renegotiation of self- and community identity, especially among rural youth. Though some authors have dwelt on findings that television takes away from study time, another side effect will be discussed in this study, and it is one that has not been explored in the literatureaspiration may lead to an increased emphasis on educational achievement, for in developing societies, education is often the 'only ticket out.' In other words, television, through inspiring children to dream of bigger worlds, may lead indirectly to higher levels of education. 


\section{Methods}

The current study is based on fieldwork conducted during the month of August 2004. The core of the analysis draws from qualitative in-depth interviews with end-users of hybrid wind-solar household systems, the majority of which were installed under the DOE/MOST Pilot Project. The analysis also relies on interviews with Central and provincial Government officials and technicians who installed and oversee maintenance of the systems. All interviews were conducted in Chinese and, in some cases, Mongolian. The PI asked all questions in English and took all field notes herself; she was assisted by several translators, as described below.

In total, six interviews were conducted with government officials and academics affiliated with the project or with China's development strategy. Four of these people have been involved in the project from the very beginning and in renewable energy before then. First, Li Xiuguo of CAS, coordinator of the Pilot Project for the Chinese side, was interviewed for an overview of project development and rationale. Second, Liu Zhizhang of the Inner Mongolia Polytechnic University (IMPU), who provided technical and strategic support for the Pilot Project, was interviewed regarding project funding and lessons learned. Third, Pang Shu Qin, Senior Engineer of the provincial-level MOST in Hohhot, was interviewed concerning the development of renewable energy in the province and future steps. Mrs. Pang maintains records from the Pilot Project and oversees other renewable energy development efforts at the provincial level ( $\mathrm{Lin} \mathrm{Li}$, who originally headed the project at the Science and Technology branch in Hohhot and was instrumental in its execution, has since been promoted to Vice Director of Inner Mongolia's MOST; she was unavailable at the time of fieldwork). Fourth, Wang Sangui, Director of the Division of Poverty and Development of the Institute of Agricultural Economics, Chinese Academy of Agricultural Sciences, was interviewed for an overview of China's poverty alleviation and development programs.

Finally, two officials at the local county level of government were interviewed regarding project implementation and experience in their specific areas. The first was Yang Yi, who was formerly Deputy Director of the local MOST office for Saihantala (see Figure 2 for map of area, page 31) and now owns and runs the SiXu Brightness Program Company, which installs renewable energy systems under the national Brightness Program. Mr. Yang installs and disseminates renewable energy systems for the entire Suniteyou Banner, and oversaw the Pilot Project installations there. Of the 404 systems installed, 79 of them were in the area surrounding Saihantala, where $\mathrm{SiXu}$ Company is located. One of Mr. Yang's five employees, Mr. Dong, was also interviewed for his experience in maintaining the systems and knowledge of key maintenance issues. Both men served as local guides for Suniteyou and Siziwang Banners, facilitated household visits, and assisted with coordination of research activities.

The second local official to be interviewed was Gao Xiuhe, Director of the Dongwu MOST branch. Mr. Gao was himself a herdsman on the grasslands until 1969; he has been involved in renewable energy for many years. The Dongwu MOST has been the source point for renewable energy systems since the early 1980s, and Mr. Gao and his employees installed and maintain all of the Pilot Project systems there. Of the 404 total systems installed, about 130 are located in Dongwuzhumuqin Banner. Mr. Gao and one of his employees, Mr. Siqin, were interviewed for their experiences in renewable energy development and their maintenance of the systems. Both 
also served as guides, facilitated interviews, and coordinated research activities in the Dongwu area.

A total of 37 household interviews were conducted in three different banners of Inner Mongolia (see map, Figure 2-each subdivision represents a county or banner). The first banner of study was Suniteyou Banner in Xilinguole League; interviews were conducted in two different areas surrounding the towns of Saihantala and Erlianhaote (Erlian). The second was Dongwuzhumuqin of the same League; interviews were based in the vicinity of the town of Dongwu. The last area of research was Siziwang Banner in Wulanchabu League; interviews were conducted in the eastern portion of the banner, closer to Saihantala than to Siziwangqi. Together, Suniteyou and Dongwuzhumuqin Banners received more than half of all Pilot Project system installations, as initial demand was highest there.

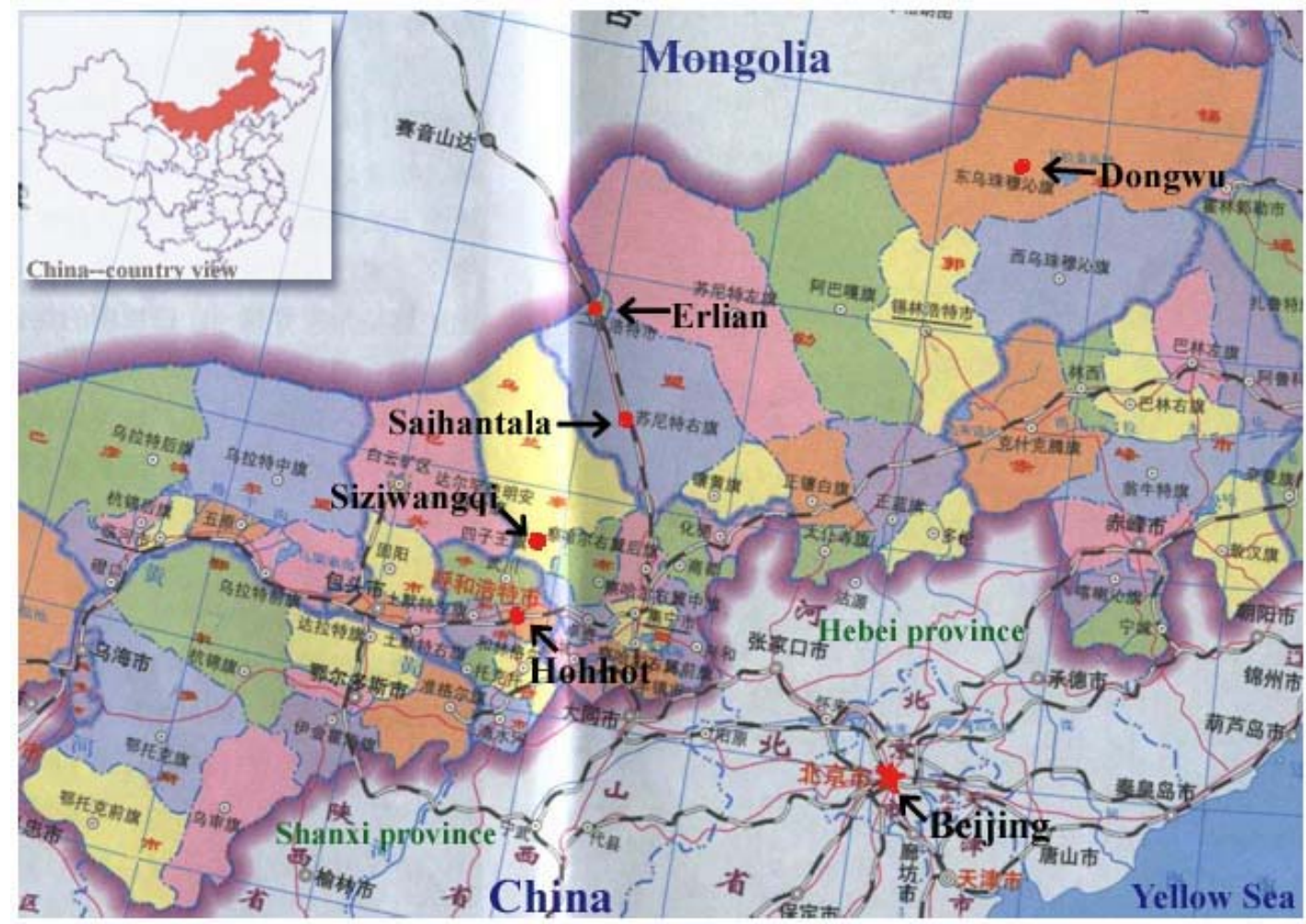

Figure 2. Map of central Inner Mongolia Autonomous Region highlighting research areas and other landmarks.

Inset: China country view, Inner Mongolia in red.

Table 1 provides a breakdown of interviews by area. Within the 37 families interviewed, 109 respondents were present for and/or participated in the interview process. Thirty-one families were still using original Pilot Project systems; three used systems provided under the Brightness Program, and three used systems funded entirely by the family (two cases) or by a private donor (one case). 
Table 1. Distribution of households surveyed; projects under which systems were supplied.

\begin{tabular}{|c|c|c|c|}
\hline Location of households surveyed & Number & Origin of household system & Number \\
\hline Saihantala area (Suniteyou Banner) & 15 & DOE/MOST Pilot Project & 31 \\
\hline Dongwu area (Dongwuzhumuqin Banner) & 14 & Brightness Program systems & 3 \\
\hline Erlian area (Suniteyou Banner) & 4 & Self-funded or donated systems & 3 \\
\hline Siziwang Banner & 4 & & \\
\hline Total & 37 & Total & 37 \\
\hline
\end{tabular}

The study sample was selected purposively, since the population of study was confined to users of Pilot Project systems. Families were selected for interview by the local government officials who served as guides for each area. Because of the way the original Pilot Project was set up, local government officials are the only people familiar with the location and situation of each household, since it was through them that the systems were installed and are now maintained. The PI requested that officials locate families of varied income, including those who lived close to town and those who were more isolated. Because of the nature of grassland life and travel, however, finding a family to interview was often contingent more on logistical circumstances than on planning.

Though there are a few paved county roads that traverse parts of the grasslands, it is rare to find herdsmen who are located directly off a paved road or even in sight of one. Often, herdsman households must be reached by driving across pastures that contain no roads or place markers. This process can be disorienting - given the flatness and monotony of the grassland topography, all but the most knowledgeable are easily lost, and even the PI's local guides were fallible in this regard. This situation is confounded by the quickly changing landscape-when herdsmen erect new fences for their livestock, it can be difficult to locate a gate and one must drive around the entire fenced area or simply change course. In addition, during times of heavy rain (such as occurred in August 2004), the grassland can become flooded and whole swathes are impassable. For these reasons, it was often the case that the household a local guide intended to reach was not located; sometimes, the PI and team would stop at a randomly encountered house and a neighbor would be consulted as to an alternative. Grassland residents are familiar with their neighbors, including what sort of energy system they own.

The result was that households were sometimes chosen by chance. It is for this reason that six households using Brightness Program or other non-Pilot Project systems were included in the sample - the guide arrived at these houses in error. Though a potential bias would result from relying on a government official for sample selection, it is somewhat countered in this case by the intervening variables of grassland travel — indicated by the fact that the PI encountered a sufficient number of dissatisfied customers and six non-Pilot Project families. In fact, as this report will demonstrate, the interview sample represents a fairly wide range of experience.

It is important to note that the guides did not call ahead and warn families of the impending visit; no visits were planned in advance. The result was that households were always surprised by the arrival of the PI and team, and this arrival constituted an unusual occurrence of grassland life (add to this surprise the fact that very few grassland residents had encountered foreigners before). Except for two days of the fieldwork, the PI and team numbered five individuals who traveled in one car - a fairly luxurious SUV, uncommon on the grasslands. However, on two days, two cars were required to transport extra assistants. 
Support of overall research preparation and execution was provided by Liu Zhizhang and two doctoral students at the College of Energy and Power Engineering of the Inner Mongolia Polytechnic University in Hohhot. Liu Zhizhang is the Director of the Energy program and he identified the counties in which to conduct interviews (based on his knowledge of where systems were installed), arranged for the government coordinators at each location, and provided a vehicle. In addition, he facilitated the assistance of a skilled team coordinator, Ma Tao, and two doctoral research assistants from the university, Dao Ri Na (who served as Chinese-Mongolian translator) and Ming Jie (who took technical notes and documented the research in pictures). Finally, a local Chinese-English translator, Zheng Rui, facilitated the interview process.

The PI conducted all the research evidenced in this report; designed the study protocol; prepared the interview questions; and conducted all the interviewing and note taking. However, two translators were required: English-Chinese, and Chinese-Mongolian. The English-Chinese translator chosen to assist the PI was skilled at translating accurately and precisely, rather than summarizing. However, he did not speak Mongolian. Thus, a second translator was needed. No translators were available who were fluent in all three languages.

During fieldwork, the PI asked each question in English; it was then translated into Chinese. In cases where the respondent(s) spoke only Mongolian or had difficulty speaking in Chinese (this occurred 24\% of the time: four families in Saihantala, one in Erlian, and four in Dongwu), the question was further translated from Chinese to Mongolian. The respondent's answer was thus translated, where needed, from Mongolian to Chinese, and then from Chinese to English. The PI took down these answers by hand, usually verbatim. Though a tape recorder was used in the first few days of fieldwork, the PI determined that it made respondents too uncomfortable and discontinued its use.

Interviews were conducted informally — no standard questionnaire was used — and lasted anywhere from one hour to three. The informal method was chosen because questionnaires and formal interview structures tend to alienate the interviewee and are thus ill suited for qualitative research. Instead, the interviewees were often allowed to direct the conversation themselves and thus prioritize their feelings about the hybrid system. The PI attempted to cover the same topics in every interview, however, and questions fell into four categories: technical, household demographics, daily activities, and quality of life variables. A full list of questions is available in Appendix A.

In addition to these 37 Pilot Project family interviews, four interviews were conducted among the unelectrified households of Xingmingxiang, a village in the agricultural area northeast of Hohhot. A local government official of the neighboring electrified village facilitated this visit. Instead of individual interviews, all members of the village who were present at the time (the majority were working in the community garden) gathered in the mayor's house and answered interview questions as a community. The interview followed the same format as shown in Appendix A with the exception of questions related to the hybrid system. This portion of the fieldwork proved irrelevant to the post-installation assessment and is discussed only briefly on pages 69-70. 
When attempting an analysis of the effects of any project (or, indeed, any 'intervention' that divides a society into 'pre' and 'post' stages), a necessary step is to compare the pre-project situation to that observed post-project. It is also important to allow adequate time to pass before evaluating post-project circumstances - some say a five-year post analysis is still too premature, while others feel valuable conclusions may be drawn over the short term (Boer 2000). However, among development experts, the preferred alternative to pre- and post- studies is to contemporaneously compare households that continue to live in pre-project conditions with postproject ones - for example, the study population of most of the literature outlined in this report included both unelectrified and electrified households. For "the most fundamental way to assess rural electrification's economic benefits is to observe the changes that formerly non-electrified rural populations make as they gain access. However, to understand how a region develops in response to electrification (project intervention), all other changes that affect the region's economic wellbeing must be evaluated. For this reason, policy analysts emphasize that appropriate project evaluations compare a region's situation with and without, rather than before and after, a project. However, it is impossible to observe the behavior of non-electrified and electrified households isolated from other factors that affect changes in rural wellbeing" (Barnes 2002, 63).

In essence, neither method is without its shortcoming. For the present study, neither method proved relevant. First, because only 3.6\% of Inner Mongolia's population (urban and rural) lacks electricity, locating unelectrified herdsmen households was considered impossible by local guides. Households that remain without electricity do so either because they remain mobile, in order to care for the livestock of other herdsmen, or because they are extremely isolated from commercial areas. Any analysis of the social and economic situation of this subset would necessarily conclude that lack of electrification is the least correlating variable in regard to income, quality of life, or productivity.

However, this study did include households that represented pre-project levels of electrification (i.e., 50-200 watts), even though they had participated in the project. Significant variance continues to exist from one household to another, and this was the second justification for using neither method of comparison. Though a pre-project analysis was conducted, as has been detailed above (Byrne et al 1996, 1998, 2001), no significant conclusions could be drawn from comparison of the current study's findings with this early data-there were too many other intervening factors at work in the interim. For example, Byrne and colleagues found that the average annual income of herdsmen households in 1998 was 42,227 Yuan (about US\$5100). The PI found that the average income of herdsmen in 2004 was around 40,000 Yuan. If one looks at the statistical records, average per capita annual income increased by $102 \%$ between 1995 and 2000, but fell 12\% from 2000 to 2002 (the most recent year for which information is available) (IMARBS 2003). The rise in income did not necessarily occur because of improved electrification, since many systems were not installed until 2000; the fall in income is due to several factors unrelated to electrification, including a severe drought that lasted from 20002002, causing the death of much livestock and destroying large swathes of the grassland. The carrying capacity of the grassland has continued to impede income growth of the project population, even after the drought officially ended; market prices, weather and environment, and government policies are all exacting forces on the livelihood of Inner Mongolian herdsmen. In 
short, too many intervening variables exist over time and prevent drawing conclusions based solely on project intervention.

\section{Limitations of the research methodology}

Though use of the in-depth qualitative interview was considered the best approach for this study, a few issues with the methodology merit acknowledgement. First, though questionnaires and survey forms have a tendency to alienate the interviewee and constrain the scope of the interview, the benefit of a questionnaire is that no question is omitted. Non-use of a questionnaire form in this study caused occasional omission of data. For example, all interviews included a question regarding the appliances each family owned that operated on electricity. Most of the time the respondent would point to the appliances in the room, so verification of his/her answer was quite convenient. Other times, it would become apparent upon leaving that the respondent had failed to account for the telephone that sat in the adjoining room. Perhaps the respondent did not consider the telephone an appliance, or the Chinese translation of 'appliance' would not have led the respondent to think of a telephone. In either case, a questionnaire that included a list of appliances and check boxes would have guaranteed that the ownership of a phone was documented.

Second, though the dependence on a government official or maintenance personnel for escort could not be avoided as this was a government-led project, their presence during the interviews inevitably influenced some of the answers. For example, though a few families did discuss at length their frustration with government policies and support, discussions of the Chinese government was usually off limits, and the PI quickly learned not to ask potentially political questions. And, while most families felt free to openly voice their opinions about various aspects of the system, two families were quite reserved and polite in their answers (both were located in remote areas around Dongwu and spoke only Mongolian), which calls into question the value of the opinions they supplied.

It is worth repeating that the local government retains much influence over pastoral life in the province. This relationship is a hybrid of the traditional Mongolian social order where herdsmen kept nobles and religious authorities in good favor as a matter of custom: "The metaphorical construction of the political sphere places senior agencies above communities and central to the polity as a whole. This is not a new conceptualization, introduced by the modern Chinese nationstate, but is an older and indigenous Mongolian notion of political order" (Sneath 2000, 144). Therefore, even in instances where family members were outspoken and bold in their opinions, they remained respectful of the local guide.

A few of the households visited around Erlian and Dongwu were located close to the border with Mongolia, fairly far from a town. One of the two Dongwu-area families mentioned above illustrated in the extreme the difficulties of conducting fieldwork in China. At the beginning of the interview, much discussion ensued in Mongolian before the head of the household would participate in the interview. Explanation was left for afterward, and the interview proceeded. However, the man remained very guarded and his wife never entered the room. This was unusual, because the Mongolian people are very hospitable. It was often the wife, not the husband, of other families who received the PI with the most friendliness and openness; further, 
it is customary for the female head of household to provide visitors with milk tea and dried milk curd snacks. After the interview concluded, the MOST employee acting as guide explained that until "fairly recently," this area was not open to visitors, and herdsmen were not even allowed to visit each other. During the Maoist era, the Chinese government was particularly concerned about border areas because of the potential of spies entering from Mongolia. Thus, the herdsman had required reassurance from the guide that consenting to the interview would not get him arrested. Though the Maoist era ended more than 26 years ago, the area in which this herdsman resides remains cut off from the modern world; it is difficult for herdsmen in this area to even acquire commodities, and the history of the province casts a much darker shadow in areas far from modernization's reach. In this case, the guide's presence was a saving grace, for he had himself brought news of the hybrid system to the household, and was trusted there.

Third, the PI's reliance on translators prevented her from capturing the richness and specificity of language and experience that is afforded when one interviews in the language of the study population. Instead, she had to rely on the ability of one and sometimes two translators to relate the respondent's words. As a result, the field notes from this study often read more as an interpretation or story than a conversation, despite the fact that translations were almost always recorded verbatim. Further, the PI failed to probe into the meaning of certain words. For example, the word many herdsmen used in describing the experience of 24-hour electricity and television was 'colorful.' The English-Chinese translator was expert at literal translations from the Chinese, and this is a literal rendering of the word many people used. However, a more accurate translation relative to the reader's experience may be 'rich' or 'exciting.' In other words, it is not adequately understood what the herdsmen mean when they say 'colorful.'

In addition, because interview questions and answers were translated once and sometimes twice, the consistency of language cannot be guaranteed. The PI was careful to phrase questions in non-directional ways. For example, instead of asking, "has your life improved since you acquired the system?," the PI might say, "what is the biggest change in your life since you acquired the system?" However, it is conceivable that the interpreters, having already heard many families state that their lives had improved since acquiring the system, may have been prone to anticipate the respondent's answers in the phrasing of questions. Though the research assistants were directed to translate exactly, using the words the PI used, in Dongwu the Chinese-Mongolian translator was not in attendance and the PI was forced to rely on the government guide for Mongolian translation during four interviews. Though this was not a common occurrence, the potential for bias must be acknowledged.

Finally, the majority of households attested to watching television an average of three to four hours per day, and only in the evening. However, as people got more comfortable and the conversation progressed, a respondent might reveal that their children watched TV all day when school was out. Or, in two separate instances, the male head of household stated that television was a waste of time and he never watched. Later, however, he began to talk about how his life was different from the lives of people on TV, indicating familiarity with some popular serials. In another case, the household indicated that they watched the standard three to four hours per day. Later, the male head of household admitted that he rarely worked anymore, as his wife and daughter could handle his chores, and spent most of his time watching TV. Thus, if one were to conduct a household survey in order to estimate the rural household load, and survey work did 
not allow for time to converse on a more personal level, the load analysis might underestimate the daily use of electricity. This suggests that despite some drawbacks, the in-depth interview is still the best method by which to assess qualitative outcomes. 


\section{Survey Results}

\section{Respondent demographics}

The total number of households interviewed was 37 . However, at most interviews at least two and as many as eight people were present in the room at the time of the interview, though there was either one main respondent, or a husband and wife responding jointly (in a few exceptions, a parent and child would respond equally, owing to the Chinese language advantage of the older children). All in all, 109 people of 37 households were present at the time of the interview, out of 164 family members accounted for in the interview sample. The recorded number of family members included all people presently living in the house that was serviced by the renewable energy system. In two cases, the main respondent was an offspring who had moved away and no longer lived in the house or area at present, so was not counted as part of the total family members.

Main household demographics are presented in Figure 3 (next page). All households interviewed were of Mongolian descent and were born in Inner Mongolia; the main respondent during the interview was male $43 \%$ of the time, female $41 \%$ of the time, and equally represented $16 \%$ of the time. In eight interviews (22\%), all household members present, including the main respondent, were female.

The average age of the main respondent was 39. However, the range was 14-75. Because in remote areas only the younger generation spoke Chinese, $22 \%$ of respondents were between the ages of 14-25; the majority were aged $30-55 ; 11 \%$ fell between the ages of $60-75$. Some families were located close to town, and some were fairly remote. Only one was located directly off a paved road, which is rare. The average household size was 4.4, but ranged from one to eight. Fifty-nine percent of households had four (19\%) or five $(40 \%)$ residents.

Initially, herdsmen who received Pilot Project systems were of middle or upper income but time, drought, and other factors have caused many herdsmen's incomes to fall. About a third of the families were of lower or lower-middle income relative to other herdsmen in the area, and owned 300-400 sheep; a third were of middle income and owned 500-700 sheep; a third were of upper income and owned 800-1000+ sheep and other livestock - most notably cattle, horses, or camels. Estimated annual incomes reported by herdsmen ranged from 10,000 to 100,000 Yuan (US\$1,200-12,100). Though this metric is changing, the income of pastoral families can still be fairly accurately judged by the number of livestock they own. In cases where a family wasn't able to estimate their annual income, an income level was estimated for them based on number of livestock owned and condition of household. In one case, the family was not home so their elderly parents were interviewed (see page 65); they were not asked about livestock, and the income was estimated by the guide and by the appearance of the family's house.

Where families seemed to have overspent their disposable income either on expensive household appliances or college tuition for several children, more than the usual percentage of livestock was slaughtered or sold. Thus, in these cases the association of income with sheep ownership was skewed. As previously discussed, overall income levels appear to have fallen from that recorded pre-installation. 


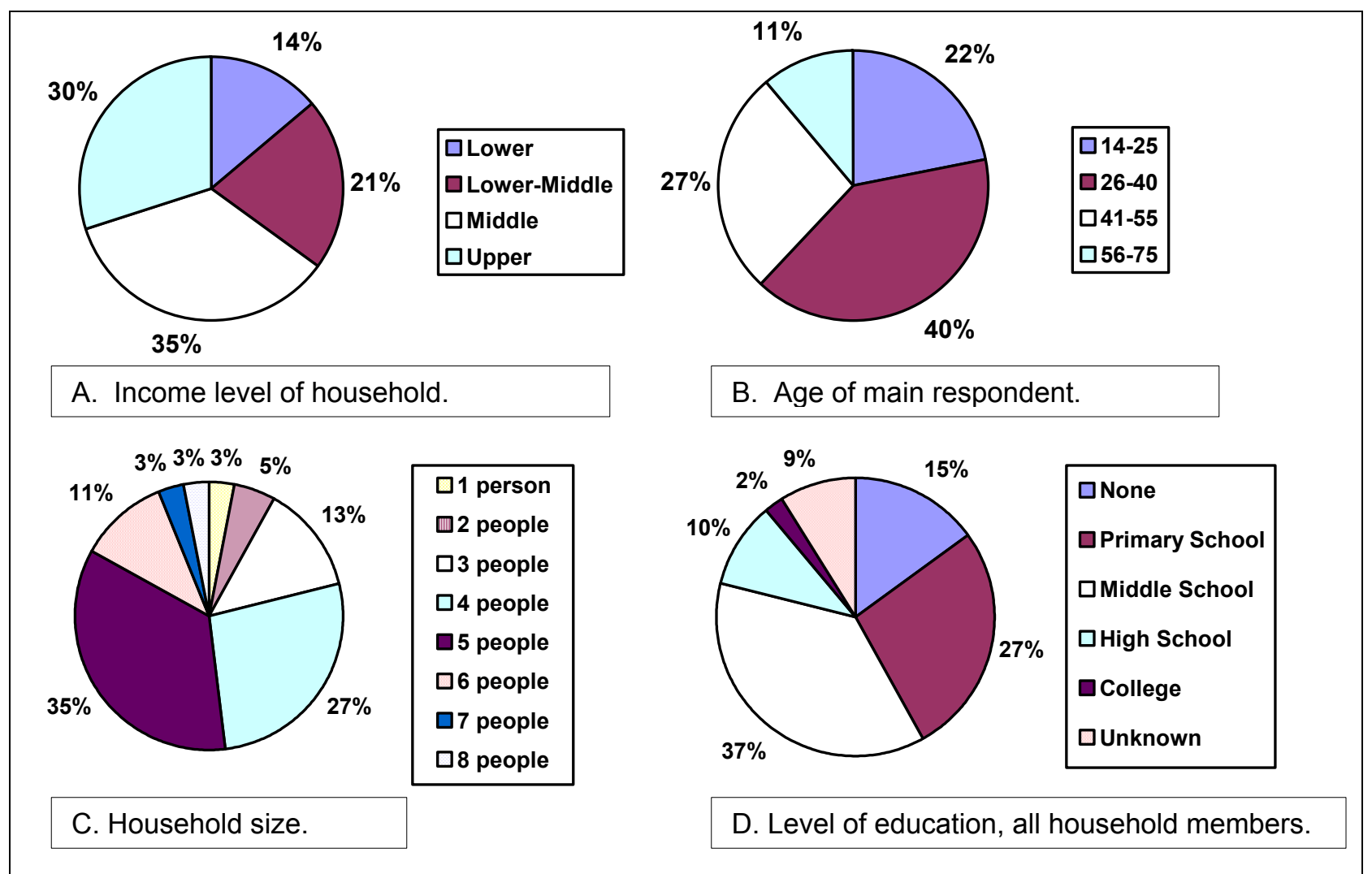

Figure 3. Distribution of main sample demographics.

\section{Household expenses}

When asked to name their main expenses, a few families cited as many as six categories but most named only two or three. Table 2 (page 40) contains this information: the middle column accounts for all categories named by households; the far right column counts only one response per family and eliminates their secondary expenses. 'Daily necessities' was the category most frequently cited - almost half of the families mentioned necessities as a main expense but only $21 \%$ named it as the main expense. When families cited necessities, they primarily referred to food, personal items, and alcoholic beverages as one category. It must be noted, however, that other families specifically ordered the importance of food and alcohol separately. In the case of 'food' and 'daily necessities', the categories overlap $-17 \%$ of families cited both. No families cited both 'daily necessities' and alcohol, however.

Significantly, $37.5 \%$ of families named their children's tuition or support of children's futures as one of their main expenses, and 33\% named tuition as the main expense. Non-tuition support included building a house for newly married offspring, or saving money to assist the offspring in moving to an urban area. Though it is not possible to compare this finding to pre-project circumstances for verification, it appears that the emphasis on education is a relatively new phenomenon. For example, Gao Xiuhe (the Dongwu MOST official and guide) noted that in the Dongwu area herdsmen put little emphasis on education in the past. However, he said that in recent years they had begun to "take education very seriously" and to hope that their children could attend school and receive a higher education, especially in regard to language - Chinese 
was of first importance (the older generations in the Dongwu area mainly speak Mongolian), but English was a close second. He referred to the father of one family who was making plans to rent a room in town so that he could move there during the week and ensure schooling for his child. Thus, the data on education expenses may point to an increased emphasis on education

Another significant finding was that $12.5 \%$ of families reported spending the majority of their income on appliances, commodities, or beautification of the house. This seems to be a new trend, and an indicator of the development of consumer society. This effect may be attributed to two impacts: first, the volume of advertising on Chinese television is equivalent to that seen in the United States and this is bound to have an effect on consumerism. Second, with the popularity of Chinese serials among the herdsman population, it is possible that viewers identify with urban or wealthy characters in the serials and begin to desire better things.

Table 2. Main expenses/use of disposable income cited by families.

\begin{tabular}{lcc}
\hline \multicolumn{1}{c}{ Expense } & $\begin{array}{c}\text { Percentage of families } \\
\text { citing it as } \boldsymbol{a} \text { main expense } \\
(\mathbf{n = 3 7 )}\end{array}$ & $\begin{array}{c}\text { Percentage of families citing } \\
\text { it as the } \text { main expense } \\
(\mathbf{n}=\mathbf{3 7})\end{array}$ \\
\hline Daily necessities & 46.0 & 21.0 \\
Children (tuition, savings, or general & 37.5 & 33.0 \\
future) & 33.0 & 12.5 \\
Hay & 29.0 & 17.0 \\
Store-bought food items & 29.0 & 12.5 \\
Commodities/appliances/house & 17.0 & 0 \\
Clothes & 12.5 & 4.0 \\
Livestock/additions to herds & 8.0 & 0 \\
Grassland festivals & 8.0 & 0 \\
Alcohol & 8.0 & 0 \\
Tools for maintenance of herd $\quad$ & \\
$\quad$ enclosures, shearing, etc. & 4.0 & 0 \\
Grass seed for sowing pastureland & 4.0 & 0 \\
Animal medical care & 4.0 & 0 \\
Family healthcare & & $\mathbf{1 0 0 . 0}$ \\
Total & & \\
\hline
\end{tabular}

This study's findings regarding main expenses do not match exactly the statistical record for herdsman households in 2002 (the most recent year for which information is available). According to the Inner Mongolia Bureau of Statistics (2003), in 2002 herdsmen households spent more of their income on food than on any other category (food accounted for $34 \%$ of total expenditure). This is surprising given the fact that herdsmen produce the majority of the food they consume. In order of importance, the other categories accounting for living expenditure in this study were residence (14\%); education, cultural and recreational activities $(13 \%)$; transportation and communications (12\%); medicine and medical services $(9.5 \%)$; clothing (9\%); household facilities, articles, and services (5\%); and other commodities and services (3.5\%). The reason for discrepancy is the method of data collection. The Bureau of Statistics bases expenditures on macro indicators such as retail sales and school enrollment, which do not account for unrecorded expenses such as boarding a child in town to attend school, or informal sector spending such as grassland festivals. 

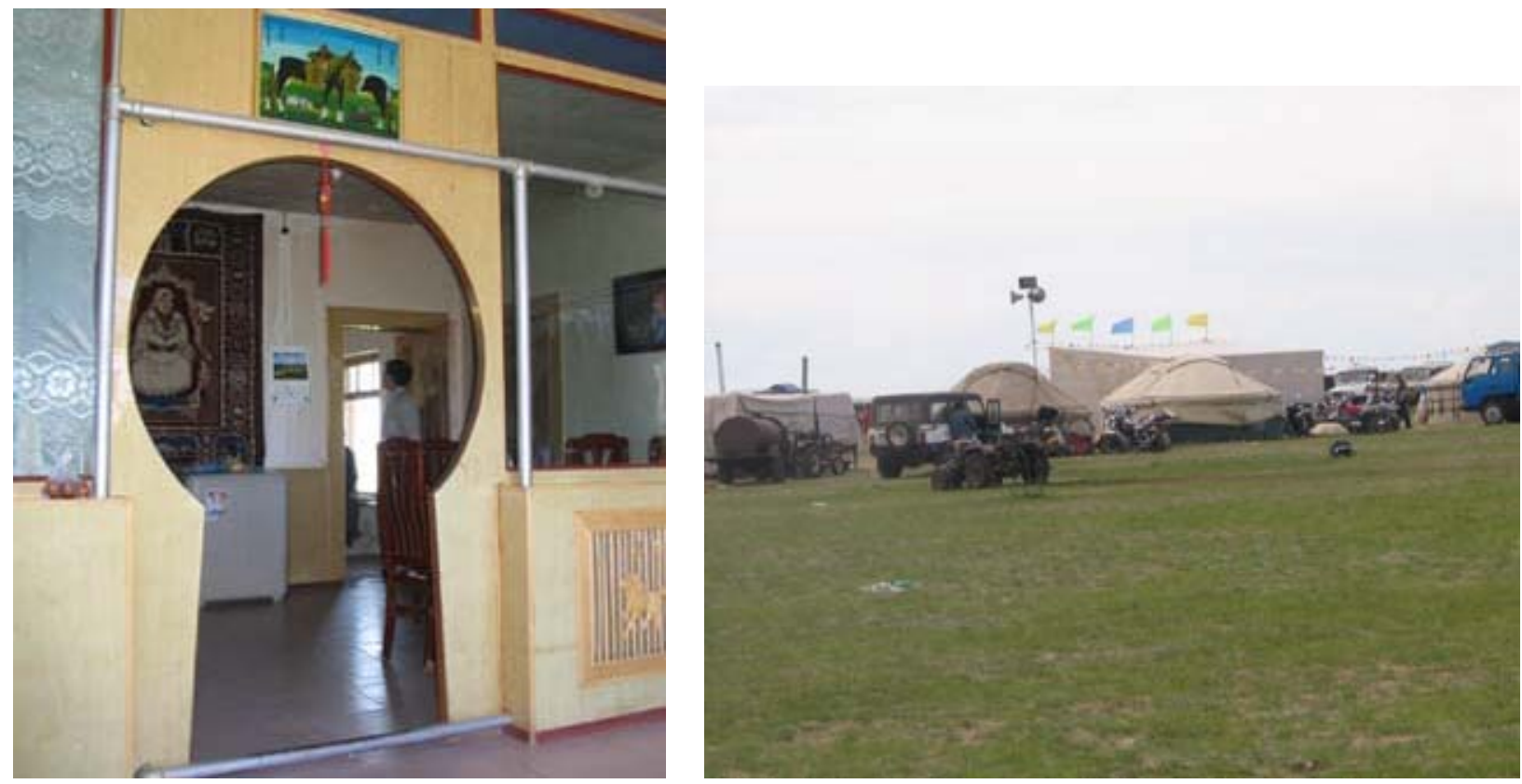

Unusual detail in interior decorating; an impromptu grassland festival springs up beside the road.

As for transportation, all of the families interviewed owned at least one motorcycle, which was used for trips into town and sometimes for herding livestock. More than half of the families also owned a tractor. A surprisingly large number of families owned a soft-top Jeep or standard car (31\%); a few owned a three-wheeled utility truck or other vehicle—one family owned a nice SUV.

\section{Education}

In China, children attend elementary school for six years. Middle school is three years, and high school is another three. There are both three-year and four-year colleges, and specialized vocational schools. In principle, tuition is covered by the government through middle school, but families are responsible for all textbooks, lodging, and other expenses. However, in many rural areas the county-level government is made responsible for financing education without being given adequate resources. Therefore, many rural residents of China must pay for all education, including elementary school, despite the fact that China has a nine-year compulsory education law (Wang, personal interview, 2004). In addition, high school and college tuition is fully the responsibility of the family, though some scholarships are available. There is almost no schooling available on the grasslands, so children go to school in the nearest sumu center or town. In very remote areas, there are a few elementary schools. However, by the time children are of middle and high school age, many of them board in town in order to attend school during the week.

Of the households sampled, close to an equal percentage of household members had completed only an elementary $(27 \%)$ or middle school (37\%) education. Fifteen percent $(15 \%)$ had never attended school. Only $2 \%$ had completed college or vocational school, and $10 \%$ had completed high school (for 9\%, information was unavailable) (see Figure 3). Of course, the children in households are included in this count. Children who were in middle school and planned to 
continue on to college are not well represented by these statistics but as they pursue their education in the coming years, the educational achievement levels of the province should continue on an upward trajectory. Indeed, the official record shows that between 1995 and 2002, enrollment in secondary school (includes middle and high school) increased 36\% while enrollment in institutions of higher education (includes full-time universities, colleges, professional schools and short-term professional universities) increased an astounding 224\%. Though the PI could find no official explanation for this increase, it is significant nonetheless.

Inclusion of this statistic is not meant to imply that the increase is a result of electrification solely or even in large part - after all, the statistic refers to the entire province, and during the sevenyear period the increase in teachers at institutions of higher education was also significant$36 \%$ - thus it is difficult to pinpoint what led to the change. In addition, the beginning number was relatively small. In 1995, there were only 16.4 university students per each 10,000 people in Inner Mongolia; in 2002 this number had only increased to 50.79 per each 10,000 - still a very small percentage $(0.5 \%)$.

\section{The renewable energy system}

Interview questions regarding the renewable energy system focused on three main areas: the configuration of the system, its operating condition and performance history, and the main issues encountered in its use. For this area of questioning, the household respondents would often defer to the government or maintenance representative present, as the latter was more familiar with the technical jargon (for example, where a household described an inverter as suddenly "exploding," the official or technician could clarify that the inverter had short-circuited, and why). For this reason, household and official responses are intertwined in this section.

The PI did not ask questions regarding specific measurements of the household load or the watt requirement of individual appliances. Some of these technical specifications were covered in pre-installation assessments (Byrne et al 1996, 2001). The PI's objective in regard to the renewable energy system was to determine its long-term sustainability.

\section{System configuration}

Of the 37 households surveyed using renewable energy systems, the majority (76\%) had systems comprised of a 300-watt wind turbine and 100-200-watt PV panel-this was the standard configuration designed by the implementation team. Exceptions included one household that used only wind, and their system was self-funded; three used only PV, and two of these belonged to the DOE/MOST project. Of the 37 households, 31 belonged to the DOE/MOST project; three belonged to the Brightness Program, and three were privately funded.

All but one of the wind- or hybrid-powered households used domestic wind turbines; most of the PV- or hybrid-power households used U.S. PV panels (68\%). All systems were equipped with a Chinese-manufactured inverter, charge controller, and battery bank. The majority of the systems had been in operation for four to five years, as most Pilot Project systems were installed between 1999 and 2000 (65\% of turbines and 73\% of PV panels were installed during this time period). However, one household visited had used their system since 1996, and this system was in near- 
perfect working condition. This is mainly because the son of the household had taken electrical classes in high school, and the installation technicians taught him how to operate the system when it was installed.

Table 3. System configurations owned by household sample.

\begin{tabular}{clclcccc}
\hline $\begin{array}{l}\text { Watts } \\
\text { wind }\end{array}$ & $\begin{array}{c}\text { Turbine } \\
\text { make }\end{array}$ & Watts PV & PV make & $\begin{array}{c}\text { Total } \\
\text { watts }\end{array}$ & $\begin{array}{c}\text { Number of } \\
\text { systems } \\
\text { (n=37) }\end{array}$ & Project & $\begin{array}{c}\text { Percentage } \\
\text { of total }\end{array}$ \\
\hline 300 & Domestic & 150 & U.S. & 450 & 15 & DOE/MOST & 40.5 \\
\hline 300 & Domestic & 165 & U.S. & 465 & 4 & DOE/MOST & 10.8 \\
\hline 300 & Domestic & 100 & U.S. & 400 & 3 & DOE/MOST & 8.1 \\
\hline 300 & Domestic & 155 & U.S. & 455 & 2 & DOE/MOST & 5.4 \\
\hline 300 & Domestic & 120 & Domestic & 420 & 2 & DOE/MOST & 5.4 \\
\hline 300 & Domestic & 50 & Domestic & 350 & 1 & DOE/MOST & 2.7 \\
\hline 300 & Domestic & 50 & Domestic & 350 & 1 & Brightness & 2.7 \\
\hline 300 & Domestic & 150 & Domestic & 450 & 1 & Brightness & 2.7 \\
\hline 100 & Domestic & 200 & Unknown & 300 & 1 & DOE/MOST & 2.7 \\
\hline 300 & Domestic & 200 & Unknown & 500 & 1 & Brightness & 2.7 \\
\hline 600 & Domestic & 400 & U.S. & 1000 & 1 & Brightness \& & 2.7 \\
\hline 1000 & U.S. & 400 & Unknown & 1400 & 1 & Self-funded & 2.7 \\
\hline 0 & N/A & 800 & European & 800 & 1 & DOE/MOST & 2.7 \\
\hline 0 & N/A & 210 & Domestic & 210 & 1 & Donated & 2.7 \\
\hline 0 & N/A & 50 & European & 50 & 1 & DOE/MOST & 2.7 \\
\hline 400 & Domestic & 0 & N/A & 400 & 1 & Self-funded & 2.7 \\
\hline Total & & & & & & & $\mathbf{1 0 0 . 0}$ \\
\hline
\end{tabular}

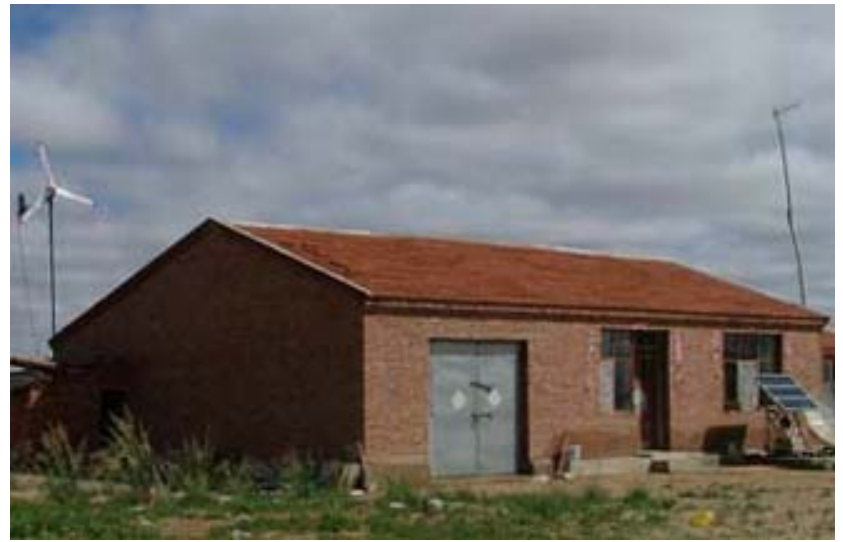

Typical set-up of Pilot Project hybrid system.

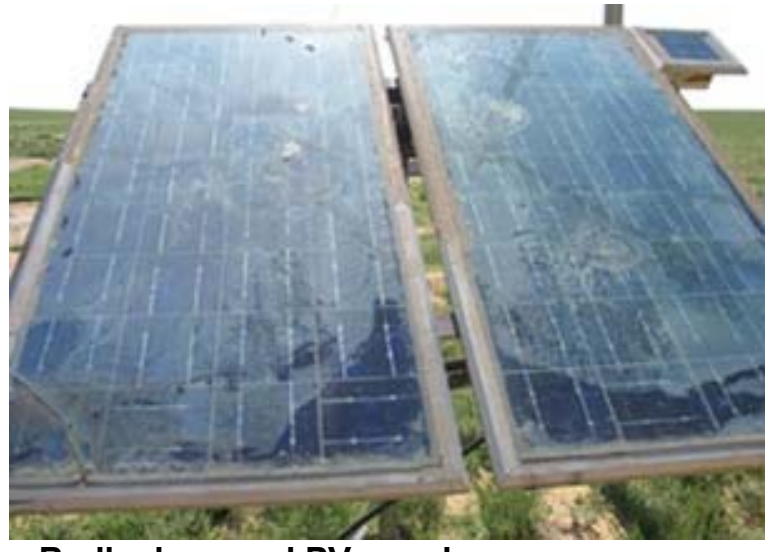

Badly damaged PV panels. 


\section{System performance and technical issues}

Though many systems had performed quite well, others had experienced significant problems. Almost half (49\%) of the systems were assessed both by the household end-users and government/maintenance representative present as being in good condition, fully functioning; $35 \%$ were experiencing sporadic difficulties, mainly with the inverter or battery bank; $16 \%$ were in poor condition, barely functioning. Families were asked to state the

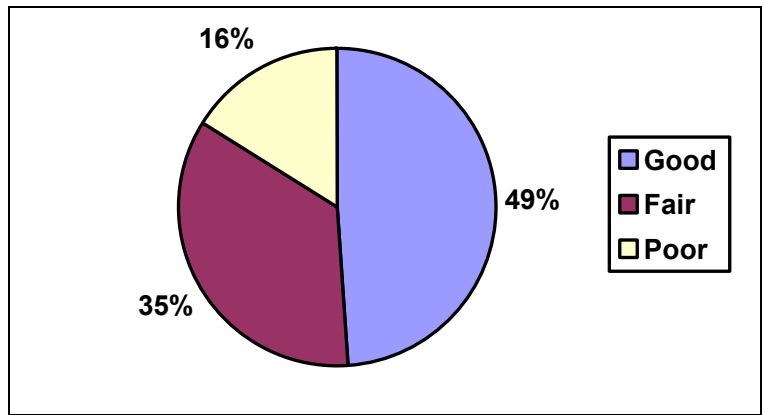

Figure 4. Operational condition of systems. main problems they had encountered with the systems. Most families gave just one reason, but $35 \%$ listed two to four reasons. In the below Table 4, the middle column includes all the reasons cited by families; the far-right column cites only the main reasons and eliminates secondary explanations provided by $35 \%$ of respondents. The main problems cited by families for system difficulty were a weak or old battery (35\%) and a faulty inverter (38\%).

\section{The system inverter.}

All inverters and charge controllers used in Pilot Project systems were of Chinese manufacture and consisted of 500 to 600 watts. Both households and system technicians attributed inverter problems primarily to poor manufacturing quality rather than user error. Sixteen percent of households admitted that user error was at least partly to blame for system difficulties, and this factor, along with poor manufacturing quality of inverters, was also frequently cited by system technicians as the main problem with system performance. It should be of especial note, however, that a full $35 \%$ percent of households reported no problems with the system-either in the past or at the present time.

Table 4. Main problems households cited for poor system performance or failure.

\begin{tabular}{lcc}
\hline \multicolumn{1}{c}{$\begin{array}{c}\text { System problem/cause of } \\
\text { failure }\end{array}$} & $\begin{array}{c}\text { Percentage of families citing it } \\
\text { as } \boldsymbol{a} \text { problem } \\
(\mathbf{n = 3 7 )}\end{array}$ & $\begin{array}{c}\text { Percentage of families citing it } \\
\text { as the } \text { problem } \\
(\mathbf{n}=\mathbf{3 7})\end{array}$ \\
\hline Inverter & 38.0 & 22.0 \\
Battery: weak or old & 35.0 & 22.0 \\
No problems & 35.0 & 35.0 \\
Weather-damaged PV panel & 16.0 & 8.0 \\
User error or poor maintenance & 16.0 & 2.5 \\
Low manufacturing quality & 11.0 & 8.0 \\
Weather-damaged turbine & 5.4 & 2.5 \\
Low wind or sun resources & 2.7 & 0 \\
Total & N/A & $\mathbf{1 0 0 . 0}$ \\
\hline
\end{tabular}

Mr. Siqin (a system technician employed by the Dongwu branch of MOST), who maintained that poor manufacturing quality was a greater problem than user error in regard to the inverters, was familiar with a number of systems installed in the area under a Spanish project that utilized Spanish-made components. These inverters, he said, performed much better. Because he had witnessed the exact same problem occur with Chinese-made inverters for a number of families at once, he was convinced user error was not to blame. 
According to Yang Yi, former MOST official and owner of the Saihantala renewable energy company, there are two main reasons for the poor manufacturing quality of inverters. First, the technology has not had time to mature; Chinese manufacturers are still in the learning phase. In the late 1990s when the systems were installed, inverters were not yet popular for electricity use so there was only one Chinese manufacturer of them. Though more companies are now manufacturing the component and the technology has improved, it has not had time to mature adequately. Of the 79 hybrid systems installed in the Saihantala area under the DOE/MOST project, the inverters come from three different manufacturers. This makes holding a manufacturer accountable for quality standards a difficult task, especially when the other system components come from different manufacturers (Yi, personal interview, 2004).

The second reason for poor manufacturing quality is the price ceiling on the inverters. The Pilot Project implementation team considered using U.S. or other foreign inverters, but the price was too high because the market had matured. Because the Pilot Project had only limited funding, the Chinese government established a company to begin manufacturing inverters at a low price, acknowledging that the quality would also be lower. The systems were only guaranteed to operate for three years, and no contingency planning was put into place as to what provisions would be made for herdsmen after that time. It did not appear that herdsmen were aware of this three-year lifespan. The absence of a long-term vision remains one of the main problems facing the Chinese government today in various development projects. This point will be discussed further in the Discussion section, page 71.

\section{User error.}

User error is a significant issue, and it almost surely occurs more frequently than most families are willing to admit; of the 37 interviewed, six families cited their own error as a problem with system function. Every family observed and assisted in installation of their system, and each was provided with basic training in best-care practices - how often to clean the PV panels; how to anchor the panel and the turbine blades, and when to take extra precautions because of wind; what the positive and negative terminals on the battery mean, how to connect the terminals correctly, how to monitor battery discharge levels, and how to keep the battery filled with distilled water. Each family was also provided with a technical handbook. The installation team in each area sought out the more highly educated younger generations of each family and explained the system to them, in order to ensure that at least one member understood the basics. After two years of ownership, most families were assumed to understand the system, and this is generally when the warranty expires. However, a significant number of families had experienced problems beyond their comprehension, such as when a surge of power from strong wind caused the inverter to short-circuit and shut off all power. Other issues arose because of confusion about disconnecting or powering off the inverter when battery maintenance was required. Most households reported that they understood how to install the system, having participated in and/or observed the initial installation, but not how to fix or maintain it. Only one-third of families interviewed stated that they understood basic best-care practices. For this reason, the local service team is quite familiar with many households.

Appendix B contains the Chinese version of the user manual with which each household was provided; an English translation of the manual is presented in Appendix C. Manuals were also written in Mongolian, for the families that did not read Chinese. The manual is included with 
this report to demonstrate the breadth of information provided to each household upon installation of the system. The limited extent of most households' understanding of best-care maintenance practices - most only knew to keep the surfaces of the PV panel and battery bank clean-would suggest that the information in the manual is not presented in an accessible manner for novice users, or that the level of technical understanding necessary to operate such systems is beyond the capacity of Inner Mongolian herdsmen. However, the extent of training appears to have been a matter of choice on the part of the service team as well.

Yang Yi, whose company serviced Suniteyou and Siziwang banners, stated that he and his employees only trained households in simple maintenance practices for a reason- $\mathrm{Mr}$. Yang thought it wiser that trained technicians be consulted when more complicated problems arose. That Mr. Yang and his employees provided reliable and efficient maintenance services to the herdsman population was apparent, and is a credit to his company. However, that households remain dependent on his expertise is problematic. Of course there were exceptions to this, such as the herdsman described on page 64 who was very diligent in monitoring the battery charge times - he took it upon himself to learn about the system and seemed to enjoy owning this knowledge. His experience suggests that educating herdsmen about technical complexities is not necessarily limited by their level of formal education - this man had completed no more than middle school.

According to project leaders, training was a point much emphasized during the development of the Pilot Project, and note it is of interest that this component of project implementation is still chronically weak in Chinese rural electrification projects. While this situation is improving in China, some of the most effective training examples have been where international experts have participated in all levels of the training development and execution, working with domestic teams. In the case of the Pilot Project, international expert involvement in the training was limited to establishing principles for training development and reviewing manuals, since the funding level for the project could not support experts in the field. ${ }^{10}$ In any case, lack of adequate training is a shortcoming of the project, and this point will be revisited on page 75 .

\section{The battery bank.}

Pilot Project systems of standard configuration were initially equipped with three Chinese-made lead acid deep-cycle batteries for a total of 150 Amp hours and 36 volts. Smaller systems could run on only one or two such batteries. Quite a few families complained about the short lifetime of the batteries (three to five years is the average lifetime but it is less if batteries are improperly used), which some could not afford to replace, leaving the system in near disuse (batteries cost about 500 Yuan apiece, or US\$60). Batteries had been replaced by most families at least once; three families had replaced their battery twice. The local MOST officials and technicians blamed user error quite frequently, whereas household respondents blamed the short lifetime of the batteries. However, during system installation, families were told that batteries have a limited lifetime and they should expect to replace them after approximately five years. The performance of the batteries in this project would seem to be consistent with what is generally known about the quality of Chinese batteries.

\footnotetext{
${ }^{10}$ Per personal conversation with William Wallace, UNDP/GEF Renewable Energy Project in Beijing.
} 


\section{Damage to PV panels and turbine blades.}

Another cause of system problems cited by households was weather damage to PV panels (16\%) and wind turbines (5\%) - strong winds knock down PV panels that are not adequately anchored, or stones carried by the wind break the panel surface; strong winds have also broken turbine blades. In addition, one family's PV panel had been damaged when a feud between two brothers resulted in a fistfight and blows landed on the panel. Though households are taught how to anchor turbine blades during periods of strong winds and to secure PV panel frames with rocks or heavy equipment, this procedure is often neglected.

\section{Resource availability.}

Only a few families complained of low wind or sun resources, and this was understood to be an infrequent problem. Also, it should be noted that survey work occurred during August, a month of low wind. In addition, August 2004 was a month of unusually heavy rainfall (and thus weak sun) for the area.

\section{Perceptions of energy source.}

Despite the difficulties described above, $62 \%$ of the families surveyed enjoyed 24-hour or near24-hour power; the rest used power mainly at night for an average of three to five hours. Regardless, a frequently repeated refrain heard from families was that electricity is precious. Whether the family had the potential for 24-hour power or not, most were of the opinion that electricity should be conserved and used only at night, for lighting and watching TV. Though women would sometimes speak of doing emergency chores at night, such as machine- or handsewing festival garments or children's clothing for the next day, electricity corresponded to evening expectations of rest and enjoyment. In fact, 16 of the 31 families (52\%) who owned refrigerators used them only occasionally, in order to conserve power for television.

Some families were asked how they perceived renewable energy systems compared to the gridconnected electricity they observed in town; others were asked which they would prefer, if given a choice. The responses were mixed, and perceptions varied. Most herdsmen agreed that hybrid systems protected the grasslands from pollution and thus had many benefits over using coal or diesel. One respondent felt that renewable energy-based systems are more appropriate to the grassland because people have control over the source of electricity themselves in contrast to people living in town, who are at the mercy of local government's decisions, which can cause the power to be shut off. Another mentioned that people in town have to pay for the amount of electricity they use, whereas with hybrid systems the cost is free after the initial investment.

Despite these advantages, and based on observations gleaned from visits to town or conversations with local residents, other respondents felt that grid-connected electricity is more reliable and convenient, because it requires less personal commitment and attention. The main difference in opinion seemed to be whether a respondent considered that control of one's energy supply is a convenience or a nuisance, and would seem to reflect a personal preference regarding the state's involvement in one's daily life as well as the level of familiarity with system maintenance. No one opinion was more prevalent than the other-within families both opinions sometimes coexisted - and unfortunately, no solid conclusion can be drawn on this question. 
Some families volunteered the opinion that their hybrid systems were more environmentally responsible than fossil-fueled gen-sets or grid connection. Concern for the wellbeing of the natural environment is an integral part of the grassland lifestyle (since the wellbeing of pastoralists is dependent on a healthy grassland ecosystem); however, the PI speculates that awareness of the harmful effects of fossil fuel use is most likely an effect of access to the national media. Either way, most families placed high value on the grassland lifestyle, and use of renewable energy seemed to be correlated to this valuation, whether implicitly stated or not. Household respondents consistently associated grid connection with the busy, noisy life of the town. Families associated renewable energy systems with maintenance of a peaceful undisturbed lifestyle.

\section{Appliance ownership and use}

Table 6 (next page) displays the range of appliances owned by project families and their frequency of ownership. All 37 families owned at least one electric light, and many had purchased energy-saving compact fluorescent bulbs, which require only 9-17 watts compared to regular bulbs that use 25-40. Not all households had light fixtures in each room of the house. It appeared that lighting the main room, where guests are received, was the common priority.

All families also owned at least one TV, and all but two of these were color TVs. Most TVs were at least 21 " on the diagonal; $14 \%$ of families owned two TVs, and one family owned three. More than half (55\%) of the families interviewed reported watching TV an average of 3-5 hours per day. Only one family admitted to watching more than five hours a day; $19 \%$ estimated they watched $4-5$ hours, and 23\% estimated viewing time at 2-3 hours per day (the reader is reminded that page 36 discusses caveats to these estimates).

Although four families declined to specify favorite television programs, in most households all family members present were ready to name their favorites. Among children, kung fu movies were a favorite; among adolescents and teenagers, serials - especially ones that dealt with romantic love- and music TV were most often preferred. Children and young adults were also the ones to name non-Chinese movies, especially U.S. movies. The male head of household was usually the one to mention news. However, the main favorite was Inner Mongolian programming, which consisted of coverage of grassland festivals and serials dealing with traditional ethnic Mongolian themes. Favorites are listed in Table 5, next page.

In addition, 78\% of families owned at least one DVD or Video Compact Disk (VCD) player; three families owned both. TVs and entertainment centers were almost always located in the main room and enjoyed central placement. Stereos were also quite prevalent, and $73 \%$ owned one, which ranged from a simple "boom box" to a multi-unit console (all families owned at least a simple radio). Four of the wealthier families owned stereos that were quite luxurious, with large floor-standing speakers and/or karaoke machines. 
Table 5. Television favorites named by family members.

\begin{tabular}{lcc}
\hline \multicolumn{1}{c}{ Program } & $\begin{array}{c}\text { Number of household } \\
\text { members listing it as a } \\
\text { favorite }(\mathbf{n}=\mathbf{3 7})\end{array}$ & $\begin{array}{c}\text { Percentage of total } \\
\text { households } \\
(\mathbf{n}=\mathbf{3 7})\end{array}$ \\
\hline Mongolian programming & 23 & 31.5 \\
Serials (Chinese) & 15 & 20.5 \\
News & 12 & 16.5 \\
Movies (esp. non-Chinese) & 6 & 8.0 \\
Music TV & 5 & 7.0 \\
Kung Fu & 4 & 5.5 \\
None specified & 4 & 5.5 \\
Sports & 3 & 4.0 \\
Technological/science & & \\
$\quad$ channel & 1 & 1.5 \\
Total & & $\mathbf{1 0 0 . 0}$ \\
\hline
\end{tabular}

Table 6. Appliances owned by herdsman households.

\begin{tabular}{|c|c|c|}
\hline Appliance owned & $\begin{array}{c}\text { Number of } \\
\text { households } \\
(n=37)\end{array}$ & $\begin{array}{c}\text { Percentage } \\
\text { of total } \\
(\mathbf{n}=\mathbf{3 7}) \\
\end{array}$ \\
\hline One color television & 29 & 78.0 \\
\hline Two color TVs & 5 & 14.0 \\
\hline Three color TVs & 1 & 3.0 \\
\hline Black \& white TV & 2 & 5.0 \\
\hline Total & 37 & 100.0 \\
\hline Two or more lights & 33 & 89.0 \\
\hline At least one light & 37 & 100.0 \\
\hline Refrigerator/icebox & 31 & 84.0 \\
\hline One DVD or VCD & 27 & 73.0 \\
\hline Two DVDs/VCDs & 3 & 8.0 \\
\hline Total & 29 & 81.0 \\
\hline Satellite telephone & 26 & 70.0 \\
\hline Cell phone & 3 & 8.0 \\
\hline Total & 29 & 78.0 \\
\hline Electric stereo & 27 & 73.0 \\
\hline Washer/dryer & 14 & 38.0 \\
\hline Dryer only & 1 & 3.0 \\
\hline Electric water pump & 4 & 11.0 \\
\hline Solar water pump & 1 & 3.0 \\
\hline Diesel water pump & 6 & 16.0 \\
\hline Total & 11 & 30.0 \\
\hline Rice cooker & 5 & 14.0 \\
\hline Room floor fan & 2 & 5.0 \\
\hline Electric wok & 1 & 3.0 \\
\hline Electric keyboard & 1 & 3.0 \\
\hline
\end{tabular}

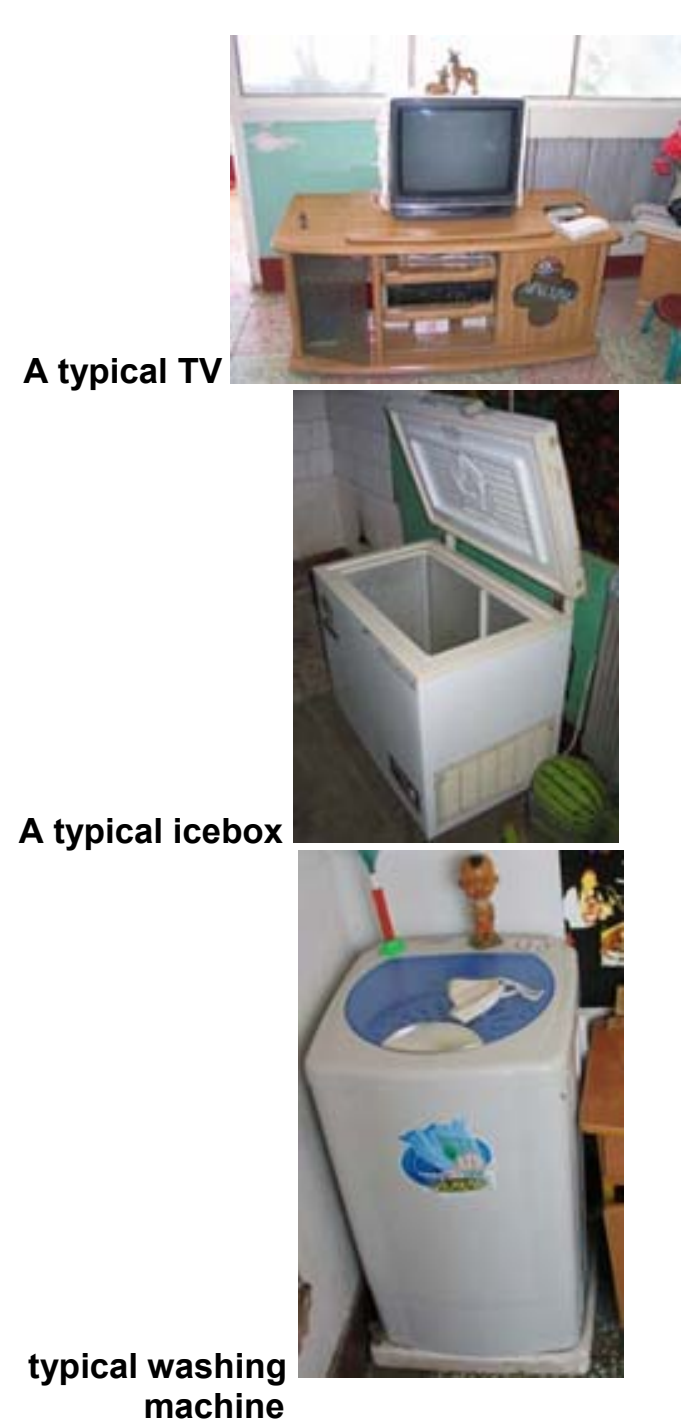


Though $84 \%$ of families owned an icebox or refrigerator (which usually also contained a freezer compartment), most were not operated full-time. Use of refrigerators and freezers appears to be at least partly seasonal, since in winter they can be utilized for storage in the cold environment, without needing electricity. Summer use seems to be largely intermittent—only when the need arises for preservation of fresh meat or the occasional produce. Though some families attributed infrequent appliance use to insufficient electrical power, whether they enjoyed 24-hour power or not, most families preferred to use appliances only when necessary. The exception to this rule was, of course, the television and it appeared that if the choice had to be made between the refrigerator and the TV, the TV was chosen (as previously stated, 52\% of families volunteered this opinion).

However, refrigerators were the appliance most often attributed with making housework and meal preparation more convenient and enjoyable. Previous to obtaining Pilot Project systems, women of the household had to cook each meal from scratch, and leftovers had to be consumed in a relatively short period of time. If a sheep or cow was slaughtered for consumption, the meat had to be preserved by drying or eaten immediately. When produce was purchased in town (the only vegetable that grows naturally in the grassland is a wild onion), it also had to be consumed relatively quickly. With a refrigerator, freshly slaughtered meat can be stored for several days or frozen, and the preparation of the carcass can even be postponed. In addition, meals can be made ahead of time and leftovers preserved for days, requiring less labor in cooking. Finally, refrigerators allow for the purchase of perishable produce and other food items in town that can be consumed over several days or weeks, making trips to town less frequently necessary. One family spoke at length of their enjoyment of fresh peaches and watermelon from town, just one of the ways in which the quality of life had improved since acquisition of the system.

Thirty-eight percent (38\%) of families also owned a washing machine, but most used it infrequently as well-water is even more precious than electricity. Even so, one family reported washing laundry twice a week, and the households that did rely on the washing machines reported a decrease in daily chores. Washing clothes by hand is a time-consuming endeavor.

Sixty-eight percent of families had their own well or shared one with a nearby relative. The majority used either a manual pump to retrieve water or simply used the well to store water that was carried from elsewhere. One family used a solar-powered pump, and four had electric pumps that ran on the hybrid system. No family enjoyed indoor plumbing. However, one family did have a separate room that had been constructed for a bathroom, though it contained only a bathtub. Most families kept a simple bowl for washing up and performed other bathroom duties outdoors.

Various other appliances were owned by some herdsmen. Many kitchens were equipped with an electric cooking fan, which kept the oven fire going strong; traditionally, a laborious handpowered fan is used to keep the oven plates hot (see page 56 for further elucidation). The kitchen fan and the washing machine were the appliances most frequently cited by women as making their lives more convenient.

Rice cookers are one of the most common kitchen appliances in China. However, only $14 \%$ of the families surveyed owned one. Most likely, this is because rice cookers use 300-400 watts of 
electricity and when used, necessitate non-use of almost all other appliances. The rarity of rice cookers may also be attributed to the fact that the Mongolian diet consists of meat, dairy products, and wheat - very little rice. Surprisingly, one family owned an electric wok and a rice cooker. Woks require a large amount of power for operation as well.

Two families owned electric oscillating floor fans which made the resting period after the noon meal much more enjoyable - it helped to keep the house cool and flies away. A few families owned electric sewing machines, and these were especially useful during the summer months when grassland festivals present the necessity of revamping traditional costumes. Other infrequent appliances included an electronic keyboard (incidentally, the family that owned the keyboard was also the one to install a bathtub). Another family that did not own a washing machine did own a "dryer"- basically, a hose that blows warm air. This is especially useful in winter when clothes take much longer to dry. Most washing machines are equipped with this component.

Aside from the TV, the most common appliance owned by families was a satellite telephone. Some areas of rural Inner Mongolia are served by phone lines from a nearby town, but none of the pastoral grassland observed in this study benefited from that convenience. Instead, most herdsmen use very basic satellite cables to receive a telephone signal. Telephones, along with TVs, have wrought the largest change in daily and business practices of herdsmen. Herdsmen can connect with potential buyers of livestock in real time and over further distances, and now have a wider access to and choice of buyers. Like television, telephones facilitate access to information in real time, which can be crucial in cases of emergency such as illness of a family member or sheep. In addition, telephones have facilitated better communication among the community-herdsmen report that they interact with their neighbors more now than they did prior to the project.

\section{Productive uses of electricity}

It is the premise of this study that services not commonly considered a productive use, such as household lighting, are indeed capable of contributing to the household's growth in tangible and implicit assets. In the case of lighting, high-quality illumination facilitates studying, which improves a child's potential for excelling in school and later down the line, increases his/her income earning potential. Similarly, if natural capital is considered, the use of renewable energy in lieu of diesel lessens the environmental impact of air pollution, and prolongs the productive potential of the fragile grassland ecosystem. Thus, in this study a productive use can be found in two categories: direct and indirect.

\section{Direct productive applications of the hybrid system}

\section{Animal care.}

When asked if and how electricity helped them to generate income, most herdsmen laughed and retorted that electricity was too precious to use on sheep. Only $8 \%$ of families had put a light in the animals' shed for performing animal caretaking tasks after sundown, and only 5\% reported they used electricity during the spring to care for newborn sheep. However, as reported above, 
four families used an electric pump to retrieve water from the well, and since this water was also for animal use, this constitutes a productive use.

None of the families used their refrigerator or washing machine for income-generating activities such as sale of milk products or manufacturing of butter. Because every herdsman's family produces its own milk and milk products for consumption, there is no market for the sale of milk. However, one family did utilize their renewable energy system for tourism activities and reported selling milk and dried milk curd snacks to guests as well.

Though some expressed interest in obtaining these commodities, none of the families utilized electric wool shearers or electric machines for pumping and processing cow milk. Herdsmen who had tried electric shearers before were not enthusiastic about them, and reported that the shearers immediately clogged up with dirt and would not work unless sheep were bathed before shearing - needless to say, with water scarce, bathing sheep would constitute a significant cost and outweigh the benefit of electric shearers. In addition, small amounts of dirt or sand particles woven into the wool increase its weight and will bring a higher price. Thus, seasoned herdsmen prefer to use hand shearers (the reader will note that other herdsmen did mention a desire for electric shearers). In addition, use of electric milking machines was regarded as pointlessmany families own fewer than 20 cows and can more quickly milk these by hand.

As far as direct income-producing applications for electricity, Inner Mongolian herdsmen have few. Because their lifestyle is based on pastoralism, there is a limit to the ways in which use of electricity can directly increase their production; their income is based solely on sheared wool of sheep and cashmere goats, sale of livestock, and sale of meat. However, 'productive uses' are not confined to direct applications - many tasks contribute to the pastoral economy. Table 7 presents the range of productive uses employed by herdsmen. The middle column represents the herdsmans' perspective on whether they the use was productive; the far right column is the PI's estimate, based on her observations in the field, of how many herdsmen actually benefit from the productive use.

Table 7. Productive uses cited by herdsmen; reported vs. likely employment of each use.

\begin{tabular}{lcc}
\hline Productive use & $\begin{array}{c}\text { Number of families } \\
\text { citing the use } \\
(\mathbf{n}=\mathbf{3 7})\end{array}$ & $\begin{array}{c}\text { Number of families } \\
\text { likely employing } \\
\text { productive use } \\
\text { (n=37) }\end{array}$ \\
\hline None & 23 & 1 \\
Television: weather/news/economic & 5 & $\mathbf{3 3}$ \\
$\quad$ indicators/medicine/science/technology & 3 & 3 \\
Lights in animal stable (convenience) & 2 & $\mathbf{2 9}$ \\
Satellite telephone (business facilitation) & 2 & 4 \\
Water for animals & 2 & 2 \\
Lights/heat lamp to safeguard health of baby & & 1 \\
$\quad$ sheep & 1 & 1 \\
Doctor: treating patients & 1 & 1 \\
Tourism & 0 & 0 \\
Refrigerator for sale of milk products & 0 & \\
Electric shearer & & \\
\hline
\end{tabular}




\section{Tourism.}

Two of the 37 families visited derived productive uses from their systems entirely apart from the pastoral lifestyle. Both of these families were located in the vicinity of Saihantala. The first family was easily the wealthiest family in the area, grossing over 100,000 Yuan (US\$12,082.00) per year. This family had set up two yurts in front of their house, which they had electrified and used for tourism (one of the yurts is pictured at right; note large PV panel behind). Each yurt contained a TV, stereo, karaoke machine, and light, and earned the family

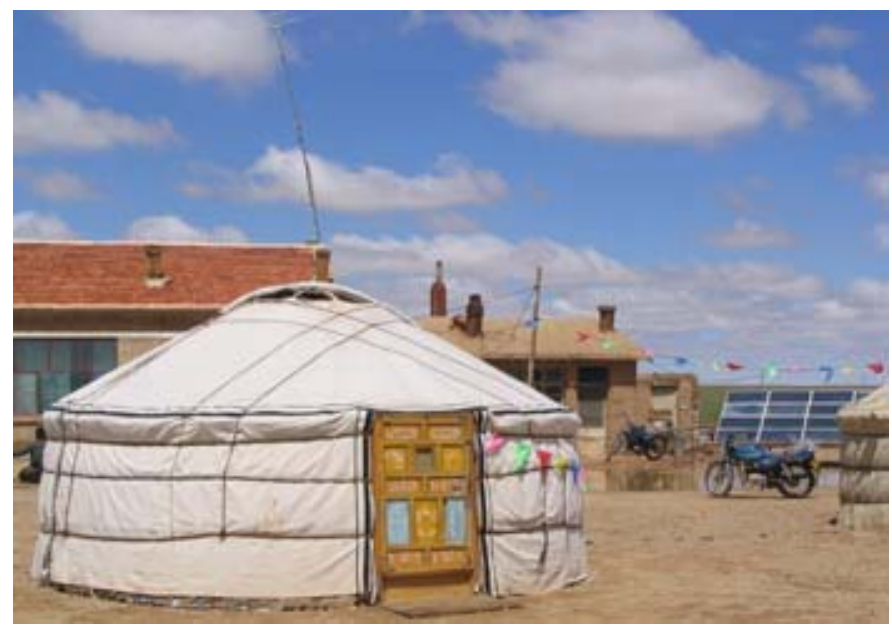
1000 Yuan (US\$121.00) per tourist visit. During the year that the yurts had been in operation, the family had hosted 200-300 tourists. In the main room of the family's house, a picture hung on the wall that showed a large tourist group they had hosted. The family's 800-watt PV system, installed as part of the Pilot Project in 1998, supplied sufficient electricity for both yurts and the family's residence, which contained a refrigerator, freezer, TV, lights, washing machine, and phone; they also utilized an electric water pump to extract water from the well.

This family also earned income from their 800 sheep and cashmere goats, and 10+ cows. In addition to selling wool and meat from the livestock, they sold their milk products to the tourists who stayed there. The female head of household emphasized several times during the interview that without electricity, their lifestyle would be significantly diminished, because they could not host tourists. Tourism of the grassland has increased in recent years; in 2002 Inner Mongolia was visited by 439,400 international tourists, the majority of which were from Mongolia, Russia, and Japan (IMARBS 2003). The number of Chinese nationals visiting the grasslands is not accounted for, but indications point to a growing trend in ethnic tourism within China - as one anthropologist aptly puts it: "Ironically, China's minority nationalities, once the objects of pity and disparagement, have more recently become objects of 'desire.' This gradual shift began in the 1980s with the growth of domestic tourism, but quickened in the ideological vacuum of the 1990s, when China, as a nation, began searching for its soul" (Hillman 2003, 181). An unexpected side effect of globalization may well be an emphasis on the once-ostracized "otherness" of ethnic identities. The Saihantala family provides tourists with an authentic experience of grassland life with the added convenience of modern appliances. A family visited in the Erlian area indicated interest in a similar operation.

\section{Traditional medicine.}

The second family demonstrating an alternate income-generating activity was headed by a Mongolian medical doctor. This family used a Pilot Project system installed in 2001 that consisted of 165 watts PV and 300 watts wind. Primarily the family's income came from their 700 sheep and $40+$ cows, but the doctor's work brought in supplemental cash. On the day of the interview, the doctor was caring for a patient in the next room who was hooked up to an IV. The doctor's patients came mainly from nearby, but he had received some in the past from far away. In the back room of the house, many bottles of Mongolian medicine sat on shelves. They had 
been labeled by hand, and were filled with powders, herbs, and roots. Traditional Mongolian medicine occupies an important part in the culture, just as traditional Chinese medicine continues to flourish even in China's westernized cities.

The doctor had previously owned a computer, but it had recently been sold. Otherwise, his medical practice was supported by the hybrid system only in the use of lights and the telephone (however, the patient was watching TV in the next room while being treated). The IV machine was not electric, but the doctor did plan to acquire some electronic medical instruments in the future. However, his system was not of sufficient power to run all of his appliances at onceincluding the refrigerator-so new appliances would necessitate a larger system.

The doctor spoke of his desire for his two daughters to get out and experience the world; both of them had taken the college entrance exam, and were planning to go to university; the eldest, fearing bad marks on the exam, was also considering attending the provincial police academy. They were encouraged to forego housework in order to study. The doctor had only received a primary school education, though he had received a year of medical training.

\section{Indirect productive uses}

The range of indirect productive uses is detailed in Table 7 (page 52) and includes television viewing and use of the telephone. Indirect productive applications that are harder to quantify by survey are discussed below.

\section{Telephone and television.}

Though only $19 \%$ of herdsmen volunteered the opinion that TV programs and satellite phones aided them in income-generating activities (care and sale of sheep and wool), the argument must be made that the percentage of herdsmen utilizing the TV and/or phone as an indirect productive use is at least $75 \%$ and most likely much higher. An estimate of the true count is also included in Table 7.

First, satellite phones allow herdsmen to conduct business over long distances and in real time. Those who acknowledged the business aspect of telephone communications reported that previous to system installation, they were obliged to travel by motorcycle, horse, or the rare car in order to find buyers for wool and meat. Use of the phone saves precious time and allows herdsmen to shop around for the best offer, even if it is farther away.

Second, television is a significant productive use. As Richter (1999) has reported, weather forecasts have a positive impact on herd productivity by reducing risks-livestock, especially the young, can be safely secured in enclosures when deadly dust storms or other severe weather occurs; the health of the sheep is protected by planning ahead and shearing only in warm and dry weather; drying hay can be moved indoors when rain approaches; and when a drought is expected, herdsmen can prepare by reserving money for animal fodder. TV is beneficial beyond 
weather forecasts, however. Herdsmen also utilize TV programs to ascertain the market price of wool and cashmere and decide when and where to sell their products. There are other programs that inform herdsmen of new medicines for diseases and conditions that might threaten their livestock, as well as other best-care practices for pastoral tasks. Finally, news reports inform herdsmen of the condition of the grassland - families often maintain two pastures at a distance from one another, one for summer and one for winter. Grassland deterioration can necessitate searching for other pastures on which to feed the animals, such as those reserved by the government for drought emergencies.

Though some of this information was likely previously available on the radio, television was noted as a 'productive use' by several families; moreover, almost all pointed out that TV simply betters the herdsman lifestyle. Not only does television boost a family's quality of life and entertainment potential, but it also provides educational opportunities. National programming includes a channel that is dedicated entirely to topics in science and technology. Though an understanding of plate tectonics would not necessarily raise a herdsman's income potential, ecological or medical information might. Adults of families remarked that they appreciated being able to continue learning.

Another example of television's indirect productive use is social networking. One question asked of many herdsman families was whether they interacted more with their neighbors and friends before they received the hybrid system or after. All reported that there has been more socializing since the systems were installed. This is partly because telephones allow people to connect much more easily and plan events in advance. According to the herdsmen, it is also because TV and the movies available on DVD or VCD provide a forum by which to come together. Even without social visits, families get together often and gather around the TV in the living room to watch their favorite programs. Herdsmen explain that TV has brought their family closer together.

In addition, interviewees spoke of the fact that herdsman communities unite to build each others' houses, slaughter sheep, store grass for the winter, and celebrate weddings or attend funerals. When hay-making season comes around, it is often a communal activity. One head of household specifically stated that one of the biggest changes brought about by more electricity is "the development of society on the grassland...electricity has connected the community more." Thus, though income is not directly produced by most social activities, a "stream of benefit" is, and in social capital terms "mutually beneficial collective action" triggers the flow of the streamcollective goods are produced rather than strictly individual gains, and the potential of the society as a whole is boosted (Uphoff and Wijayaratna 2000, 1876). As the Chinese state moves ever closer to a market-driven commodity economy, social capital will become increasingly important, especially among ethnic minorities in economically marginalized areas.

\section{Daily activities}

Access to 24-hour or near-24-hour electricity has changed the daily routine of herdsmen in quite a few ways. Primarily, women have experienced the most significant change because of the way household chores are performed. The main influence has come from television, however, as 
families structure their day around watching TV in the evenings and sometimes after the noon meal.

The introduction of 24-hour or near-24-hour electricity has had little impact on the daily activities of male Inner Mongolian pastoralists. The only exception is in the cases where an electric pump is used at the well. Pumping water by hand is a laborious activity, and the men who enjoyed electric pumps reported saving a significant amount of time. Many families who relied on hand-powered pumps listed an electric pump on their 'wish list' of new appliances.

For women, daily activities have been affected to the greatest extent. The time savings and convenience afforded by refrigeration has already been illustrated. Similarly, families who own washing machines reported that housework requires much less time than when clothes were washed by hand; drying clothes is much easier as well, especially in the winter when clothes take much longer to dry outdoors. In fact, the modern appliances most frequently cited as lessening women's workload were washing machines and the electric cooking fan used to keep the oven fire going. As previously mentioned, hand-powered cooking fans require much more labor and a constant presence in the kitchen. With an electric fan, women can involve themselves in other activities or even watch TV while the family meal is cooking. The first picture below shows a kitchen stove with an electric fan to its right, on the floor; the picture to the right shows a woman using the traditional hand-powered fan, operated by pushing in and pulling out the long handle to turn the fan inside.

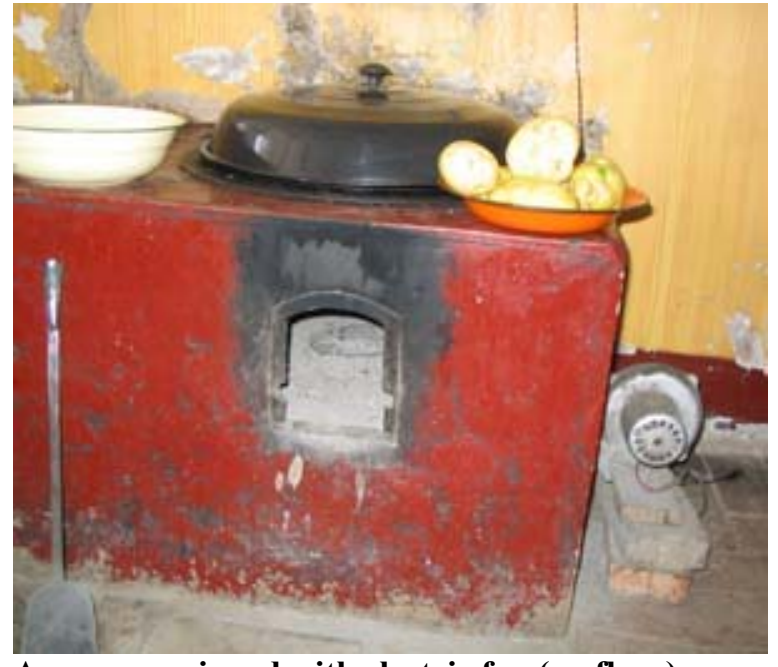

An oven equipped with electric fan (on floor).

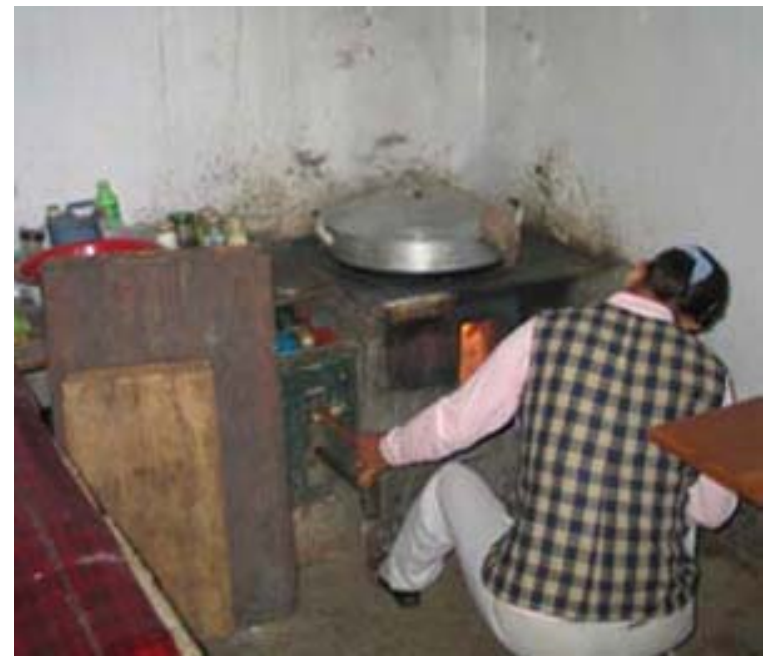

Woman uses hand-pumped fan to revive flames.

The few families that owned electric woks and rice cookers reported a substantial savings of time in the kitchen. In addition, during the winter when darkness falls early, women used to cook the evening meal in insufficient light or using candles. Now, preparing the evening meal is accomplished much more easily. Similarly, the women who own sewing machines spend less time mending clothes. In the past, all of a family's clothes were made by hand. However, nowadays almost all garments are store-bought, so the change wrought by an electric sewing machine is not as great as it would have been in the past. 
All herdsman households continue to rely on dried dung for cooking and heating the house during the winter. Though dung may not seem as polluting to indoor air as coal, burning dung actually produces more carbon monoxide and particulate matter than burning wood or Indian coal (Haines and Kammen 2000). It falls beyond the scope of this paper to evaluate the potential for improved energy-efficient or solar stoves among the herdsman population, and the Pilot Project was not intended to affect these aspects of the herdsman's lifestyle. It did appear that a good number of households were equipped with ceramic ovens rather than open brick, which lessens particulate matter somewhat. Suffice it to say that heating and cooking (and gathering dung for fuel) occupy a significant part of the herdsman's winter, when weather can be severe and bitterly cold.

\section{Women's work}

None of the families interviewed spoke of 'women's work' or seemed to regard housework as a burden shouldered by women. This held true even in the $22 \%$ of cases where all respondents were women and no household men were present to influence the conversation (the PI's research team, however, was composed of three men and only one woman). During the initial stages of fieldwork, the question of whether having electricity had changed a woman's place within the household was pursued; if other ways of life shown on TV had caused women to adjust their perceptions of themselves or alter their aspirations and satisfaction with life. Neither appeared to be true. However, finding a common ground of cultural understanding from which to frame these questions presented a significant barrier.

Dao Ri Na, the research assistant and interpreter, is a woman of Mongolian descent in her late twenties, who had grown up on the grassland and now lives and teaches university in Hohhot; she has nearly completed her PhD degree. Even though Dao Ri Na was intimately familiar both with the traditional Mongolian rural lifestyle and the modern Chinese urban lifestyle - and their respective gender norms - she herself found it difficult to understand the point of the genderrelated questions. The traditional gender norms of the Mongolian household appear ingrained and entirely uncontested. Upon reflection, a woman's unquestioning performance of housework is common-sensical - for her to feel burdened by this responsibility and desire the freedom to work outside the home would necessitate there being something of interest outside the home. Few rational women herdsmen would prefer passing the day outdoors in the strong wind and sun, or bitter cold, herding animals and enduring heavy labor, over looking after the children and household indoors. Both women and men explain this division of labor by physical ability. Dao $\mathrm{Ri} \mathrm{Na}$ and household respondents alike explained that both women and men have daily tasks that are considered their societal duty.

In fact, the roles expected and indeed welcomed by both genders were illustrated in a conversation which occurred over lunch one day during a household visit. At this lunch, in addition to the PI, five women and seven men were present. After several individuals had taken turns singing traditional grassland ballads, a discussion ensued over Mongolian totems. In Mongolian mythical tradition the wolf is a powerful totem, equivalent to the dragon in Han Chinese culture. The wolf represents strength and prowess - the ancient Mongolians believed that they were descended from the wolf - and like the dragon the wolf symbolizes a protector as well. As for Mongolian people, it was said, women are like wildflowers, and men are like 
hawks. On the grasslands, both wildflowers and hawks have their respective place in the order of life; indeed, on the grasslands, both are as ubiquitous as the grass itself. It was apparent from the shared conversation that both genders were pleased and proud to associate themselves with these symbols of grassland life.

That said, anyone familiar with traditional Chinese or Mongolian culture recognizes that to a certain degree, sexism is an institutionalized part of the household and society. Mao's Great Leap Forward and Cultural Revolution (1958-1966 and 1966-1976, respectively) did alter somewhat the conceived role of the woman in Chinese (and Inner Mongolian) society - part of the institution of the People's Communes involved freeing women of traditional norms that confined them to the household and encouraging them to participate in labor formerly considered male (Sneath 2000). Despite this historical adjustment, however, in both cultures, tradition continues to tie the woman to the private sphere and the man to the public; thus traditionally, it is the man who receives and entertains guests. This tradition may account for the shy, intimidated, and subordinate behavior of three of the women encountered in the PI's interviews, but these represented an extreme and not the norm.

The unquestioning acceptance of gender roles may change over time and would certainly be expected to undergo adjustment with migration to an urban area. However, in such cases a change in the productive activities of the family would also occur, and any change in gendered division of labor would be a product of this variable and other social factors - not electrification or modernization per se. For now, female members of Inner Mongolian pastoral households speak of housework becoming more 'convenient' — not 'less work.' Because daytime is prolonged artificially, housework may be accomplished at a more leisurely pace - the day is no longer a race against the sun.

\section{Quality of life}

One question asked of every household was 'what is the greatest change in your life since you acquired the hybrid or renewable energy system?' Overwhelmingly, the first words to be uttered were some version of "electricity has made life more colorful" or richer because of music, TV, and social gatherings. The next words to be uttered were almost always about broadened horizons. Almost all herdsmen spoke of a desire to 'follow the trend of the world' and to 'live in modern conditions' like people in the cities. When asked what that meant-if they hoped to move to a town or city, for instance - most herdsmen did not imagine so drastic a change - only 4 of the 37 families (11\%) expressed this desire out of an apparent association of the conveniences of the modern lifestyle with urban society. Instead, most (both men and women) expressed the belief that it was possible to live in the modern way while remaining on the grassland and following traditional practices-19 of the 37 families (51\%) were satisfied and happy with their current living condition, while 12 (32\%) were satisfied but wished for even more modern conveniences without having to move to an urban area. Two families $(6 \%)$ who had experienced significant misfortune were bitterly unhappy with their current situation, one of whom blamed modernization for her predicament (see page 63). On the whole, grassland life was considered superior to city life because it is more peaceful - not as busy and loud. However, members of the younger generation harbored dreams of moving away. 
Families who were unsatisfied with their current situation to any degree were asked what changes they would like to make for the future. These referred to desires for a larger renewable energy system or new appliances. Aside from electrical water pumps and wells, which were the most frequently cited 'desired' item, some herdsmen spoke of hoping to acquire hay-making machinery or grain grinders for animal feed. Households that did not own a washing machine hoped to acquire one. One wealthy family had recently acquired a solar water heater, and another family expressed interest in buying one. The same wealthy family even planned to install air conditioning. However, when household members spoke of a wish to be more 'modern,' the PI's judgment was that it appeared to be mainly an abstract concept adopted from television and having to do with the conveniences herdsmen associated with urban living.

As previously stated, children on the grassland who choose to attend middle and/or high school do not usually live at home during this time. Because secondary education facilities are situated only in the larger towns, most families must pay for their children to live in town while they attend school. These children thus become accustomed to the urban modern lifestyle much more rapidly than their parents, and they bring these changed perceptions of life home with them during the summer and on school breaks. When the home environment is modernized as well, the disparity between home and school life is not as great. According to one respondent, who was home on leave from the army and took the interview in his parents' absence, the family's hybrid system has closed the distance between home life and army life by making the two comparable. He now enjoys his home visits much more.

Most of the perceived changes of narrowed gaps and enhanced colorfulness are attributed to the influence of television. For the urban and rural viewer alike, television serves not only as entertainment but also as a window to previously unknown parts of the world and ways of being. For people who lack the money or freedom to travel, the substitute of TV provides an equally enriching experience. The ability to glimpse what lies beyond one's doorstep also leads to dreams, and it is in the dreams of Inner Mongolia's youth that the most significant changes have occurred. It is here as well that the future of the pastoral way of life will be determined.

Notes from one interview read:

The brother speaks now, with passion. He says "many changes have taken place on the grassland," and young people can learn more from the TV- "they can broaden their horizons because of TV"-and this can "narrow the gap between this generation and the one before." This makes their life more "...colorful and enjoyable. Life is better. We live in good conditions and enjoy ourselves. This is a good change and is the most important." Also, because of electrification and $T V$, children don't "waste all of their time feeding sheep and working on the grassland" (TV is highly valued by this family as a form of education). This family doesn't see their children living the same life they've lived, and doesn't want them to. "When new things come up and give our kids more ideas and a different introduction to the world, we are very happy-the future and change make us happy. Even if we don't have the chance to get out and see the world ourselves, TV offers an alternative"-it is their only chance- "but there is lots of opportunity for our children." (August 13, 2004, Erlianhaute area) 
Of course, not all respondents wished for their children to leave the grassland and the pastoral way of life. But it is apparent that all do put their hope in their children (as parents anywhere are prone to do), and even if they wish for their children to carry on the pastoral tradition, they hope this current trend of modernization will make such a life much easier and more comfortable.

Overall, it would appear that quality of life is correlated most closely with appliance ownership, with an emphasis on television. To understand this correlation subjectively, during fieldwork the PI observed television programming for several hours each night in the hotel in rural sumu and county centers. This observation suggested that both 'traditional' and 'modern' serials, the two favorites of television programming among respondents, are the most common programming available on Chinese rural TV. Modern serials often dealt with relationships between men and women that took place in the apartments and office buildings of Chinese cities. Topics included a woman's struggle with her responsibility to maintain the house and cook while working at a full-time job; implied infidelity by both sexes; and grown children's struggles with their parents to speak their minds and make their own choices in the face of traditional expectations of obedience and mute respect. Traditional serials often dealt with the same basic human topics of love and inter- or intra-generational power struggle, but characters were dressed in period costume and traditional customs were pronounced. These observations, together with respondent statements regarding household viewing preferences, indicate that household viewers enjoyand indeed depend upon-identifying with both worlds.

At the time of fieldwork, the Summer Olympic Games in Athens were in progress and Chinese athletes performed quite well. Indeed, there was an air of excitement throughout the country, and China finished a close second in number of gold medals earned (third in overall medals earned). At the same time that the Olympics were creating a stir among rural Inner Mongolians, however, the summer grassland festivals were also commanding attention. Boku (Mongolian wrestling), horse racing, singing, and dancing competitions bring people from distant parts of the grassland together and proceedings of the larger festivals are broadcast on TV. Smaller and spontaneous festivals occur along provincial roads. In addition to TV, satellite telephones contribute to the ease of gathering for festivals and other social activities. Thus, both modes of communication aid in the herdsmen's enjoyment of life and raise their feelings of wellbeing. According to the herdsmen whose systems remain in good or fair condition, the biggest benefit to the quality of their lives post-project is there is less work and more time for enjoyment.

This report has suggested that quality of life is not only a measure of health, knowledge, and freedom from poverty but is also closely interwoven with other aspects of life such as socialization, self-development, and opportunity. Though it may seem trite, it is true that no metric exists for happiness except for one's own words. Thus, investigation of the quality of life variable is qualitative in the truest sense, and findings in regard to this research variable are best illustrated in the stories of the people themselves.

\section{Electrification's impacts on the individual and society: A personal look}

A wide-angle view of the Inner Mongolian pastoral society reveals a land in transition. The majority (84\%) of herdsmen feel that in recent years, life is better. Local provincial officials claim that incomes have risen, despite the disruption of the drought in 2000 that caused 
widespread misfortune and loss of assets. According to official figures, incomes declined between 2000 and 2002, but the publication of more recent figures may reveal a turning tide. Four families volunteered the opinion that the grassland community is more connected now than in the past, and that transportation is also easier. The days are longer because of artificial light, life is more colorful, and work is not as strenuous. Meals are more varied as are future options for the children. Social gatherings have a different mood. Some herdsmen's living rooms are modeled after the kind of interior decorating seen in magazines. Of course, attributing all of these changes to electrification would be erroneous. Many changes that have come about can only be attributed vaguely to modernization, globalization, and the metamorphosis of Chinese society as a whole. The political and economic apparatuses of China have been revolutionized; however, despite the opening up of the state to global forces, societal change continues to occur mainly under a state-led and top-down structure.

Electrification itself is only one instrument in the machine of state-led modernization. Modernization of historically poor and rural areas is part of a larger attempt to raise the economic wellbeing of the country as a whole. As has been shown, this attempt has been in full force in China for more than 50 years. The difference now is that for most herdsmen, modernity has become an object of desire. Though the structure of Chinese society is shaped by its history of socialism, the increased freedom of private ownership is in the process of redefining success.

Culture is less a thing than it is a process; it is made up of practices, rituals, language, shared meanings, taboos, myths, and geography-it exists as a place marker by which people define themselves. To speak of a society in transition would be to imply that each individual within the society is willingly undergoing metamorphosis. This would be erroneous. The truth looks more like a tug-of-war between the majority view or surficial current, and its quieter but no less powerful undertow. As herdsmen daily negotiate their societal and individual identities, they draw from both forces. The following narratives are presented to help the reader understand the daily reality of the herdsman's life.

\section{Snapshot: at the crossroads of today and yesterday}

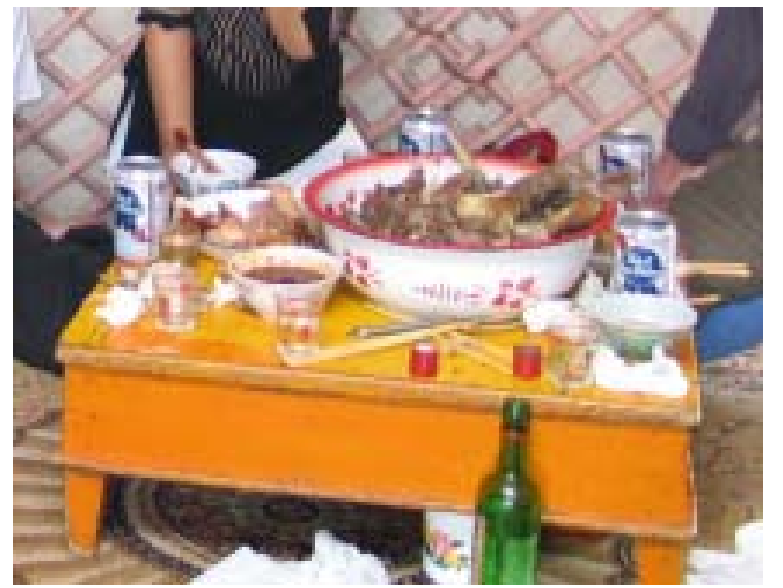

Intersections of tradition and modernity may be illustrated in the following: a man herds his sheep and cattle on the back of a motorcycle instead of a horse; standing far from any road next to his PV panel in the yard, a herdsman removes his cellular phone from its belt holster to check the time. At a remote herdsman's household a sheep is slaughtered and prepared for lunch in honor of the visitors; inside the yurt, women dressed in modern fashion and heels delicately pick apart the entrails with a large knife and offer them to fellow diners, along with cans of Pabst Blue Ribbon. In the small sumu center, a meal is shared with hosts in a modern restaurant, complete with Chinese jasmine tea and the national Tsingtao beer; the hosts take turns singing songs about the grassland - songs filled with longing, nostalgia, and appreciation for the 
old ways and the Earth. With each song a gulp of bai jiu, the strong sorghum-derived liquor of Mongolia and China, is thrown back in honor of the singer's grassland ancestors.

\section{Snapshot: What dreams may come}

TV's influence on the dreams of children is illustrated in the story of one family visited in Siziwangqi. The family's house was located fairly far from the road, and was powered by a Pilot Project system that consisted of 100 watts PV and 300 watts wind that was installed in 2000.

The female head of household took the interview along with her elementary-school daughter and a niece who was in early middle school. The woman's husband and son were in a nearby city repairing their car. Much of the interview was consumed in talking to the young girls, both of whom dreamed of leaving the grassland. The niece, reflected behind her aunt in the picture below, wore a T-shirt emblazoned with the slogan "A Hapy Newyr" [sic] and was quite talkative. When asked what she wanted to be when she grew up, she spoke of being a pop star like the ones she sees on TV.

She then sang, to demonstrate her ability for this dream. The song was a traditional Mongolian ballad about a camel that is looking for its mother. The girl had an impressive singing ability and confidence. In this song and its singer is found the nexus of tradition and modernity - the meeting of the modern worldview and the roots of the old soul. Chinese music television and its pop music are very similar to styles seen in the West. Though the girl's dreams were in emulation of the stars she saw there, her avenue of approach was wholly traditional.

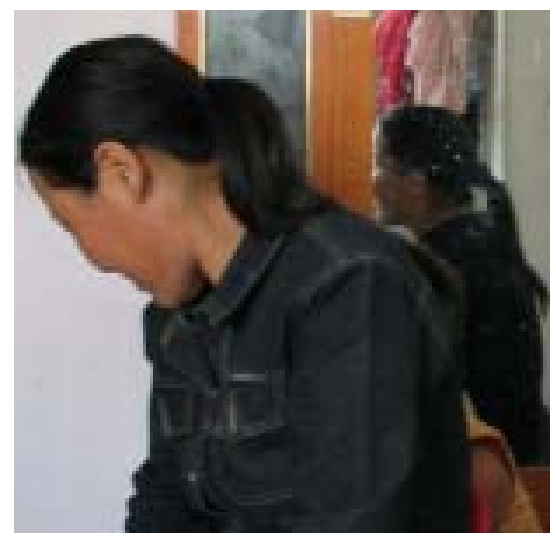

In another instance, a family interviewed in the Dongwu area was represented by their 14-yearold daughter who had just completed middle school. She was the only household member who spoke Chinese fluently. When asked what her future aspirations were, she spoke of 'special work for women' in southern China, which she had learned about on TV. There, women create delicate hand-sewn silk cloth. This was her ambition, and the goal was to support her family. She had no interest in continuing her education, wishing instead that her younger sister and brother would have the chance to receive a higher education. She was especially interested in her younger sister going to college. She had already counted herself a responsible incomeearning family member and differentiated herself from her younger siblings, who were still considered 'children.'

TV has not only led Inner Mongolian youth to dream bigger dreams, it has led in some cases to an increased emphasis on educational achievement. Another high-school-aged youth who was interviewed said that from his perspective, the biggest change to come about since system installation was being able to watch TV and sing karaoke. "The life of people on TV is much better than my life," he said. "This is why I want to go to college and change my life." Before the system installation and access to TV programs, he didn't know much about the outside world. Now, he knows what is possible. One mother added to this sentiment in saying, "good 
education is the most important thing, even if the family has to sacrifice for it. But even if my kids want to return to the grassland and continue raising animals after their education, that's okay too, because then they will still be better business-people about it."

\section{Snapshot: Struggling to survive}

At the lowest end of the social spectrum is a family that continues to live in poverty and difficulty. This family represents the living condition of many herdsmen prior to project installation in the late 1990s. The family's house is small, very basic, and dirty. It consists of two rooms, one for sleeping or visiting, and one for cooking. In the bedroom is a traditional Chinese platform bed, which is raised up off the floor a few feet, its hollow space heated by the oven in the adjoining kitchen. Across from the bed, a small black and white TV sits on a table alongside a battery-powered radio. On the floor beside the bed is a 12-volt battery, covered in dirt. The visitors are ushered into the bedroom, and are joined by the household matriarch and her younger sister, who is visiting with her small son. The child accepts the crayons and notebook he is offered, but never smiles.

This family received a Pilot Project system in 1999, which consisted of a 50-watt PV panel. The family had owned a small wind turbine before, but decided the PV was better so they sold the turbine. The only appliances they own are the small TV and two light bulbs. They receive a TV signal from a nearby town and have a choice of two channels, which provide varied programming from 6:30 to 11:00 pm. The matriarch says that it was difficult for them to afford this small system, but the cost was worth it because otherwise the house is dark at night. They paid 3100 Yuan (US\$375.00); the government paid the remaining 500 (US\$60.00). The system has performed fine except for the two batteries, which are both past their prime. The household switches between them to prolong their usefulness. They cannot afford to replace them.

Mostly, the matriarch lives alone now. She tells a story of terrible luck. Her husband died last year of SARS, and both of her sons are crippled. One broke his leg, and is having trouble finding a job because of it. The other is deaf. Both are away from home, looking for jobs; neither lives there to support her. Her daughter got married and moved far away, to a town located at the upper reaches of the Yellow River. The sons completed one year of high school; the daughter completed all three years. The matriarch has the equivalent of a fourth-grade education.

She grew up in an agricultural area of the province, and was in the process of moving during decollectivization in the late 1970s/early 1980s when the government divided up the agricultural and pastoral areas among residents. Because she was in transition, she had no residence permit for either area and thus was forced to forfeit her right to land. All she has is the plot of land the house rests on, and she can graze her animals only in this small area. For this reason, she owns very few sheep. She moved here over 20 years ago, but still the government will not grant her more land and provides her with no assistance, she says. Though she does not think the Maoist policies were better, she wishes things would go back to the way they were before. Her face is contorted in frustration and pain as she explains that the current policies just aren't fair. "All of our problems came about because of modernization," she says. 
Her income is about 10,000 Yuan per year (US\$1,200). This is nowhere near the poorest in China, but it is the poorest relative to her area and grassland way of life. She earns her income from shearing the few sheep she has, and from involvement with a local restaurant - it is not clear what her role is there. The matriarch and her sister talk about the inequity of the woman's situation during the entire interview; the words erupt forcefully from their mouths. There is no shame in this poverty, only indignation. Since she lost her husband and her children moved away, her life has been in a slow decline. Electricity is of little import to this conversation. She has very little to say about it.

Despite her poverty, she offers her visitors plump wild-onion dumplings, for it is mealtime. This offering is one of the most generous of all the household visits made during survey work. It is not only comparatively generous because no other family offered a meal, but because there is a difference between those who give of their surplus, and those who give of the little they live on- the difference is profound.

\section{Snapshot: Interior decorating}

At the other end of the social spectrum, and not terribly far across the plains, is a family of five. Their house is very modern and nicely decorated with wood-paneled walls, luxurious couches with brocaded pillows, and an inlaidwood coffee table. The ceiling is also covered in fancy wood paneling. On top of a dresser in the adjoining bedroom, complete with modern mattressed beds, there sits a pair of nice suitcases. An embroidered picture of Genghis Khan adorns a far wall. The visitors are served milk tea in dainty china bowls. The father of the family proudly explains that he is the richest herdsman in the area. He designed the interior of the house himself, and carried

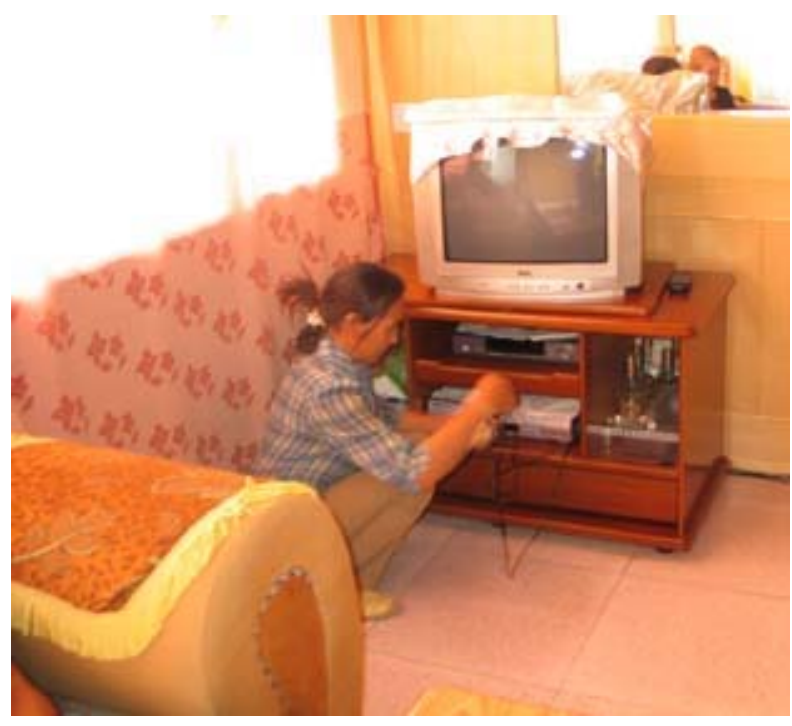
all the components from nearby cities, including a large mirror on the living room wall. He seems gratified by the astonishment on the visitors' faces as they note the meticulous detail in the room.

The family received their Pilot Project system in 2000. It consists of a 155-watt PV panel and a 300 -watt wind turbine. The battery has not yet needed to be changed, and the inverter has performed well. The father pays close attention to charge times, and this has made a big difference. He remembers the instructions he received upon installation, he says, and brings the PV panel indoors when the wind is fierce. The system fully supports the family's appliances, which include a refrigerator/freezer, TV, VCD, phone, and stereo, for 24 hours a day.

The couple has three sons, two of whom graduated high school and one of whom completed only middle school. All three live at home and help with the livestock. The family owns more than 700 sheep, 50 cows, and about 80 camels. The mother brings the visitors several photo albums 
that are filled with pictures of the livestock. One of the albums, which also contains a few baby pictures of the boys, is decorated with a still-frame from the movie Titanic-Kate Winslet and Leonardo DiCaprio stand at the prow of the ship under the caption "Everybody lives for sometsing [sic] better to come." The father has traveled some in the province, and got his ideas about decorating from cities he's visited. He has the money to travel beyond the province, but the thought of doing so scares him. He speaks very little Chinese, mostly Mongolian. He enjoys watching TV, and the family usually watches from 7:00 pm until midnight. They get more than 30 channels. The father believes that the things and lifestyles he sees on TV are fantastic, but not realistic. He would like to live in a better house, but remain on the grassland. He is realistic about the fact that he and his sons have no ability to live the life of townspeople. All they know is caring for the animals.

Throughout the interview, the wife stands behind her husband's chair, sometimes leaning and sometimes standing erect. She never utters a word or expresses interest, though when her husband tells the visitors he alone decides how the money is spent in the house, she looks down and busies herself in arranging the already perfect chair cover. Indeed, it is significant that the parlor or public room, where visitors are received - traditionally, the male domain-is luxurious and well-attended while the kitchen, at the back of the house - traditionally the woman's domain - is dirty and lacking any modern appliances. The oven is in the old style of bare brick, and is still operated by a hand-powered fan.

\section{Snapshot: Ownership is better for the land}

In the middle of these two lifestyles is much variation. A grandmother of a family in Suniteyou banner admits to being nomadic up until 1983. She is reluctant to expound on that, but says modern life is better. Her daughter, the female head of household, explains that since the family is settled, the animal death rate is greatly reduced. It is also better for her two children's education. They are 15 and 18, both in high school. She says it is better to be settled because people invest in their land, since they own it. Before, the land was communal so no one invested in its quality. "Ownership is better for the land." Her words are hauntingly reminiscent of the party line for land reform.

\section{Snapshot: the old way}

Another Pilot Project family in Suniteyou banner is not home. Instead, the wife's mother and her husband, who live on the property, consent to be interviewed. They are 70 and 75 , respectively, and they have lived here since 1960. They work for the daughter's family, and take care of their livestock. In exchange, they are supported by the family and live in a mud and straw house on the property. Sometimes, the old woman goes over to her daughter's modern house to watch TV. The old man, however, is not allowed-he is the second husband of this woman, and not welcome. Neither of them received any education. The old woman also has three brothers, one of whom is the village mayor, and two other daughters, who live elsewhere. While she is occupied in her story, her husband complains about not being allowed in the house but says that he doesn't care for TV anyway - he is accustomed to the old way of life and since he never received any education, he has no incentive to learn anything new. He doesn't think that modernization and electrification are good things, and looks down on modern trends. His wife, 
hearing the end of his speech, indicates by her face that she does not agree. However, she keeps this to herself.

\section{Snapshot: a People's Representative}

Outside of Dongwu, a nice house marks the day's final interview and is reached just as the sun begins to set. Unlike the area around Saihantala, where the grassland stretched flat to the horizon in an endless sea of unbroken green, the Dongwu area is hillier and the landscape made of richer colors. Almost three full days of driving span the distance between the two towns, and they have distinctive characteristics. Some of the households in Dongwu speak only Mongolian and have had much less contact with outsiders; most have had no experience with foreigners. History has retained a lasting shadow in the memories of herdsmen here, especially those located in remote areas.

In contrast, this house is filled with laughter. It is finished with white tiles on the outside, unlike the brick of most houses; two dragons sit atop the red tiled roof, and painted scenes of songbirds and bamboo flank the doorway. The household contains five members: the senior father and mother, and their son, his wife, and their young child. They own a hybrid system provided under the Brightness Program in 2001. It works well and powers their two TVs, VCD, gigantic stereo, floor-standing speakers, washing machine, lamps and light fixtures, sewing machine, and fullsized refrigerator/freezer. Not a single family member understands anything about the system, including how it produces electricity. Not surprisingly, they have encountered a number of problems with it.

The mother is the People's Representative for the Autonomous People's Congress-a government entity that represents the ethnic Mongolians of the area. She is the primary respondent for the interview, and commands respect by her presence. The family is very jovial, though, and laughs a lot. The father jokes that if he had more money he would use it to meet more Americans. The small girl of the younger couple is frightened and mesmerized by the strangeness of the foreigner-her eyes, coal-black saucers, remained fixed through the entire interview.

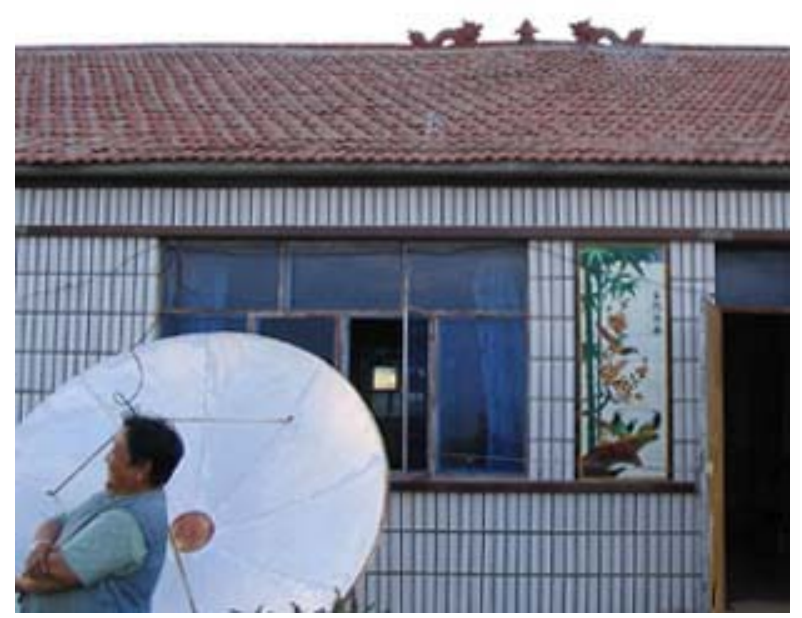
This is cause for much amusement in the family.

Though they are quite comfortable, the family outlines three factors that limit their income potential. First is the health of the grassland - the number of sheep it will support is limited, and its condition determines the quality of those sheep. Second is labor-to earn more money, they need more sheep, and more labor is necessary to care for more sheep. Third is production, because to produce more they need more tools, like a water pump for the well. The mother/representative declines to answer a question about the role of government policies in instituting the limits on sheep and grassland. As the interview draws to a close, it has become 
very dark inside but much time passes before someone remembers and jumps up to turn on the light.

\section{Snapshot: preserving tradition}

In a house outside Erlian, a mother and her daughter-in-law are home alone. Her husband and two sons are away. Their home is modest. They moved here in 1980 with one sheep; now they have 400. They occasionally sell some milk from their 20 cows to supplement their income. The mother says she is very satisfied with their current living condition because the days are long and even when it's dark she can sew or watch TV. The biggest benefit, however, is not having to eat all the food in one day since it keeps in the refrigerator and freezer.

She smiles when asked how her life compares to the people she sees on TV. She says when she sees people living in a better condition than she does, she takes it very seriously. She looks down on the crime she sees on TV, and on many things that seem fake or unrealistic as they are portrayed on TV. She takes very seriously the family getting together for grassland festivals. The family's favorite shows on TV are those that help them relate to life before, to look back into the past. Her dream, though, is for her children to move to the city and earn more money. She is old, she says - she has no energy to go out into the world herself, and her job and her destiny are taking care of the family. She says there are many things she would like to discuss with the PI, a sympathetic stranger from another world, but speaking through multiple interpreters is too difficult. Before the visitors leave, she puts on her traditional Mongolian dress and proudly poses for the American. Tradition provides a foothold on an otherwise slippery slope.

\section{Perception of renewable energy system maintenance costs}

No families mentioned energy or repair and replacement of hybrid system parts as an "expense" or use of income. However, families that were experiencing problems did complain about the cost of repair and replacement. This rift in perception appears to be because herdsmen feel they should not be responsible for full repair and/or replacement costs.

Because almost all families maintained that they could not afford to repair or replace system components, it is of interest to compare the price of major appliances owned by herdsmen with that of the hybrid system components. 
Table 8. Average retail price of main appliances owned by households.

\begin{tabular}{l|c}
\hline Appliance & Price (Chinese Yuan/U.S. Dollar) \\
\hline General light bulb & 2 Yuan (US\$0.24) \\
CFL light bulb & 20 Yuan (US\$2.40) \\
25-inch color TV & 2000 Yuan (US\$242.00) \\
20-inch color TV and DVD player & 1800 Yuan (US\$217.50) \\
Black and white TV & 700 Yuan (US\$85.00) \\
Radio & 100 Yuan (US\$12.00) \\
CD player & 1000 Yuan (US\$121.00) \\
Karaoke player & 500 Yuan (US\$60.00) \\
Satellite receiver & 1000 Yuan (US\$121.00) \\
10 cubic foot refrigerator & 800 Yuan (US\$97.00) \\
16 cubic foot refrigerator & 1200 Yuan (US\$145.00) \\
15 cubic foot ice chest & 1000 Yuan (US\$121.00) \\
$1 / 5$ horsepower water pump & 500 Yuan (US\$60.00) \\
Washing machine & 800 Yuan (US\$97.00) \\
Room fan & 100 Yuan (US\$12.00) \\
\hline
\end{tabular}

Table 9. Average price of Chinese-manufactured hybrid system components.

\begin{tabular}{l|c}
\hline Hybrid system component & $\begin{array}{l}\text { Estimated price (Chinese Yuan/U.S. } \\
\text { Dollar) }\end{array}$ \\
\hline $\begin{array}{l}\text { Standard system price before subsidy or discount } \\
\quad \text { Price with 3000 Yuan subsidy (for standard }\end{array}$ & 10000 Yuan (US\$1208.00) \\
$\quad$ configuration of 300W wind/100-200W PV) & \\
$\quad$ Price after 10\% discount only & 9000 Yuan (US\$1087.00) \\
36V 150Ah battery (average lifetime 3-5 years) & 500 Yuan (US\$60.00) \\
600-watt modified sine-wave inverter and box (average & 1200 Yuan (US\$145.00) \\
$\quad$ lifetime 3-5 years) & \\
Repair of charge controller per year (estimated) & $300-500$ Yuan (US\$36.00-60.00) \\
Cables and other support equipment & 300 Yuan (US\$36.00) \\
Domestic 150-watt PV panel & 5500 Yuan (US\$665.00) \\
Domestic 300-watt wind turbine & 3300 Yuan (US\$400.00) \\
\hline
\end{tabular}

Comparison of prices available in the above tables reveals that an inverter costs about as much as a large color TV, or 5\% of the average households' yearly income (assumed at 40,000 Yuan or US\$4800). Repairs of the charge controller and replacement of individual batteries represent about $1.25 \%$ of the yearly income. Thus, households seem able to afford occasional replacement and repair costs. The difference in ability and willingness are marked, however, and point to discrepancies in project expectations of low system cost and the realities of ownership and thus accountability. This issue will be taken up in the report's Discussion section (page 71).

\section{Miscellaneous outliers and effects}

There was little evidence to suggest that electrification affects migration. In Saihantala, the local guide estimated that because of the severe drought of 2000 , about $20 \%$ of the original Pilot Project population had abandoned their grassland property and its renewable energy system, and moved to town. They were forced to do this because of the economic losses they incurred in losing livestock and thus their livelihood. However, no evidence was found in support of claims 
of other studies that electrification either led to an in-migration from other areas, or to an outmigration above the normal ebb and flow. Though the children of herdsmen leave home to attend middle and high schools and sometimes colleges in neighboring towns and cities, many return home to continue the pastoral way of life after education has been completed. This trend will likely change as the forces of modernization and the powers of popular culture tighten their hold on the dreams of youth. For now, the way of pastoral life remains dear to most of those who practice it.

Because herdsmen have enjoyed some form of electricity since the 1970s, when wind systems first became common, an increased investment in sedentarization cannot be attributed to the hybrid system Pilot Project. An increased association with the commodity economy do appear to have come about, but it is difficult to pinpoint whether electrification led to this association, or whether the modernization of Chinese society led to the electrification that encouraged purchase of modern appliances. Similarly, there are too many vying forces at work to accurately tie the increased focus on private ownership to higher levels of electrification.

Further, there was not sufficient evidence to suggest that the use of renewable energy has created a unique relationship between the rural energy user and his energy source. Problems encountered in manufacturing quality and user error of hybrid systems have created barriers to any significant effects of empowerment that might come from distributed generation. The prevalence of off-grid systems in China is significant in any case, for electrical generation has always been a state-controlled system. Placing herdsmen in control of their own energy source is in itself a form of utility privatization, and represents a revolution in the concept of energy distribution. However, until herdsmen are adequately educated about and trained in the maintenance of their renewable energy systems, empowerment will remain a somewhat elusive goal. This point will be revisited in the Discussion section (page 71).

\section{An unelectrified village: Xingmingxiang}

As mentioned in the Methods section, the fieldwork for this study included a visit to an unelectrified village, located to the northeast of Hohhot in an agricultural area. Instead of individual interviews, all members of the village who were present at the time (most were away, working in the village field) gathered in the mayor's house and answered interview questions as a community. Four families were represented. Though the visit was meant to provide a standard of comparison for the project interviews, the differences between the families and areas proved too significant for any useful analysis.

The village is composed of about 20 Mandarin Han Chinese households engaged in small-scale agriculture. In addition, most village households own a small number of sheep or cows, which they shear for sale of wool or sell as newborns. The village shares a field that is divided into equal sections. Each household member is relegated one section for growing peas, potatoes, and other crops. The harvest from each section is the property of the family it belongs to, but if one family's section yields a better harvest than the rest, this surplus is divided up within the village by the government. Mostly, the work is communal, and the village shares a tractor for plowing. 
Though the village is unelectrified, power lines are visible just up the hill (evident in picture). The government official who provided escort for the visit explains that converting the power supply to a lower voltage for village use would cost 40,000-50,000 Yuan (US\$4833.00-6041.00) and there is no funding for this task. In addition, the local government does not feel that village families would be able to afford the electrical meter and appliances that electricity would require. The local government maintains that food, clothing, and water are higher priorities.

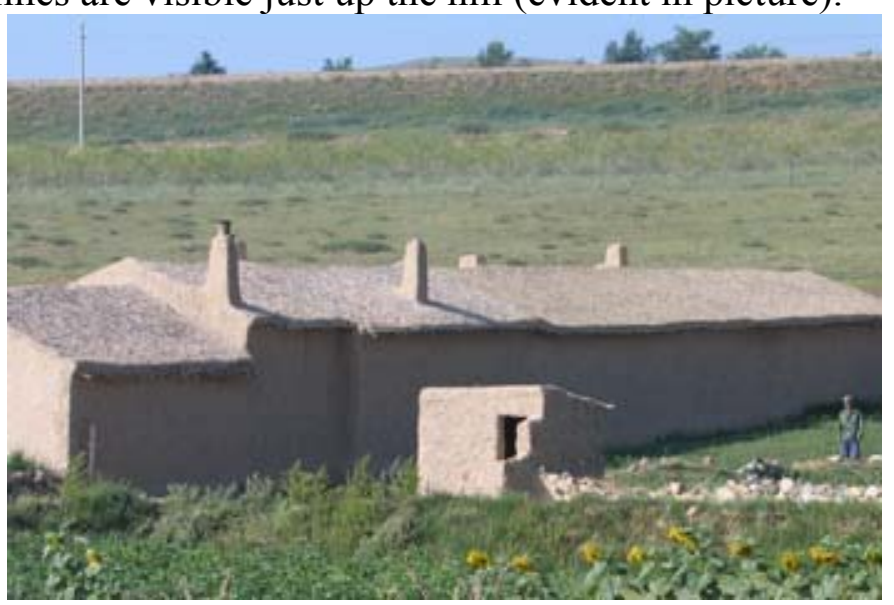

Villagers agree with this assessment, though they also maintain that they suffer from the lack of electricity. At present, water for the fields and for household consumption is manually carried from a distant spring and results in heavy labor. An electric pump would lessen this labor, as would an irrigation system. At present, the range of crops the village can grow is limited by insufficient irrigation, though the water supply is bountiful. However, most village families are already burdened by school fees for their children and have barely enough food to eat. They do not consider pooling their own money for an electrical system a viable option.

The daily life of village residents is determined by the length of the day. Occasionally, the village gets together to chat or play cards, but mostly the day ends when the sun sets. The average income is 5,000 Yuan per year (US\$604.00), so even candles are considered expensive at 1 Yuan apiece (US\$0.12). Increasingly, families are leaving the village to find better work and an improved living situation in nearby urban areas. The village population has declined by $70 \%$ in the last ten years, since development of this rural area has stagnated.

Every child of the village attends school; middle and high school students board in Saihantala, and there is an elementary school in the nearby town. Every family takes education very seriously, and shares the opinion that the future of their children is their only hope of changing the village lifestyle of poverty. Surprisingly, all but one of the family members represented completed middle or high school (one woman completed only elementary school). The grandparents represented received no schooling. However, a few of the former residents of the village reportedly attended college; in addition, the Dean of a well-known Chinese university hails from Xingmingxiang. For this reason, aspirations are very high and each family present reported spending most of their meager income on education.

The potential for productive uses of electricity include irrigation; lighting for studying and/or small-scale crafts; refrigeration for sale of milk products; access to information and communication; and an improved standard of living, which includes self-empowerment, social integration, and entertainment. Houses are grouped close together, so a village-scale system would be feasible. Unfortunately, it does not appear that electrification is on the horizon. The high rate of out-migration is likely to continue, with village members joining the increasing population of impoverished migrant workers in China's urban areas. 


\section{Discussion}

\section{Implications of the research findings}

This study had three objectives: (1) to assess the overall project outcome; (2) to evaluate the technical performance of the systems; (3) to document the social and economic impacts of the project. As regards the first objective, by all accounts the project represents a critical success. For U.S. business, it has been a success because, according to several of the officials and experts involved in the project, U.S. PV panels are preferred over their domestic counterparts by hybrid system end-users. For the renewable energy industry in Inner Mongolia, it has also been a success - more than 10 factories in the region are engaged in production of renewable energy system components. As of late 2000, annual production of small-scale wind turbines was over 35,000 units; annual production capacity of PV cells was over $100 \mathrm{~kW}$; and production of solar heaters, batteries, and other components was significant (IMMOST 2000). For the international renewable energy agenda, it has also been a noteworthy success - between 6,000 and 8,000 government-subsidized hybrid systems have been installed in the province over the last four years as a direct result of the Pilot Project (Pang, personal interview, 2004; Liu, personal interview, 2004), and the government aims to install thousands more over the next five years. However, there are lessons to be learned from the project as regards funding and oversight, and these will be illustrated in the below subsections.

In regard to the second objective, it has already been seen that there is room for improvement in technology as well. The overriding technical issues occurred because of (a) poor manufacturing quality of the inverters, and (b) end-user error. It is beyond the scope of this report to discuss the state of the inverter and charge controller market in China, and its relative infancy has already been explained. However, user error indicates a breakdown in training, and this will also be discussed at more length below.

It bears repeating in regard to the third objective that it is often difficult to separate the chicken from the egg. For unidirectional causality between two variables is often difficult to establish outside the research laboratory. This study sought to evaluate the effects of improved electrification on quality of life, including television viewing; productive uses, and educational achievement, among other indicators of household wellbeing. If a satisfactory quality of life is contained in a way of life in which opportunities for self- and societal advancement are available for consumption; in which people are allowed strategies for escaping poverty; and in which people are able to pursue their own ideals of happiness, then study results indicate that the sample population has achieved a higher level of wellbeing than they knew previous to project implementation (there are two exceptions, one of which was narrated above in the section Struggling to survive (page 63); the other family had experienced similar difficulties - the death of the family's father had caused economic troubles).

Overall, it appears that changes in quality of life have come about because of access to modern commodities, access to information, increased cohesiveness of the herdsman community, and a broadened horizon. Though these concepts may seem too abstract for a project that began as inherently technical, what is most relevant to herdsmen is their satisfaction and comfort in life. Thus, these objectives must be given equal weighting in an analysis of the project's outcome. 
In regard to productive use applications, this study has shown productive uses to accrue from activities that are not traditionally considered relevant. Time, labor, and income savings are garnered by the use of labor- and resource-efficient appliances, resulting in higher overall productivity, not to mention a more convenient way of accomplishing daily tasks. In addition, the information available on television provides herdsmen with the opportunity to learn about veterinary care for their sheep, the market price of wool, the weather forecast, the condition of the grassland, and a host of other business-relevant information. Finally, television seems to offer many adults a welcome chance to educate themselves about diverse topics; for both adults and youth, television provides the doorway to the outer world.

Because education may result in higher returns for the pastoral individual—not only in terms of income but also in terms of human development and opportunity - it is considered one of the most important impacts of access to 24-hour power. Another DOE/NREL project in China adds support to this assertion. Xiao Qing Dao is an island located off the coast of Shandong province, and is electrified by a hybrid wind-diesel village system provided under joint cooperation of U.S. DOE and the Chinese government. The island community was surveyed briefly in September 2004 and yielded one very surprising result. Since the system was installed in November 2000, eleven children have gone to college-some have even continued on to graduate school. Previous to system installation, no resident of the island had ever gone to college. Given the island's population of about 370 people, this statistic is astounding. The mayor of the island, and its residents, attributed the children's success entirely to high-quality lighting that allowed for increased study time during the evening. These facts lend validity to the claim that electrification leads, whether directly or indirectly, to higher educational achievement.

Modernization, it has been seen, is not only a process of technological change but also one of ideological transformation. Though it is sobering (in environmental and anthropological terms) to think that the pastoral lifestyle may vanish from many areas of Inner Mongolia in coming years, the ultimate hope of herdsmen is that their children will lead happy and productive lives, and that is also the ultimate goal of true development initiatives.

The father of a family situated very close to the town of Dongwu talked about how his world had changed since he acquired his TV and phone. He said his view of the world had changed and his mind had become modernized. He was asked if he thought the grassland way of life - the pastoral way of life - would fade away because the world is changing. He answered that the family's entire history is placed within the great grassland, and he had hoped his children would support themselves by caring for sheep and learning how to decipher the weather. However, modern trends have changed herdsmen's minds because of the new technologies and science they learn about on TV, he said - they have more opportunities to spend their money, so they must earn and learn more. Communication has also changed within the community. Now people get together and talk about new electronic appliances or the renewable energy systems. Such conversations between neighbors, he said, are how people determine whether or not to make the changes that are happening around them. But change is inevitable.

When a technology or innovation enters the colloquial language of a society, it has made an impact. The fact that herdsmen associate renewable energy systems with promoting the peaceful lifestyle of the grasslands is a significant finding. Television has made herdsmen's lives more 
colorful, and renewable energy has allowed them to improve their standard of living without abandoning their traditional way of life - for the present time at least, and for now, these are workable solutions.

\section{Issues in system subsidization}

As previously mentioned, the price of each standard system, configured with 300 watts of wind and 100-200 watts of PV, was 10,000 Yuan (US\$1,208.00). According to Chinese project leaders, the systems were to be sold to every herdsman with a 3000-Yuan subsidy (US\$362.00), resulting in a $30 \%$ discounted price for the system. Based on the interviews conducted for this study, however, it does not appear that the system for subsidization was standardized in this way.

When asked the amount of subsidy they received, most households initially answered that they received none. After deliberation, most realized that they had received a discount price and this constituted the subsidy. Many were not aware that this subsidy or discount was provided by an international agreement. In fact, the genesis of the project was not known by herdsman households.

Information offered by local government officials varied. According to Mr. Yang, each family in Suniteyou Banner received a 3000-Yuan subsidy for purchase of the standard system configuration (in fact, it is more likely the subsidy was reflected in the price of the system - thus the equipment provider received the subsidy from the government, rather than the household). For smaller system configurations, a smaller subsidy was provided — in other words, the discount depends on the price. However, in the Saihantala and Erlian areas, of the 19 households interviewed, only two reported receiving a 3000-Yuan subsidy, and one of these belonged to the Brightness Program. Seven could not remember the amount of subsidy they received, three reported a 1000-Yuan subsidy, two reported a 10\% discount, and two reported a 500-Yuan subsidy.

In Dongwu, the situation was similar. Most households could not remember what discount or subsidy they had received. Of the 18 households interviewed there and in Siziwangqi, all but two of the systems belonged to the DOE/MOST project and were comprised of 300 watts wind and 100-165 watts PV. Two families reported receiving a 3000-Yuan subsidy, one reported a $10 \%$ discount price, and the rest could not remember or did not know. According to Mr. Gao in Dongwu, installations there occurred in two phases and only families installing systems during the first phase received a 3000-Yuan subsidy; second-phase families received 2000 Yuan. Data is detailed in Table 10, next page. 
Table 10. System subsidy amounts as reported by herdsmen.

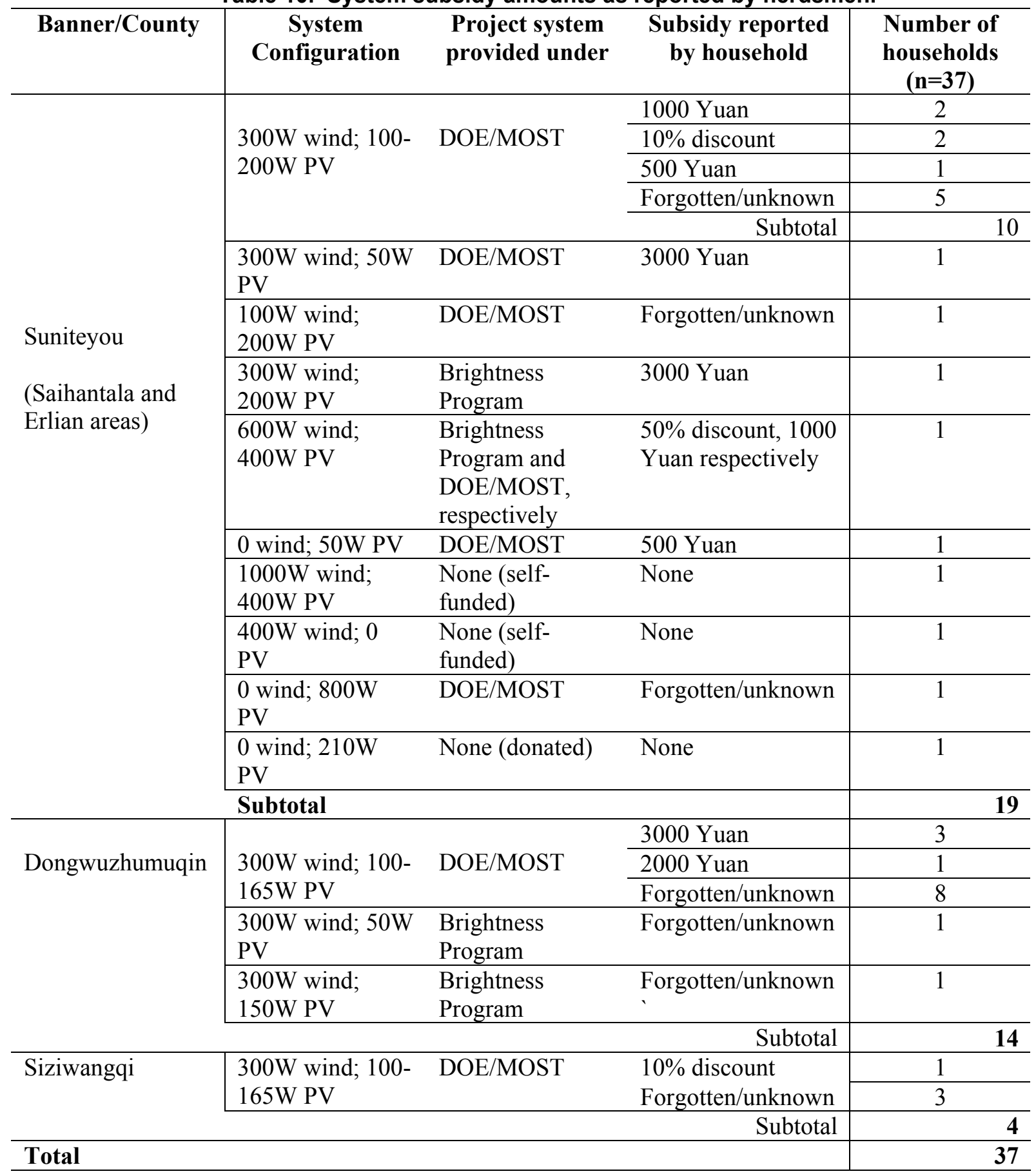

That so much data was unobtainable makes drawing a firm conclusion tenuous at best, but there is significance in the fact that only four of the 31 DOE/MOST project families interviewed could report having received a 3000-Yuan subsidy or 30\% discount. In addition, it seems surprising that the Chinese government would not make its financial support of these rural households more apparent. It would have been interesting to note how households' feelings toward the government correlated with their knowledge of the system subsidy. Unfortunately, since households' satisfaction with government support was a sensitive topic during this survey, such a 
correlation was not explored. In any case, the inconsistency in subsidization between the different banners supports the conclusion that lack of oversight was substantial.

\section{End-user education}

Educating the renewable energy system user is critical to the success of off-grid projects, for the household residents ultimately hold sole responsibility for the operation and maintenance of their systems, especially after the one- or two-year warranty expires. At a very basic level, users must understand that simple maintenance practices can minimize recurring costs and prolong the life of the battery. One important component is learning how to monitor battery charge and discharge levels, for lack of attention to the battery is often the reason for system inefficiency.

Another part of education is explaining the capabilities and limitations of the system. A 450watt system can manage a certain load, but expecting to operate a 300 -watt rice cooker while simultaneously running the TV and DVD can overload the system and cause frustration for the household. Educating households up front about how the system functions and what load it is designed for is therefore important.

An inherent barrier to rural electrification programs that rely on single-household systems is understandably end-user education, especially in areas marked by low levels of education and little or no experience with electronics. Though the training component of the Pilot Project was ambitious, and service teams exist in almost every county of the province, the PI's observations suggest that training of end-users fell short of the mark. Since it is impossible to know how training was accomplished aside from hearsay, it is also difficult to pinpoint the shortcoming of the approach. It did seem that some herdsmen were unwilling to make the time investment to learn about the system; they had therefore become disgruntled with it.

Despite their eagerness for hybrid systems and their willingness to pay a significant amount, many households have failed to make sound maintenance practices a part of their commitment. For, as has been noted, at best only one-third of households sampled understood best-care practices, much less maintenance. According to the pre-project analysis conducted by CEEP (Byrne et al 1996), capital cost, equipment quality, and after-sales service were the most important criteria for households in deciding whether or not to invest in a hybrid renewable energy system. In Saihantala, Mr. Yang reported providing a two-year warranty for project systems; in Dongwu, the warranty period was only one year. Thus, households should have been aware from the beginning that after-sales service was provided at a price. Though sufficient education of end-users in best-care practices for maintaining their systems could have prevented later costs for repair, the service industry has benefited from the high volume of business.

Manufacturing quality of the inverters is another significant roadblock in sustainability of household systems. Often, poor oversight of battery discharge and inverter malfunction combine to create a frustrating situation. In one household where both the inverter and the batteries had frequently failed, there was significant anger on the part of the herdsman that only five years since the system was installed, it was barely functioning. Because the family had fallen on hard times financially, they had little hope of replacing the necessary parts. When other herdsmen in the area hear of such situations, they are less likely to purchase a renewable energy system 
themselves. One of the system maintenance personnel in Dongwu said that there were a significant number of families in the area who had decided to rely on diesel instead of taking on the cost of a renewable energy system like their neighbors had done.

This creates a problematic future for renewable energy in the province. Improvement in manufacturing quality of inverters and batteries, and strategies to improve system affordability, policy support, and end-user education are critical, for positive attitudes toward renewable energy utilization is an important factor in sustaining efforts like the Pilot Project. These are significant challenges for the future that may take China a number of years to sort out.

Every pioneering venture contains its lessons, and ultimately, these are of as much value as the obvious successes. In fact, if projects were based on a requisite absence of limitations, no progress would be made in renewable energy development. Despite Project setbacks, it has achieved its initial goal - the wind-solar hybrid systems have out-performed the gen-sets and wind- or solar-only systems previously used by herdsmen, and have served to raise the quality of life for Project families. In addition, a burgeoning renewable energy industry exists in the province - in part because of Inner Mongolia's strong wind resource and history of wind power utilization, and in part because of the newfound popularity of hybrid systems and the strength of the service infrastructure.

\section{Issues in management of project funding and oversight}

The initial stage of the project—which included infrastructure development (identifying local support), resource assessment and data collection, personnel training, technical analysis, and documentation of the undertaking — was funded equally by the Chinese and U.S. governments. For the second stage, installation, the Chinese government covered the wholesale costs of the wind turbines, inverter/charge controllers, batteries, and connecting equipment (all of Chinese manufacture); training, installation and maintenance; and other miscellaneous costs. The local county governments were in charge of disbursing this money. U.S. DOE's investment occurred in the form of PV panels manufactured by U.S. Siemens and Solarex.

The plan was to equip 20 of the systems entirely with U.S. components and 20 entirely with Chinese components, in order to compare performance between systems. The remaining 160 systems were to be equipped with U.S. solar panels and the rest of the components would be manufactured in China. By the time the first installations began in 1996, word-of-mouth among the herdsman population had raised project demand so high that the implementation team decided to install 404 systems instead of 200. Thus, the available funds for the wholesale cost of each system were diminished, and the implementation team decided to equip approximately 240 systems with U.S. PV panels and the rest with entirely Chinese components. The original plan for 20 systems composed entirely of U.S.-manufactured components was discarded due to the expense.

U.S. DOE's investment in the installation phase of the project was therefore accomplished through provision of PV panels of varying sizes. The principle of this investment was the establishment of a revolving fund to be collected from the sale of 240 systems. For these systems, households were to pay cash up front or on a credit system (a payment plan in two 
installments) for the total cost of the systems without a subsidy or discount, and the revenue from the entire system was to be deposited in an account and turned over at least once toward the purchase of additional systems for the project. These additional systems would collect revenue in the same way, which would again be set aside and reinvested in a third wave of installations. In this way, the project would sustain its own momentum.

Unfortunately, the revolving fund did not work as planned. The systems equipped with U.S. PV panels were sold at the discounted price decided upon for the other systems (a 3000 Yuan subsidy or $30 \%$ discount). Local MOST offices sold the systems to herdsman households and then maintained control of project funding at the local level. Because of economic losses experienced in the area from the two-year drought and other hardships, Chinese project leaders determined that the credit or installment plan was not practical—some herdsmen made only the first payment and defaulted on the second. Because of this, officials quickly decided to require that herdsmen pay the entire cost in cash up front, but losses had already been incurred and insufficient revenue was garnered to sustain the revolving fund. Instead, according to Chinese project leaders, some of the funds raised from the project were invested in IMPU's renewable energy demonstration center in Hohhot, including a U.S.-manufactured anemometer installed at the site.

At this point, it is difficult to determine the reasons the revolving fund was not sustainable. The main reason cited by Chinese project leaders for the closure of the fund is the lack of reliability on the part of the herdsmen in paying the second installment for their systems, and the subsequent loss of revenue. Whatever the cause, the end-result would suggest that oversight of funding and revenue collection was inadequate. Indeed, U.S. project leaders recognized that the addition of the revolving fund to the project was risky and that very little experience with this type of mechanism was available in China prior to the project. In fact, a more successful use of a revolving fund under the U.S.-China Protocol was achieved in a solar home system program in Gansu province, under a different mechanism (private, non-profit company), in which the fund was turned over twice during the course of the project.

Because the revenue from the systems containing U.S. PV panels was never reinvested in additional systems, the potential for the project's impact was reduced. However, NREL's experience with successful revolving funds in other projects, most notably the one in Gansu, suggests that when supervised properly an initial investment can double or triple its impact in a relatively short amount of time. U.S. project leaders suggest that the subsidy-based attitude of the Chinese government precludes effective management of a revolving account; such accounts are likely better established and managed by a non-profit organization (as was the case in Gansu), a business, or a rural credit union. It also appears to be the case that negotiations with the Pilot Project's Chinese partners in Inner Mongolia proved difficult in terms of establishing an effective mechanism for oversight and transparency to the U.S. partners.

\section{Recommendations for further study}

A substantial amount of planning, research, innovation, and documentation went into the Pilot Project during the early stages, but by the end of the installation period, most oversight was concentrated within the individual sumu centers and there was very little from the wider 
perspective, including from the side of the U.S. Regrettably, the lack of a long-term commitment and follow-through is an inherent part of many government-led development projects and such projects are consequently limited in impact. According to U.S. project leaders, this is frequently a function of inherent restrictions in working with the primary funding agency in such projects, as the project leaders themselves — as with the Inner Mongolia Pilot Projectare indeed generally interested in pursuing projects more aggressively and in a longer timeframe. However, the uncertainties in funding for U.S. renewable energy programs frequently preclude taking a long-term view of project management. In addition, foreign contributions to such joint projects are frequently limited in funding for foreign travel that would allow for a field presence and more in-depth involvement of foreign experts during the implementation phase of projects.

The problems incurred when funding partners exhibit a limited vision to project follow-through are illustrated most recently with the Township Electrification Program. The Chinese government has already installed 1065 off-grid village systems using renewable energy and plans to electrify 29,000 natural villages in the next few years. However, the 1065 systems already installed have not been adequately secured - no formal scheme has been finalized for their maintenance and ownership. Such rural development programs are undertaken by the government to raise the wellbeing of people who are not adequately equipped to do so for themselves. Such programs are not instituted for profit - investment is not undertaken with an eye on the literal return but, rather, the figurative. However, unless the government provides a mechanism for long-term funding and support of such projects, they are not self-sustaining because of their higher operating cost. In urban electrification schemes, end-users pay for the electricity they consume and thus provide for the operation cost of the electricity. However, the Township Electrification Program is targeted at low-income and often impoverished rural areas, so requiring them to pay a tariff that would support system upkeep would be beyond their means and ultimately cancel out the aim of poverty alleviation. It must be said that the Chinese government, most notably the Energy Bureau within the NDRC, is very much aware of these shortcomings and is working aggressively to find solutions to the infrastructural issues of the Township Program as well as ways to improve project development for the follow-on Song Dian Dao Cun program. ${ }^{11}$

Utility companies are generally unwilling to take on ownership of the systems because there is no return on the investment. This is being seen all over China in numerous off-grid electrification projects. System components have a finite lifetime and necessitate replacement and repair every few years. Costs borne by part replacement - especially of village system batteries — can be substantial, numbering in the tens of thousands (U.S. dollars). Unless a strategy is implemented whereby costs are distributed over the main electrical grid or subsidized by the government - as is currently being integrated into the Renewable Energy Law — rural electrification programs will fail. For this reason, this next step in policymaking for the government will be crucial; institution of long-term purchasing power agreements would encourage utility companies to invest in renewable energy projects. The government must guarantee that investment in such projects will generate revenue; this is requisite to establishing a market for renewable energy technologies. Currently the Chinese Government is in a state of retroactively repairing some of the inevitable problems encountered after the installation of township systems, and has recognized that any follow-on program to extend renewable energy

\footnotetext{
${ }^{11}$ Per William Wallace of the UNDP/GEF Renewable Energy Project in Beijing.
} 
electrification to natural villages must be done with more adherence to sustainable development principles. ${ }^{12}$ A detailed analysis of the Township Electrification Program is beyond the scope of this document; however, this program as a case study would provide an interesting opportunity for future investigation.

The other side of the coin is that when governments fully fund projects with no responsibility assigned to the end-users, paradoxically, this also puts end-users at a disadvantage since they are encouraged to remain dependent on the state - this arrangement guarantees that they lack a voice in how project decisions are made in the long term. In the case of the Inner Mongolia Pilot Project, according to both Chinese and U.S. project leaders, one of the initial objectives was that the project lead toward commercialization of the hybrid systems, with a clear shared responsibility on the part of the user to pay reasonable maintenance and replacement costs for the system him or herself. One of the reasons for establishing an infrastructure for continued service and maintenance support was to accommodate the user in this regard. It is significant that the service system has worked quite well — never did a household complain during fieldwork that system support was unavailable. In fact, it appeared that such support was immediate when requested, and thorough. The officials and technicians with whom the PI interacted gave the impression of being fully dedicated, both personally and professionally, to the Project families and the other families in the area that depended on renewable energy systems.

Though not an issue of semantics, the end-users of Pilot Project systems were technically customers as much or more than they were benefactors of the project, and they thus accepted a certain amount of responsibility when they purchased the hybrid systems. Part of the barrier to sustainability of this project and other development initiatives therefore belongs to the user. In the case of China, it appears that some rural populations have become used to receiving rural subsidies from the government, so that the concept of taking on some of the responsibility -in other words, exhibiting a willingness to pay-is not considered a viable option or even a reasonable notion. According to experienced project managers in China, this has been and continues today to be one of the most challenging problems for rural development in China.

Though the objective of the Inner Mongolia Pilot Project was to demonstrate the practicality of off-grid renewable energy hybrid systems for a remote population, another interest was to build capacity for the renewable energy industry in the province and thus leverage further development of such projects. Of necessity, the project was conducted largely through business channels (the service network was set up under an existing rural service infrastructure). Project leaders accepted going into the project that combining commercial intent with government programs had been problematic in the past, but the hope was that the Pilot Project might lead to a robust commercial market for rural energy systems. This objective has not yet been achieved; however, the project did result in increased demand for such systems and helped to spur the commercial market for solar home systems and small wind turbines. In addition, it helped to create an embryonic commercial market for wind-solar hybrid household systems, even though the government-subsidized market is still larger than the commercial market.

Emerging technologies do not become commercially viable overnight, and the potential for future development in Inner Mongolia does exist. Markets are not created simply from

\footnotetext{
${ }^{12}$ Per personal conversation with William Wallace of the UNDP/GEF Renewable Energy Project in Beijing.
} 
demand - and demand does exist for renewable energy systems, especially in remote off-grid areas. Thus, the government must nurture an environment in which renewable energy technologies can profit. It is widely hoped that the Renewable Energy Law now in development will address this challenge. There is plenty of international experience in evidence, from Germany to Massachusetts, that provides positive examples of how initial barriers to developing viable renewable energy scenarios can be overcome.

\section{The future of renewable energy for pastoral applications}

Interviews with officials at the provincial and local levels of MOST revealed that the next phase of renewable energy promotion in the province aims to focus on direct productive uses. Mrs. Pang of the Hohhot MOST office listed this focus as a crucial and necessary next step, and emphasized that planners should envision scenarios where herdsmen use electricity for grassland irrigation and village-to-village power. Ownership of village projects aside, she suggested that instead of developing larger off-grid household systems, mini-grid systems or remote power stations could leapfrog over current difficulties and affect a farther reach in provincial development. Power stations could make such things as irrigation systems more realistic.

That the follow-on phase for the Pilot Project has already been envisioned on this ambitious scale indicates that the project has achieved its objective - it has become a springboard for further development, if only in the brain-seeds of development planners. During project development, there was much discussion among U.S. and Chinese partners on the issue of productive uses such as water pumping, wool shearing, and even some examples of the tourist concept illustrated by the family in this report (page 53). It was clear, however, that the Pilot Project would focus on household uses and improved quality of life-i.e., indirect productive uses - with the implication being that this step might lead to the capability of supporting direct productive uses in the future.

Nonetheless - and looking at this issue within a larger context that goes beyond the scope of any single project or this report - the question must be asked as to whether further improved technology will truly serve the Inner Mongolian herdsmen. A major hallmark of the Marxist vision and indeed the ideal of human progress in general is that man may overcome nature's limits by virtue of ever-better technology. It is not clear that a higher capacity hybrid system will indeed serve the population in the long run, though it may improve their enjoyment of life in the short term. Water scarcity will continue to be a major roadblock on the road to ultimate development of the population - indoor plumbing and access to purified water is more important than larger televisions and no matter the amount of electricity, scarcity of water is now the real issue. Thus, though irrigation systems would improve the livestock carrying capacity of the grasslands, there is no water to make this vision work. When it comes to water, there is no alternative to conservation-herdsmen are as dependent on fresh water for survival as their ancient forbearers were.

According to research gathered by the American Embassy in China (AEC 1998, 2001, 2001a, 2002a), the country's land has quickly been turning to desert. Since the late 1980s, desert areas have been expanding by about 2,500 square kilometers a year, and of the seven areas in the country where desertification is the most acute, three are in Inner Mongolia. The United Nations 
Desertification convention puts the rate of desertification there through the 1990s at roughly twice the size of Delaware each year. The direct economic cost of this is estimated at 54 billion Yuan (about US\$6.5 billion) per year. Meteorologists have recorded an increasing number and rising intensity of dust storms in recent years, and determined that they have not come from historic desert areas but newly desertified ones, such as the banner in which Saihantala is located. In effect, the Gobi Desert is expanding eastward, and for the first time, in 2001, such a dust storm rode the jet stream to the U.S. mainland, causing a visible haze over Colorado. The yield of forage grass in Inner Mongolian pastureland has declined 30-70\% in the last 50 years, and one scientist in Xilinguole League estimated that, if current trends continue, the League will be unlivable in 15 years.

Chinese experts are largely in agreement that the main cause of desertification is human activity, which includes overgrazing; uprooting of pastureland to obtain medicinal grasses and herbs; opening up unsuitable land to cultivation; inappropriate use of water resources; and loss of land to mines, factories, roads, and cities. Minor causes of desertification are considered natural, such as wind erosion and climate change. Rainfall in northern China has been below normal in recent years, and Chinese climate experts say that this is due to deforestation and global climate forces. In sumu, "Xilingol [Americanized spelling for Xilinguo League] illustrates the major obstacle to Beijing's grand plans to develop China's poor "western" regions....As one expert on Xilingol's ecology succinctly put it, "This area cannot be developed" (AEC 2001a). Solutions proposed by the experts include cutting in half the number of livestock herdsmen are allowed to own; subsidizing herders to take pastureland out of use; importing high value-added livestock like cattle for a higher return on fewer animals; feeding animals manmade fodder in place of grass; and migrating herdsmen to urban areas that offer industrial employment. However, each of the first solutions requires a substantial government investment to guard against impoverishing herdsmen, and the last solution implies human rights violations.

The Chinese government adopted a national desertification control law in 2002, which is based on command-and-control procedures, creating new protected areas, and reforestation efforts. However, it fails to acknowledge the contributory role of other national policies to the desertification problem, such as the residence permit system, whereby rural residents receive no government support - including the free education guaranteed to urban residents - if they migrate to urban areas, thus committing rural residents to their environment. As it is, between 80 and 120 million surplus rural workers are already adrift between Chinese rural villages and the cities, many barely subsisting through part-time, low-paying jobs (CIA 2004). Finally, including reforestation efforts in grassland rehabilitation is also short-sighted, since trees over-draw from precious groundwater resources in already parched areas and increase erosion of sandy soils.

It is logical to conclude that desertification is a social phenomenon, but to blame it entirely on pastoralism is not. The root social causes of irresponsible land use are found in the Chinese system of land tenure and the forced sedentarization brought about by land reform; the devaluation of natural resources by the market and the importance placed on industrial and mechanized agricultural production; ineffective pricing on water resources that fails to encourage conservation; and a lack of capital support for local conservation initiatives. Desertification is not a problem known only to China, and its causes remain controversial on a global scale. Single-factor explanations that point to the problems of overgrazing and population growth have 
merit, but exclusion of other relevant factors prevents workable solutions from being implemented. National-level policies must address underlying social and economic causes of land degradation in order to reform land-use and conservation policies, along with the implementation of corresponding alternate economic opportunities that are socially and culturally sensitive (Geist and Lambin 2004).

Any development initiative that focuses on the future wellbeing of Inner Mongolia's pastoral households must take into account the above environmental concerns. The effects of the drought that hit the province from 2000 to 2002 were significant, and the economy of the area as a whole has not fully recovered. If the experts cited in the above section are correct, the carrying capacity of the grassland is not expected to improve. Thus, in a very real sense, the environment places a ceiling on the potential wellbeing of the pastoral population, not to mention the future of renewable energy development there. This is another area in which further study is needed. 


\section{Conclusion}

This report has shown that over all, the use of decentralized off-grid renewable energy technologies is well suited to the Inner Mongolian herdsman population, and to the province - the complementary nature of strong winds and high solar insolation in the region makes wind-solar hybrids an obvious choice. Though the study has also identified some issues needing further consideration, the Pilot Project has been a success in the big-picture view. The reason for its success rests with the herdsmen, who, for the most part, have experienced an enhanced quality of life because of the conveniences and entertainment made possible by having year-round, 24-hour power. Indeed,

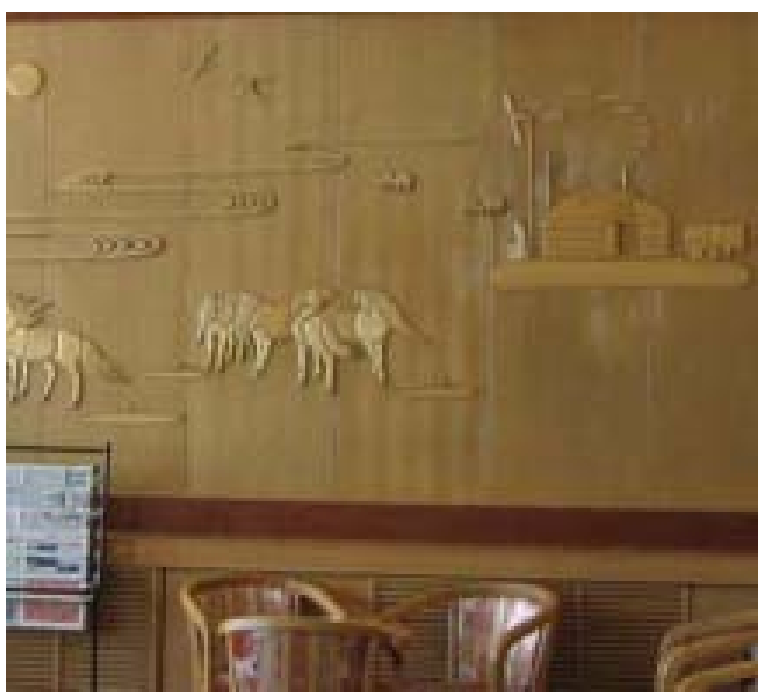
renewable energy has come to be associated with the grasslands, and wind turbines can be seen in artistic depictions of grassland life, such as in the mural pictured here (located in the lobby of a Dongwu hotel).

The aim of the Inner Mongolia Household PV/Wind Hybrid Systems Pilot Project was to demonstrate the performance advantages of wind-solar-battery hybrid systems over those traditionally relied upon by herdsmen for electricity and as such, it was an essential demonstration project for the U.S.-China Protocol of 1995. This aim of the project has been achieved, which is evident in the fact that to date, as many as 8,000 additional systems have been installed among the herdsman population. Indeed, the dissemination of these hybrid systems proves that rural electrification endeavors are advanced by the use of off-grid renewable energy technologies. Though real challenges exist in improving the quality of Chinese-manufactured inverters and developing a better system for training end-users, the technical findings of the study are encouraging.

It is the human development aspect of the project that is most inspiring. In just the last ten years the average income of herdsmen has increased by more than $60 \%$, and enrollment in institutions of higher education in the province has increased by $224 \%$. Though these statistics reflect the trends of Inner Mongolia's urban areas as well as the rural, the findings elaborated in this report point to a trend of economic and human development among the herdsmen as well. Perhaps more important, this study has shown that indirect productive uses of electricity result from time, labor, and income savings from forgone expenses on labor- or resource-intensive activitiesprimarily, this refers to the convenience of washing machines, refrigerators, cooking fans, and water pumps which lighten the labor involved in the daily pastoral lifestyle. Through use of television programs, herdsmen also enjoy higher returns on investment in terms of livestock health and timely sales of wool; profit maximization through more efficient allocation of income due to information availability (for example, when a drought is forecast, herdsmen can put aside disposable income for animal feed); and opportunities for continued adult learning. In addition, 
children learn that other options are available to them, and that education provides the 'ticket out' of the pastoral way of life, should they choose that avenue.

By virtue of the satellite telephone, herdsmen benefit from the ability to conduct business transactions in real time; in addition, a foundation of social capital is facilitated through improved communication availability. Social capital proves an indomitable asset when groups who exist on the margins of mainstream society are confronted with change and challenge. In sum, these returns on the investment in electrification represent real gains in human welfare and quality of life for the herdsman population, and should not be discounted. It is the aim of this report that these findings be used to justify future projects in off-grid renewable energy electrification.

Electrification by off-grid renewable energy systems constitutes an area of analysis that has been little explored in detail, especially in regard to qualitative impacts. The value of this report is that it provides a window into the lives of the herdsmen, three to eight years after installation of the Pilot Project systems. Economic and technical analyses are important, and in this case were crucial to the success of project. For a post-installation assessment, however, the value is in expressing the effects of the project that are not easily quantified or placed neatly into a formula. The true indicator of success for development projects, even if they begin as technical endeavors, is whether and how the project functions within the society. If it has been integrated and utilized by its end-users to further their own potential, it has been worthwhile.

The next phase of renewable energy utilization in sustainable development must necessarily focus on social and qualitative impacts as much as or more so than the purely technical aspects. This is especially true in light of China's recent experience with sustainability of the Township Electrification Program. For the long-term viability of technical endeavors depends on the context in which they are situated, which includes the social objectives of the society in question as well as the provision of government support for their continuance. The sustainability of the renewable energy effort in China depends on a commitment to follow-through and to revisiting with a qualitative eye the technical innovations embraced in off-grid renewable energy projects. What is needed is a long-term vision that merges government support with social empowerment.

The Chinese government has demonstrated a marked interest in development of energy efficient and renewable energy technologies over the last ten years. While as many as 60 million people in rural areas of the country remain without electricity, rural electrification is one of the key components of China's three-pronged poverty alleviation strategy which includes infrastructure development, financing and credit schemes, and social welfare objectives (Wang, personal interview, 2004). However, the actual work of poverty alleviation in terms of social welfaresubsidizing rural incomes, improving education and healthcare facilities - falls to county-level governments, and the allocation of funds for this purpose is rarely transparent. The result in many rural areas is a mass exodus of the middle generation, who leave in search of work in China's urban areas. These rural areas are thus stripped of a good portion of their human capital, which makes the future for these populations appear grim. The growing numbers of rural-urban migrants in China are becoming a real economic and social problem for the country, and rural development has yet to address this issue (Yardley 2004). 
The difference in providing rural populations with improved infrastructure, such as electricity, is that individuals and communities are given the means by which to themselves build on their human and social capital. As this report has argued, achieving higher human and social capital constitutes a crucial step in building upon physical and, where natural resources are conserved, natural capital as well. As the World Bank has found, a rise in per capita energy use corresponds to an increase in life expectancy and a decrease in infant mortality, illiteracy, and fertility rates; indeed, energy is ultimately required to meet all basic human needs. Thus electrification, like education, constitutes a decisive step in achieving freedom from poverty. The circumstances of the herdsmen of Inner Mongolia are not nearly as desperate as many in China's western regions. It is important to note, however, that the herdsman population remains relatively poor by Chinese standards, and the project does allow for lessons in poverty alleviation.

Inner Mongolia is undergoing a period of rapid change, both politically and socially. The strategic roles of electrification represent only strands of a vast web that encompasses China's and Inner Mongolia's march toward modernization. During the last decade, China has had to embrace capitalism in order to save socialism (Lee 2003), and this has paved the way for globalization not just of China's economy but also of mainstream culture - even the statecontrolled media has loosened some of its former restrictions. In regard to Inner Mongolia, this process has become intertwined with the process already underway for decades which blended the culture of ethnic Mongolia with that of China. Erroneously, and especially when ethnic societies are at issue, culture is often conceived of as a static identity-something that must be preserved and guarded from the forces of change. However, culture is continually being produced and negotiated; culture itself cannot be 'lost.' For many theorists, popular culture represents a site of struggle between the dominant discourse and subversive forces- there are no winners and losers in this struggle, only a myriad of possibilities.

The herdsmen of Inner Mongolia have, in opening their horizons to popular culture, begun a reconfiguration of themselves. In a sense, their opening up mirrors that of the Chinese state, and represents a tool of survival. This process should not be overlooked or its importance underestimated, for part of surviving is learning to blend the secular with the sacred, the shortterm with the long-term, the technical with the natural, and the ancient with the modern. Despite the dependency of the Inner Mongolian herdsmen on the political and environmental context in which they live, they retain control over their own destiny. In this way, they offer much in the way of lessons learned. This report has attempted to give as much weight to their words as to any concept of objective analysis. In order to ensure that their needs and the needs of China's rural population are adequately assessed and strategies accurately designed to meet them, the individuals and societies at issue must be included in consultation with government oversight. Whether this can reasonably be accomplished in China remains to be seen.

Rural electrification using energy-efficient and renewable energy technologies goes beyond simply providing electricity to forging a new road on the development pathway-creating a new vision and an improved relationship both between individuals and their environment, and citizens and their state. In the next 15 years major issues will confront the herdsmen, especially in regard to the carrying capacity of the grasslands. For the current improvements in quality of life, education, income, and productivity to continue, the Chinese government should seek creative solutions in the form of policy and infrastructure support. Though reform of the 
economy has already begun at a rapid pace, a restructuring of government oversight is likely required for realization of development in the country's western regions. Given China's vast potential for development of renewable energy resources and its demonstrated interest in promoting sustainable development, the potential for the future is considerable. 


\section{References}

American Embassy in China (AEC). 2001. China adopts law to control desertification. Internet. Available from http://www.usembassy-china.org.cn/sandt/desertification law.htm.

American Embassy in China (AEC). 2002. China tackles rural electrification. Internet. Available from http://www.usembassy-china.org.cn/sandt/Electrification.htm.

American Embassy in China (AEC). 2001a. Grapes of wrath in Inner Mongolia. Internet. Available from http://www.usembassy-china.org.cn/sandt/MongoliaDust-web.htm.

American Embassy in China (AEC). 1998. PRC desertification: Inner Mongolian range wars and the Ningxia population boom. Internet. Available from http://www.usembassychina.org.cn/sandt/desmngca.htm.

American Embassy in China (AEC). 2002a. Western China grasslands in trouble. Internet. Available from http://www.usembassy-china.org.cn/sandt/Grassland.htm.

Barnes, Douglas F. 1988. Electric power for rural growth: how electricity affects rural life in developing countries. Boulder: Westview Press.

Barnes, Douglas F. et al. 2002. Rural electrification and development in the Philippines: measuring the social and economic benefits. World Bank Energy Sector Management Assistance Programme (ESMAP). Internet. Available from http://www.worldbank.org/html/fpd/esmap/pdfs/255-02.pdf.

Blacker, William. 2002. Eumania. Ecologist, 32(4):16-20.

Boer, Derek. 2000. Impact on economic and social development of converting rural villages from part-time power to 24-hour power using a hybrid renewable power system. National Renewable Energy Laboratory publication. Internet. Available from http://www.nrel.gov/publications.

Bulag, Uradyn E. 2002. The Mongols at China's edge: History and the politics of national unity. Lanham, MD: Rowman \& Littlefield Publishers, Inc.

Byrne, John, Bo Shen and William Wallace. 1998. The economics of sustainable energy for rural development: a study of renewable energy in rural China. Energy policy 26(1): 45-54.

Byrne, John, Bo Shen, William Wallace, Ralph Nigro, Art Babbott, el al. 1996. Levelized cost analyses of small-scale, off-grid photovoltaic, wind and PV-wind hybrid systems for Inner Mongolia, China. Center for Energy and Environmental Policy, University of Delaware (http://ceep.udel.edu/ceep.html): Newark, DE. 
Byrne, John, Young-Doo Wang, Bo Shen, Aiming Zhou, and staff of Center for Energy and Environmental Policy of University of Delaware. 2001. Off-grid renewable energy options for rural electrification in western China. Internet. Available from http://www.nrel.gov/international/china/publications.html.

Cecelski, Elizabeth W. 1995. From Rio to Beijing: engendering the energy debate. Energy Policy 23(6): 561-75.

Central Intelligence Agency (CIA). 2004. The world factbook: China. Internet. Available from http://www.cia.gov/cia/publications/factbook/geos/ch.html.

China Daily. 2003. Beijing boasts nation's highest standard of living. China Daily (February 6). Internet. Available from http://www.china.org.cn/english/Life/55073.htm.

China's Agenda 21 (CA21). 1994. White paper on China's population, environment and development in the 21st century. Beijing: China Environment Science Press. Internet. Available from http://www.acca21.org.cn/ca21 pa.html.

Diener, Ed and Eunkook M. Suh, Eds. 2000. Culture and subjective wellbeing. Cambridge, MA: MIT Press.

Energy Information Administration (EIA), U.S. Department of Energy. 2004. Country analysis briefs. Internet. Available from http://www.eia.doe.gov/emeu/cabs/contents.html.

Gao, Xiuhe. Ministry of Science \& Technology, Dongwuzhumuqin, Inner Mongolia. Personal interview conducted 17 August 2004.

Geist, Helmut J. and Eric F. Lambin. 2004. Dynamic causal patterns of desertification. Bioscience 54(9): 817-29.

Goldemberg, José and Thomas B. Johansson, Eds. 1995. Energy as an instrument for socioeconomic development. United Nations Development Programme. Internet. Available from http://www.undp.org/seed/energy/policy.

Green, M.A. and D. Zwebe. 2004. From solar home systems to grid electricity, a women's view. ADB FINESSE Africa newsletter (October). Internet. Available from http://www.afdb.org/about_adb/finesse_newsletter.htm.

Haines, Andrew and Daniel M. Kammen. 2000. Sustainable energy and health. In Global Change \& Human Health 1(1): 78-87.

Hardin, Garrett. 1968. The tragedy of the commons. Science 162:1243-8.

Hillman, Ben. 2003. Paradise under construction: minorities, myths and modernity in northwest Yunnan. Asian Ethnicity 4(2): 175-88. 
Inner Mongolia Autonomous Region Bureau of Statistics (IMARBS). 2003. Inner Mongolia Statistical Yearbook. China Statistics Press.

Inner Mongolia Ministry of Science and Technology (IMMOST). 2000. Utilization and development of renewable resources in Inner Mongolia. Prepared and printed by IMMOST.

Jiyane, Veli and Dennis N. Ocholla. 2004. An exploratory study of information availability and exploitation by the rural women of Melmoth, KwaZulu-Natal. South African Journal of Library \& Information Science 70(1): 1-8.

Johnson, Kirk. 2000. Television and social change in rural India. Thousand Oaks, CA: Sage Publications.

Johnson, Todd, Feng Liu, and Richard S. Newfarmer. 1997. Clear water, blue skies: China's environment in the new century. Washington, D.C.: The World Bank.

$\mathrm{Ku}$, Jean, Debra Lew and Shenghong Ma. 2003. Sending electricity to townships: China's largescale renewables programme brings power to a million people. Renewable Energy World (September-October): 56-67. Internet. Available from http://www.nrel.gov/environment/pdfs/pubs_sending_electricity.pdf.

Leach, Athol. 2001. Information provision in a rural context: the perspectives of rural adults. South African Journal of Library \& Information Science 67(2).

Lee, Chin-Chuan, Ed. 2003. Chinese media, global contexts. London: RoutledgeCurzon.

Lew, Debra. 2001. Micro-hybrids power Inner Mongolian households. National Renewable Energy Laboratory. Internet. Available from http://www.nrel.gov/publications.

Li, Hua. 2002. China's solar thermal industry: Threat or opportunity for European companies? Renewable Energy World (July-August). Internet. Available from http://www.jxj.com/magsandj/rew/2002_04/china_solar.html.

Li, Xiuguo. Chinese Academy of Sciences. Personal interview conducted in Beijing 3 August 2004.

Liu, Yu. 2004. Harnessing the wind. Beijing Review 47(40). Internet. Available from http://www.bjreview.com.cn/ml-zhong/ml-200440-z.htm.

Liu, Zhizhang. Inner Mongolia Polytechnic University. Personal interview conducted in Hohhot, Inner Mongolia, 23 August 2004.

Mankekar, Purnima. 1993. National texts and gendered lives: an ethnography of television viewers in a North Indian city. American Ethnologist 20(3): 543-63. 
Martinot, Eric, Akanksha Chaurey, Debra Lew, José Roberto Moreira, and Njeri Wamukonya. 2002. Renewable energy markets in developing countries. Annual Review of Energy \& Environment 27: 309-48.

Nader, Laura. 1995. Energy needs for sustainable human development from an anthropological perspective. In Goldemberg, José and Thomas B. Johansson, Eds. 1995. Energy as an instrument for socioeconomic development. United Nations Development Programme. Internet. Available from http://www.undp.org/seed/energy/policy.

Pang, Shu Qin. Senior Engineer, Ministry of Science \& Technology, Hohhot. Personal interview conducted 25 August 2004.

Reiche, Kilian, Alvaro Covarrubias and Eric Martinot. 2000. Expanding electricity access to remote areas: off-grid rural electrification in developing countries. In Isherwood, Guy, Ed. WorldPower 2000. London: Isherwood Production Ltd. Internet. Available from http://www.martinot.info/Reiche_et_al_WP2000.pdf.

Richter, Marlene. 1997. Report on the use of wind and solar energy in Inner Mongolia of the People's Republic of China. On behalf of FGU.

Richter, Marlene. 1999. Impact analysis of renewable energy supply systems in several project locations in Inner Mongolia, PRC China. On behalf on SMA.

Saunders, John, J. Michael Davis, Galen C. Moses, and James E. Ross. 1978. Rural electrification and development: social and economic impact in Costa Rica and Colombia. Boulder, CO: Westview Press.

Sen, Amartya. 1999. Development as freedom. New York: Knopf.

Smil, Vaclav. 2004. China's past, China's future: energy, food, environment. New York: Routledge.

Sneath, David. 2000. Changing Inner Mongolia: Pastoral Mongolian society and the Chinese state. Oxford: Oxford University Press.

Swift, Jeremy. 1988. Major issues in pastoral development with special emphasis on selected African countries. Rome: FAO.

United Nations Development Programme (UNDP). 2004. Human development report 2004. Internet. Available from http://hdr.undp.org/reports/global/2004.

United Nations Development Programme, China (UNDP China). 2002. China human development index 2002. Internet. Available from http://www.unchina.org/undp/documents/chdr/hdr02-statistical.pdf. 
Uphoff, Norman and C. M. Wijayaratna. 2000. Demonstrated benefits from social capital: the productivity of farmer organizations in Gal Oya, Sri Lanka. World Development 28 (11): 187590 .

Van Campen, Bart, Daniele Guidi and Gustavo Best. 2000. Solar photovoltaics for sustainable agriculture and rural development. Food and Agriculture Organization of the United Nations. Internet. Available from http://www.martinot.info/productive uses.htm.

Wamukonya, Njeri and Mark Davis. 2001. Socioeconomic impacts of rural electrification in Namibia: comparisons between grid, solar and unelectrified households. Energy for Sustainable Development 5(3): 5-13.

Wang, Sangui. Division of Poverty and Development, Institute of Agricultural Economics, Chinese Academy of Agricultural Sciences. Personal interview conducted in Beijing 5 August 2004.

Williams, Dee Mack. 1996. The barbed walls of China: a contemporary grassland drama. The Journal of Asian Studies 55(3): 665-91.

World Bank. 2004. World Development Report 2004: Making services work for poor people. Internet. Available from http://econ.worldbank.org/wdr/wdr2004.

Xu, Bingxun and Songtao Wang. 1999. Inner Mongolia. Hohhot: Inner Mongolia University Press.

Yang, Yi. SiXu Brightness Program Company, Saihantala, Inner Mongolia. Personal interview conducted 11 August 2004.

Yardley, Jim. 2004. The great divide, a missing generation: Rural exodus for work fractures Chinese family. The New York Times, 21 December: A1.

Zhang, Zhengmin, J. Li, and Y. Wan. 1998. Comparison of renewable energy policies of China and the United States. National Renewable Energy Laboratory. Internet. Available from http://www.nrel.gov/china.

Zhou, Aiming, and John Byrne. 2002. Renewable energy for rural sustainability: Lessons from China. Bulletin of Science, Technology \& Society 22(2): 123-31. 


\section{APPENDIX A. Household interview questions.}

Questions were not standardized, but all interviews contained discussion of the following:

\section{The hybrid system.}

1. What year was the system installed? Note if wind and PV were acquired in different years.

2. If not part of the DOE/MOST project, under what program was the system installed?

3. Where was the turbine manufactured?

4. Where was the PV panel manufactured?

5. What subsidy amount did the family receive for the system? If no subsidy, how was the system funded?

6. What is the capacity of the system - how many watts PV and how many watts wind?

7. How has the system performed?

8. In what condition is the system presently?

9. How many hours of power does the system provide per day? Is the power sufficient to run all appliances?

10. If problems have been experienced with the system, what are the main ones?

11. Have you had to replace or repair any of the parts? If so, which ones?

12. Does anyone in the household understand how to best maintain the system so it doesn't break?

13. What does the household do in case of system problems?

14. Are you satisfied with the system?

15. How do you feel about this hybrid system and its use of renewable energy compared to the grid-connected electricity that people have in town?

16. What did you use for electricity before the hybrid system was installed?

\section{Household demographics.}

1. Record gender and age of the main respondent, as well as other family members in attendance; their demeanor, etc.

2. How many members of the family live in the household at the present time?

3. What is the highest education level completed by each family member?

4. What is the ethnic background of the family?

5. What is the average annual income for the entire family? What are the income-generating activities?

6. How many sheep/cows/horses/camels/other livestock does the family own? 


\section{Daily activities.}

1. What commodities does the household own?

a. Is the TV color or black and white?

b. DVD/VCD?

c. Stereo?

d. Washer and/or "dryer"?

e. Refrigerator and/or freezer?

f. Water pump? Is it electric, solar-powered, hand-powered, or diesel-powered? If none, is there a well? If no well, how is purified water obtained?

g. Satellite phone?

h. Rice cooker or electric wok?

i. Other appliances?

2. How often are the commodities used? Are they in constant or occasional operation?

3. Does the household use electricity in any way to care for the livestock?

4. How many hours per day of TV is watched and by whom?

5. What are household members' favorite programs?

6. What do you do for leisure?

\section{Quality of life.}

1. What are the main expenses on which household income is spent?

2. What is the main mode of transportation used by the family? Record ownership of motorcycle(s), Jeeps, etc.

3. What is the biggest change in your daily life since the system was installed?

4. Has the daily workload become lighter or heavier since the system was installed?

5. Are you happy with your present life situation and that of your family? What would you change, if anything?

6. How do you feel your life compares to the lives of people you see on TV? Do you consider yourself/your family modern or traditional?

7. Which Mongolian rituals/traditions does the family maintain, if any?

8. What are the future aspirations of the children?

9. Does the family spend more or less time together since the system was installed?

10. Given the rapid changes of recent years, do you see a future for the grassland way of life? 


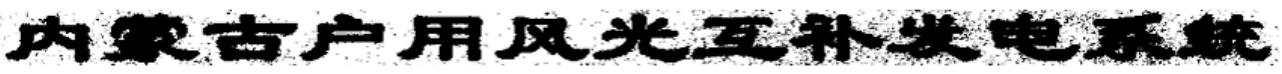 (便用手册)}

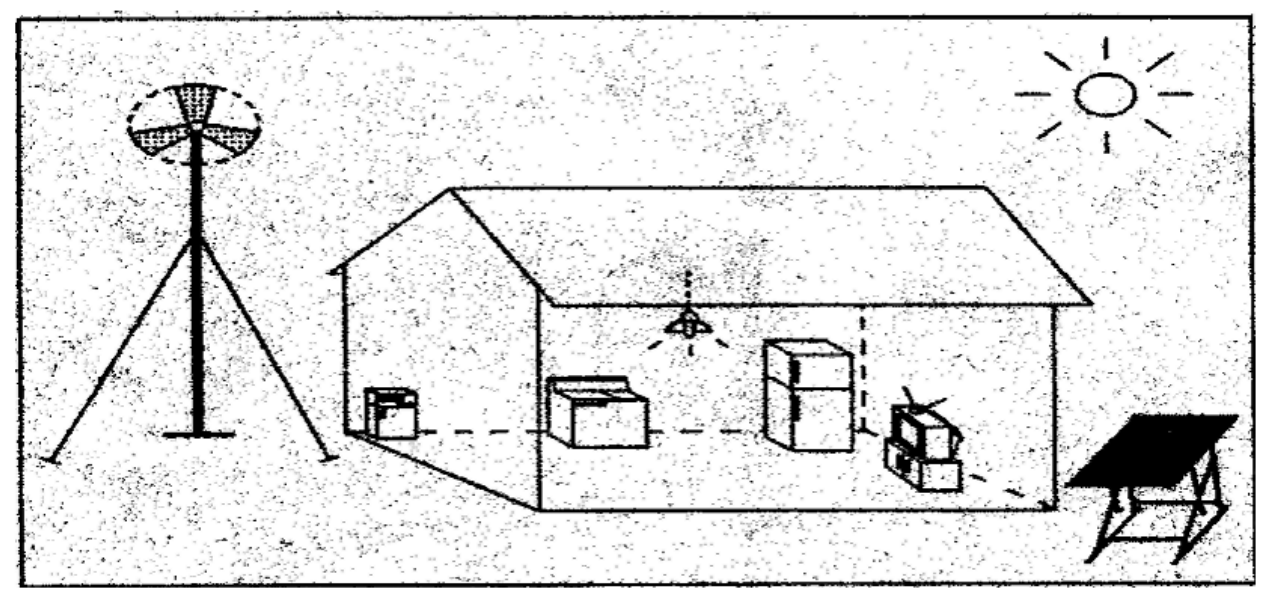

九九九年五月 


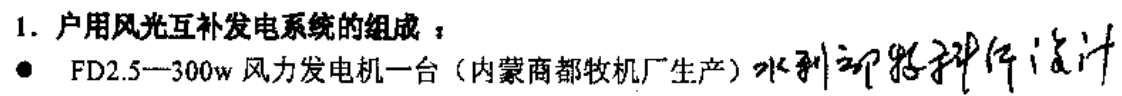

- $150 \mathrm{w}$ 太阴能电池一组 (美国西门子公司生产)

- 150Ah, 36V 堵能铅酸葜电池一组 (哈尔滨蓄电池厂生产的专用电池)

- 500 风光互补逆变器一台 (呼和浩特市电视设备厂生产)

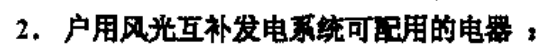

- 彩色电视机一台 (14 吋 21 时) 电功率为 $60 \mathrm{~W} \sim 70 \mathrm{~W}$ 。

- 80 升电冰柜一台(请选购节能型冰柜, 日耗电 $600 \sim 700 \mathrm{WH}$ )

- 7 瓦节能灯三个

- 卫玍电视天线一台

- 洗衣机一台

3. 风力发电机 :

3. 1. FD2.5一-3007 风力发电机的技术数

\begin{tabular}{|c|c|}
\hline 风轮直径: & 2.5 米 \\
\hline 叶片数: & 3 \\
\hline 额定风速: & 8 米/秒 \\
\hline 工作风速范围: & 3 - 25 米/秒 \\
\hline 抗大风能力: & 40 米/秒 \\
\hline 额定功率: & 300 瓦 \\
\hline 最大输出功率: 一申扎 & 500 瓦 \\
\hline 额定工况时效率: & $\geqslant 0.81$ \\
\hline 风能利用系数: & $\geqslant 0.42$ \\
\hline 整机效率: & $\geqslant 0.3$ \\
\hline 调速方式: & 偏侧 在娄 \\
\hline 发电机形式: & 永磁低道二 \\
\hline
\end{tabular}

\section{2. FD2.5一-300w 风力发电机的安装（见图 4)}

1.）安装场地的选择:

场地四周要求平坦开阔, 地质坚硬, 无高于四米的建筑物或树木。风机安装 点要尽量 靠近蓄电池存放处, 最远不得超过贯十米, 否则将因导线太长 “线损” 过大影响对蓄电池的充电。

2. ) 浇灌混㠜土基础:

具体尺寸见图 1, 水泥, 沙子和石子的比例为：1：2：3。浇灌时要找平底座 上平面并使底脚螺栓高出底座上平面 25-30 $\mathrm{mm}$ 并在螺纹上带上长絮母。浇灌后 要养护 48 小时以上。

3.) 安装拉索地脚; 
按 (图 1) 找好位置, 挖三个坑, 把地卡脚螺环放入坑内, 使拉环高出地面 $5 n-70 \mathrm{~mm}$ 浇灌混凝土或用较大的石块压年填入浮土扎实。

4) 组装风轮:

将 15 个 M10 X 80 的螺栓按 (图 2) 穿入叶片座, 把叶片座有凸台的端面 朝上放在地板上, 把三个叶片的迎风面向上分别装在叶片座上, 在叶片上垫合适 的木块用手锤轻轻㪗击使之到位。叶片盖时每个螺栓上必须加弹簧垫, 螺母要 对称拧紧, 力矩要均匀敉。紧。

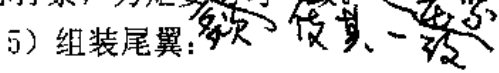

将尾翼板立起, 从喷字面穿入 $M 8 \times 65$ 和 $M 8 \times 20$ 的螺栓, 把尾翼板按（图 3) 安装在尾梁上, 加平垫和弹垫拧紧每个螺母。注意: 当尾翼板立放时缓冲器应在 尾翼板喷字面的对面。

6) 组装底座:

调节好长螺母上平面的高度, 把底架和底座用轴销联接在一起, 轴销两端加 平热并插入开口销将销的开口端䢃开。

1) 安装立柱上拉索:

将上, 中, 下三节立柱对插成一体, 插入底座孔中拧紧顶丝。三根拉索一端 用拉钩与立柱环联接另一端与松紧器扣钩联接, 把松紧器螺旋扣放到最长位置与 地卡脚拉环钩联并用 12 号铅丝在各拉环的小孔穿联加固, 防止拉钩脱落造成事 故。

安装好后要拉起立柱, 检查立柱是否位于拉索之间的中心, 是否垂直于地面, 调整无误后放倒。

8) 安装机头;

将立柱上端垫起到便于人安装机头操作的高度, 按 (图 4) 用 6 个 M $12 \times 40$ 的螺栓把上立柱法兰与组合体法兰连接, 加弹整对称打紧螺母, 拧紧扭矩要一致。

用 $M 8 \times 25$ 的螺钉加弹垫把轴藕压盖紧固在回转套上端, 待穿好电线后再装弯 头, 弯头口固定在宣出线的方向。

9) 穿输电线:

将输电线的一端与接线柱接好, 另一端插入组合体顶盖的空心螺栓孔, 沿立 柱内孔送到底座下的空间处抽出。

10)安装风轮, 机头輜, 尾翼:

- 将风轮安装在电机的输出轴上, 用 M16 的螺母加平弹垫和弹垫后拧 紧。

- 用 $M 6 \times 10$ 的三个螺钉加平垫和弹垫把机头帽固定在叶片盖上。

- 绞架下面的孔内装垫套, 将尾翼上的尾绞套插入尾绞架之际, 穿入尾 绞轴, 尾绞轴上下两端分别用 M16 的螺母紧固。

11）安装检查和立机:

- 检查各零部件的安装是否正确; 
- 检查所有螺母, 螺钉的紧固成度;

- 检查回转体和叶轮的转动是否灵活;

- 检查输电线的连接是否正确, 牢固可靠;

- 当上述检查无误后方可立机, 立机时如遇有风天气应将输电线的三相 电线短路避免风轮旋转造成事故。
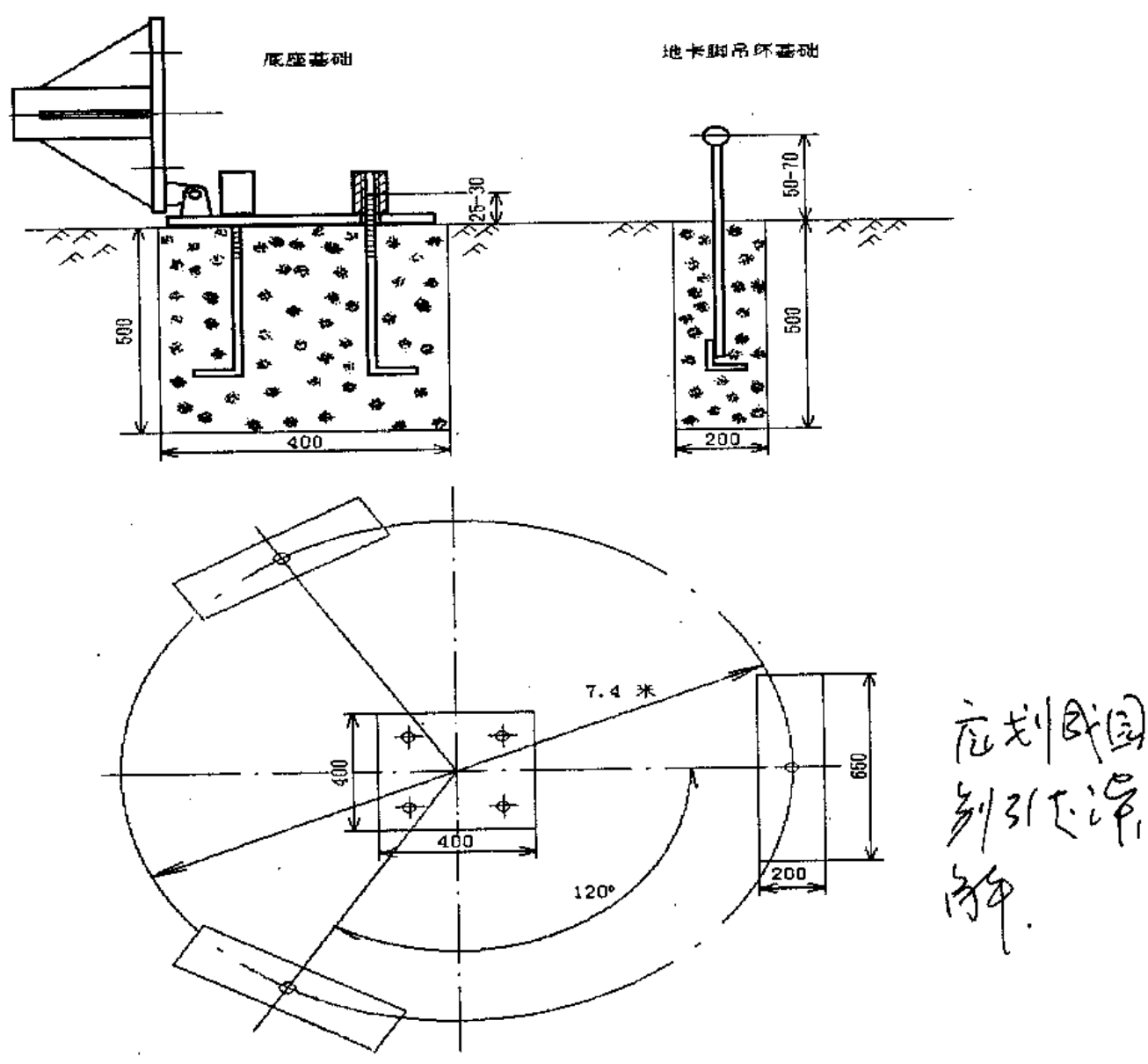

图 1 风机地脚施工图 


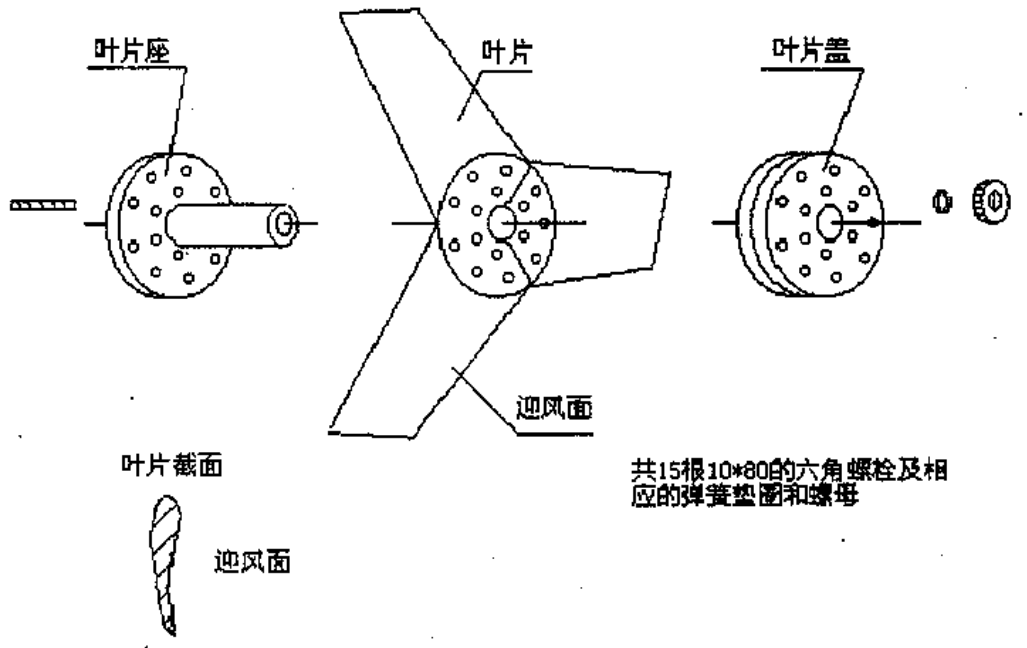

图 2 风轮组装圈

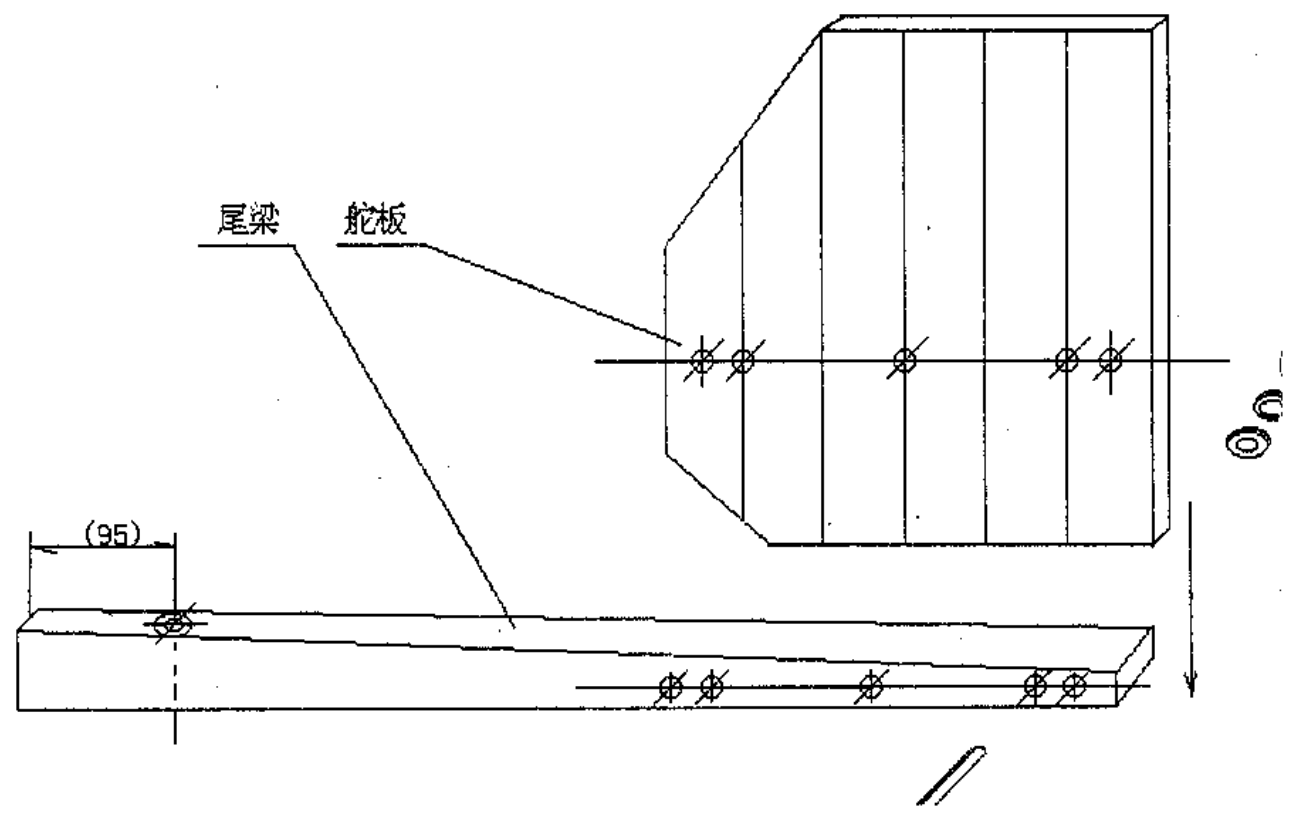

图 3 尾舵组装示意图 


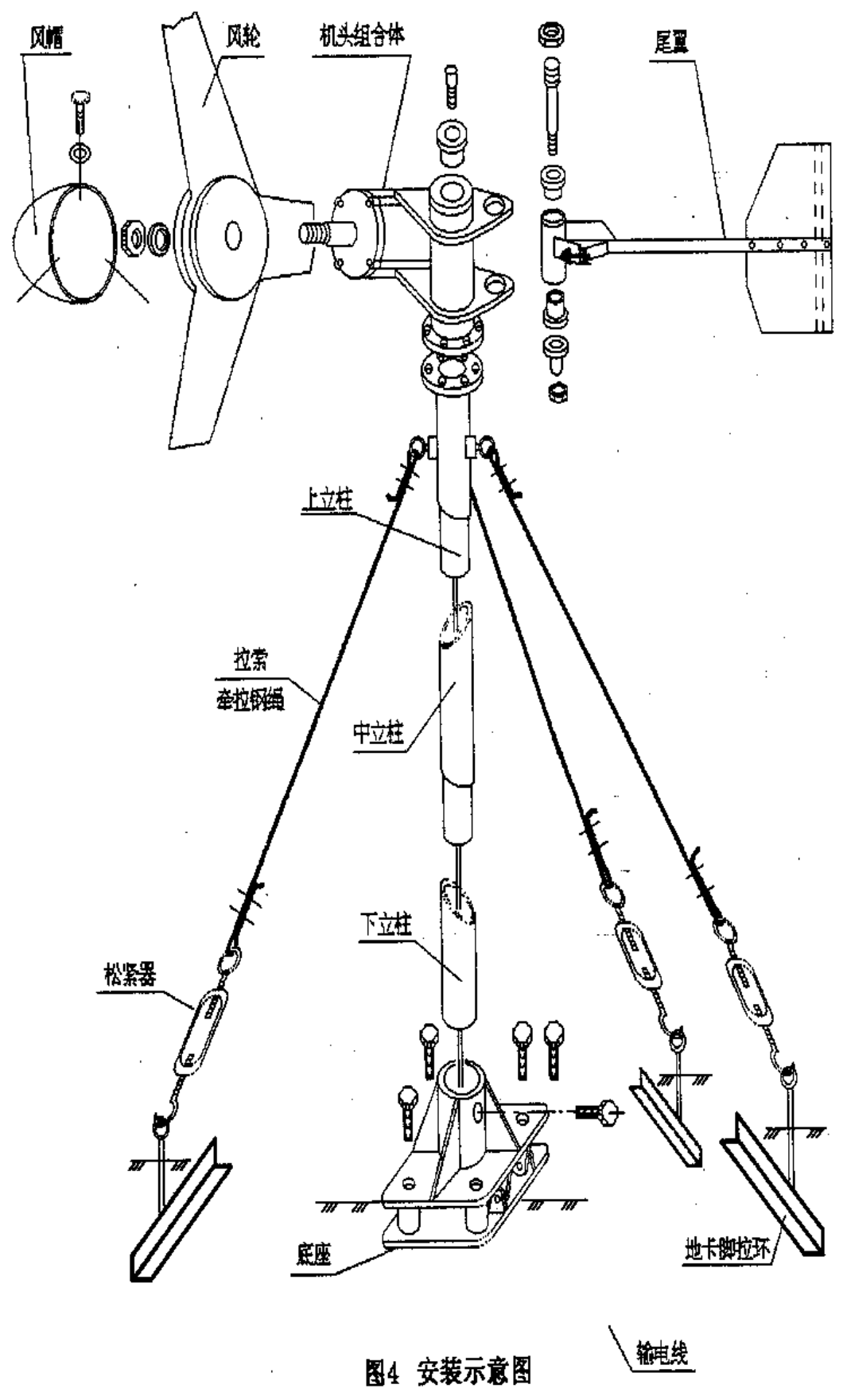




\section{3. 风力发电机组的维护和保养}

1.）经常亘噴地钉, 地锴是否松动或被拔出, 绳夹和紧线扣是否牢靠, 尤其在大 风雨后和春李开化之后。

2.）经常注意风力发电机运转是否平稳, 有无异常杂音, 出现异常要立即停机放 到检查。

3.) 具有刹车机构的风力发电机要经常检查刹车是否可靠。

4.) 风力发电机运转半年或一年后要对转动部件进行一次润滑保养, 如发电机轴 承, 机座回转体等。

\section{4. 风力发电机组的故障及排除}

风力发电机由于质量不断提高。日常运转的故障也就越来越少, 为了使用户 在使用风力发电机时更好地掌挃它, 下面列举一些可能出现的故障及排除方法, 供用户参考。表 1

\section{表 1 风力发电机组的故障及排除}

\begin{tabular}{|c|c|c|}
\hline 故障 & 产生的原因 & 排除方法 \\
\hline $\begin{array}{l}\text { 仦力机剧烈抖 } \\
\text { 动 }\end{array}$ & 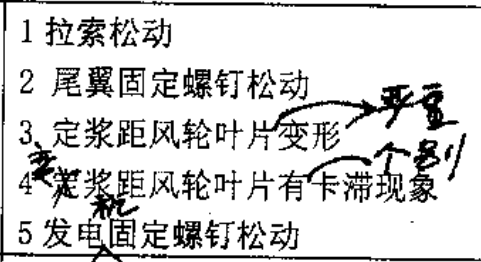 & $\begin{array}{l}1 \text { 紧定拉索 } \\
2 \text { 打紧松动部位 } \\
3 \text { 校正浆叶成更猡 } 01 \text { 片 } \\
4 \text { 拆卸润滑保养, 重新安装 } \\
5 \text { 上好弹簧垫, 紧固螺钉 }\end{array}$ \\
\hline 调向不灵 & $\begin{array}{l}1 \text { 机座週转体内油泥过多 } \\
2 \text { 机座逗转体内有沙土等异物 } \\
3 \text { 风力机摔到过, 立杆上端变形 }\end{array}$ & $\begin{array}{l}1 \text { 润滑保养 } \\
2 \text { 清除异物, 润滑保养 } \\
3 \text { 效正立杆上端 }\end{array}$ \\
\hline 异常杂音 & $\begin{array}{l}1 \text { 各紧固部位有松动之处 } \\
2 \text { 发电机轴承部位松动。 } \\
3 \text { 发电机轴承损坏 或古沟掯脂 } \\
4 \text { 风轮与其他部位摩擦 } \\
5 \text { 发电机转子与定子摩擦（大多 } \\
\text { 是轴承原因） } \\
\end{array}$ & 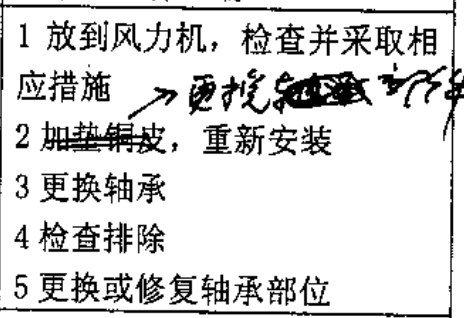 \\
\hline 刹车不灵 & $\begin{array}{l}1 \text { 刹车带磨损过度 } \\
2 \text { 刹车连接部位松动或脱落 }\end{array}$ & $\begin{array}{l}1 \text { 更换刹车带 } \\
2 \text { 检查排除 }\end{array}$ \\
\hline $\begin{array}{l}\text { 风轮转速明显 } \\
\text { 降低 }\end{array}$ & $\begin{array}{l}1 \text { 变浆距风轮叶片复位失灵 } \\
2 \text { 发电机长期不润滑 保养 } \\
3 \text { 发电机轴承损坏 } \\
4 \text { 刹车带与扇车盘摩擦 } \\
5 \text { 风轮叶片变形 }\end{array}$ & $\begin{array}{l}1 \text { 检查排除并润滑保养 } \\
2 \text { 润滑保养 } \\
3 \text { 更换轴承 } \\
4 \text { 重新调整刹抄 } \\
5 \text { 修复或更换叶片 }\end{array}$ \\
\hline
\end{tabular}




\begin{tabular}{|l|l|l|}
\hline 发电机输出电 & 1 有短路部位 & 1 检查排除 \\
压过低或不发 & 2 断路 & 2 检查排除 \\
& 3 整流管损坏 & 3 更换整流管 \\
& 4 保险管烧坏 & 4 首先检查是否有短路负载是 \\
& 5 接线头接触不良 & 否超负荷, 更换保险管 \\
& 6 发电机转子与轴松动 & 5 排除检查 \\
& 7 发电机过热或线圈烧毁 & 6 更换发电机 \\
\hline 蓄电池充不进 & 1 发电机输出电压过低或不发电 & 7 润滑保养或更换发电机 \\
\hline 电 & 2 蓄电池极柱接线锈蚀接触不良 & 2 清除锈蚀, 保持良好导通, \\
& 3 蓄电池报废 & 并涂上凡林防止锈蚀 \\
\hline 供电不足或无 & 见 “发电机输出电压过低或不 & 见更换蓄电池故障的排除方法 \\
电 & 发电”, “蓄电池充不进电” & \\
\hline
\end{tabular}

\section{4. 太阳能电池，}

\section{1. 太阳能电池的技术数}

组件型号:

类型:

串联电池的数目:

额定峰值功率 (Pmax) :

开路电压:

额定电压:

短路电流:

额定电流：
SM55 或 50

单晶硅,

36

$55 \mathrm{Wp}$

$21.7 \mathrm{~V}$

$17.4 \mathrm{~V}$

$3.45 \mathrm{~A}$

3. $15 \mathrm{~A}$

\section{2. 太阳电池方阵的安菇}

1.) 太阳电池方阵由一个或多个平板式太阳电池组件构成。如果组件不止一个, 必须用相同 参数的组件并联或品联。

2.) 太阳电池方阵的组件与支架的连接要案固可靠。

3, ) 调整太阳电池方阵的倾角, 使太阳电地方阵在使用的月份中能够获得最大的能量。

4. ) 太阳电池方阵支架必须按图 5 年固地安装在混凝士基础上。

5.）太阳电池方阵可以安装在屋顶上，但太阳电池方阵与屋顶之间的最小间距要在 5 厘米以

上。安装文架必须与建筑物的主体结构连接, 而不能连接在屋顶材料上。

\section{3. 太阳能电池方阵使用和保等}


应保持太阳能电池方阵采光面的清洁, 如积有友尘、应先用清水冲洗, 然后用干净的纱 布将水迹掽干, 切勿用有腐蚀性的溶剂冲洗, 或用硬物擦拭。週风沙和积雪后, 应及时进行 清扫。一般应至少每月清扫一次。

应注意太阳能电池方阵周围有没有新生长的树木或遮挡太阳光的建筑物, 以免影响太阳 能电池板充分地接收太阳光。一经发现要及时加以处理。

太阳能电池方阵的支架 (见图 5), 可以固定安装, 也可按季节的变化调整电池方阵与地 面的夹角, 以便太阳能电池板更充分地接收太阳光。调整的角度是;

1. ) 春分以后的接收角是当地的纬度减 11 度 48 分;

2. )秋分以后的接收角是当地的纬度加 11 度 48 分:

5. ) 全年平均的接收角是当地的纬度加 5 度。

6. ) 全年不调整的光伏优化倾角可参照表 2 中的数值进行调整。

表 2 优化的光优方阵倾角

\begin{tabular}{|c|c|}
\hline 当地纬度 $(\phi)$ & 优化的光伏方阵倾角 \\
\hline $0-10^{\circ}$ & $\phi+0-5^{\circ}$ \\
\hline $10-20^{\circ}$ & $\phi+5-10^{\circ}$ \\
\hline $20-30^{\circ}$ & $\phi+5-15^{\circ}$ \\
\hline $30-40^{\circ}$ & $\phi+10-15^{\circ}$ \\
\hline $40-50^{\circ}$ & $\phi+15-20^{\circ}$ \\
\hline
\end{tabular}




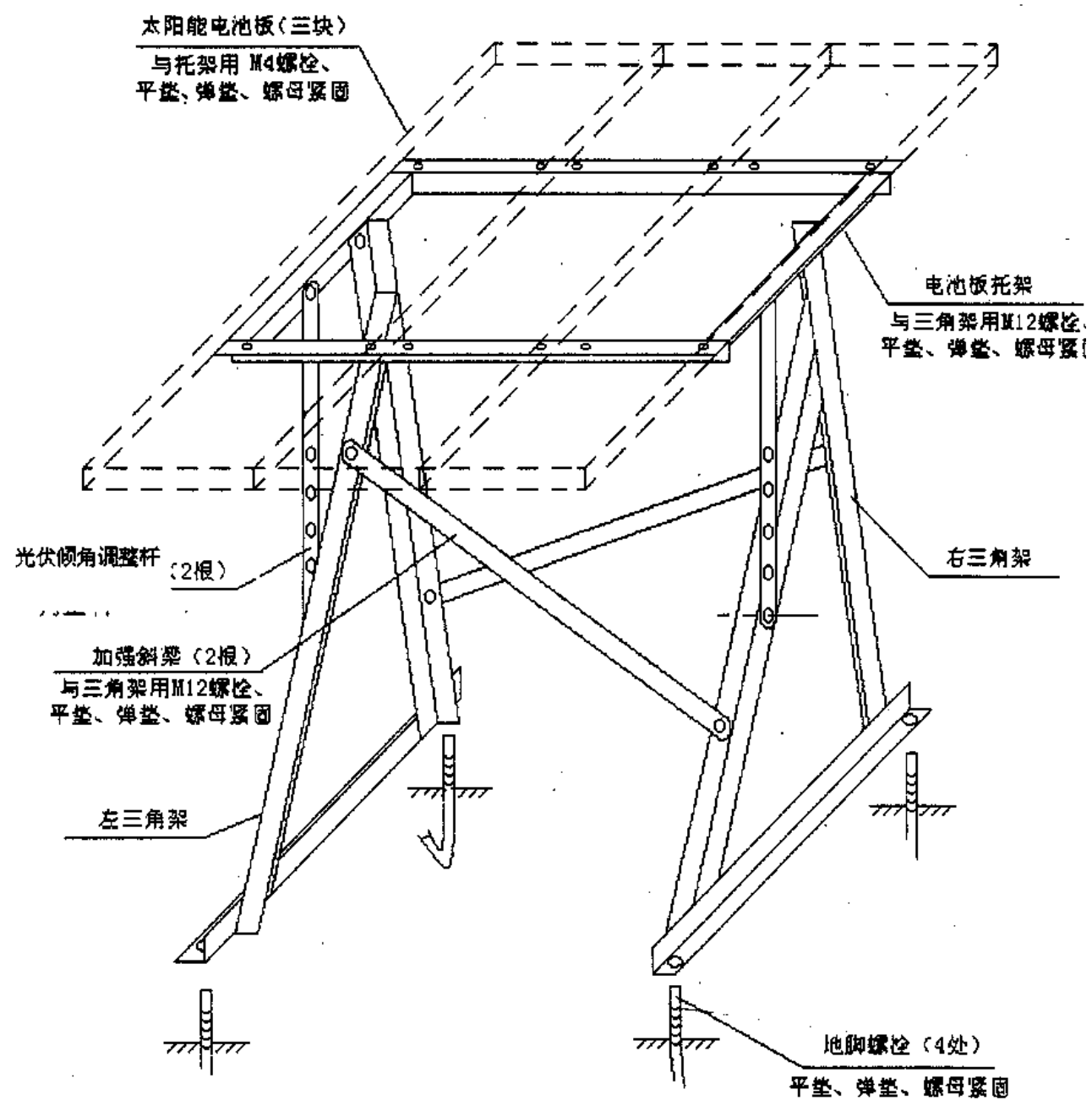

图 5 太阳能电池架示意 
7. 铅酸蓄电池

5. 1. 铅酸蓄电池的技术参数:

型号:

$6 \mathrm{UW}-150$

规格:

$12 \mathrm{~V} / 150 \mathrm{Ah}$

30 小时率额定容量: $\quad 150 \mathrm{Ah}$

20 小时率额定容量: $134.5 \mathrm{Ah}$

10 小时率额定容量: $124.5 \mathrm{Ah}$

外形尺寸：

长 499 , 宽 193 , 高 252

5. 2. 铅酸蓄电池的日常维护

1.）经常检查导线与电池接柱是否松动或腐蚀。极柱和夹头表面要经常保持一层 凡土林油膜。

2. ) 定期检查电解液液面高度 (三个月), 液面应超过隔板顶端 20-25 毫米, 不足 时要及时补充蒸流水。

3.) 一年一次检查蓄电池电解液比重, 让蓄电池充满电静置数小时后, 检测电解 液比重。如发现某一电池格电解液比重低于 1.24 时, 调配比重高的电解液使之达 到正常值 $1.265\left(25^{\circ} \mathrm{C}\right)$, 如发现某一电池格电解液比重高于 1.30 时, 可用蒸流水 进行调整使之达到正常值。

4.) 每隔一至二个月进行一次保护性充电。减少用电量或停止用电使蓄电池完全 充满, 当蓄电池电压和电解液比重达到正常值, 注液口产生强烈气泡时恢复用电。 5.) 蓄电池表面要经常保持清洁, 注液口上的孔塞要旋紧, 液孔塞上的气孔必须 保持畅通, 存放蓄电池的房间要干燥通风环境温度应在 $5-35^{\circ} \mathrm{C}$ 之间。

6.）蓄电池的上面不允许放置任何金属物品, 以免发生短路放电损失。

5. 3. 电解液的配制及灌注

1.）新电池用的电解液比重, 在内蒙地区为 $1.265\left(25^{\circ} \mathrm{C}\right)$ 。

2. ) 电解液的比重随其温度的变化而变化, 所以电解液的比重应注明温度才算准 确。如被测电解液的温度不是 $25^{\circ} \mathrm{C}$ 时, 可按下式换算成 $25^{\circ} \mathrm{C}$ 的比重。

$$
\begin{aligned}
& \mathrm{D} 25=\mathrm{Dt}+\mathrm{a}(\mathrm{t}-25) \\
& \text { 式中: } \mathrm{D} 25 \text { 一换算成 } 25^{\circ} \mathrm{C} \text { 时的比重; } \\
& \mathrm{Dt} \text { 一电解液温度为 } \mathrm{t} \mathrm{C} \text { 时测得的比重; } \\
& \mathrm{t} \text { 一测量比重时电解液的实际温度; } \\
& \mathrm{a}=0.00075 \text { 一温度系数 }
\end{aligned}
$$

3.) 配制电解液时, 应先将所需数量的净化水倒入耐酸、耐温的干净容器内, 再 将一定数量的浓硫酸缓缓地倒入水中, 并用耐酸棒不断地摚拌至均匀。切不可将 水倒入浓硫酸中, 以免賎出伤人。

\section{4。灌注电解液}

1.）待配制好的电解液的温度下降到 $30^{\circ} \mathrm{C}$ 以下时, 即可向电池内灌注。液面高度 
应保持在最高和最低液面线之间。

3.) 非干荷 电池, 在灌注电解液后应静置 4-6 小时, 待温度下降至 $30^{\circ} \mathrm{C}$ 以下时, 即可进行初充电。电池从注入电解液至开始充电, 其间隔时间不得超过 12 小时。 干电荷电池, 在灌注电解液后应静置 30 分钟, 在用直流电压表逐只测量电池的 极性无误后, 即可投入运行。

6. 风光发互补电系统逆变控制器

适用风力发电机功率在 $100 \mathrm{w}$ - $300 \mathrm{w}$ ，太阳能电池功率 $50 \mathrm{w}-200 \mathrm{w}$ 功率组 成的狈光互补发电系统。控制柜包括风力发电控制器, 风力发电泄荷器, 光伏控 制器和 $D C / A C$ 变换器等四部分。

6. 1. 风光发互补电系统逆变控制器的技术参数：

1.) 逆变器:

- 额定输入电压: DC $36 \mathrm{~V}$

- 输出电压; $\mathrm{AC} 220 \mathrm{~V} \pm 10 \%$ (输入电压为额定电压的 $90-120 \%$ 时)

- 输出波形: 方波

- 输出频率: $\quad 50 \mathrm{HZ} \pm 1 \mathrm{HZ}$

- 输出功率: 500 W

- 逆变器效率: $\geqslant 85 \%$ ( $75 \%$ 纯阻性负载时的效率)

- 逆变器噪声; $\leqslant 50 \mathrm{~dB}(\mathrm{~A})$

- 在额定负载 (500W) 下可连续工作 4 小时以上

- 在 1.5 倍的额定负载 (750W) 下可连续工作 1 小时以上

- 在 2.0 倍的额定负载 (1000W) 下可连续工作 2 秒钟以上

- 具有欠压保护, 过流保护, 输出短路保护和输入极性反接保护功能

2.) 充电器: 充电电流. $\leqslant 30 \mathrm{~A}$

3.) 光电控制器:

- 蓄电池单格电压超过 $2.4 \mathrm{~V}$ 时, 自动切断光优充电回路, 小于 $2.1 \mathrm{~V}$ 时恢复充电

- 可承受太阳能电池组件开路电压 1.25 倍 (82V) 的冲击一小时以上。

- 可承受太阳能电池组件短路电流 1.25 倍 (13A) 的冲击一小时以上。

- 具有防止蓄电池通过太阳能电池反向放电的功能

- 具有正负极反接保护和短路保护功能

4. ) 风电控制器:

- 可承受风力发电机额定电压 2.0 倍 (72V) 的冲击一小时以上。

- 可承受风力发电机额定电流 2.0 倍 $(20 \mathrm{~A})$ 的冲击一小时以上。

- 具有正负极反接和短路保护功能 
5.) 泄荷器: 泄荷功率 $\nless 600$ W

6. 2. 逆变控制器的安装:

请先仔细阅读安装示意图, 并按下列顺序操作

1.) 将逆变控制器电源开关置于关闭状态

2.) 按图 把串联好的蓄电池组接入逆变控制器上蓄电池的接线端子

3.) 按图 用专用导线把太阳能电池组的正负极接入逆变控制器上相对应的接线 端子。

4.) 把风力发电机的三根导线接入逆变控制器上的相对应接线端子。

5.) 按接线图进行仔细核查, 确认无误且接线审靠后, 将逆变控制器开关置于开 启状态, 在正常工作指示灯亮后, 表示逆变控制器工作正常, 可以供电。

6. 3. 使用条件:

1.) 环境温度: -10 至 $+40^{\circ} \mathrm{C}$ 。

2.) 逆变控制器应放在通风良好, 无导电易爆尘埃, 没有腐蚀性气体的地方。

3. ) 在逆变控制器 1 米之内不得堆放易燃易爆物品, 在逆变控制器上严禁烘烤衣 物, 以防引起火灾。

6. 4. 注意事项:

1. ) 本逆变控制器没有功率因数自动调节功能, 所以经常同时开启家用电器的总 功率不要大于逆变控制器额定功率的 $65 \%$ ( $325 \%) 。$

2. ) 请不要把使用寿命即将到期的旧蓄电池接入逆变控制器, 也不要将不同型号 不同规格的蓄电池接如逆变控制器。

3. ) 经常注意观察指示灯的变化情况, 如发现过热指示灯亮并关闭逆变器时, 要 即时减少用电设备, 逆变控制器将会自动恢复供电。

4.) 如发现欠压保护指示灯亮时, 说明蓄电池容量只剩下 $20 \%$, 待蓄电池容量大 于 $20 \%$ 时逆变控制器将自动恢复供电。, 

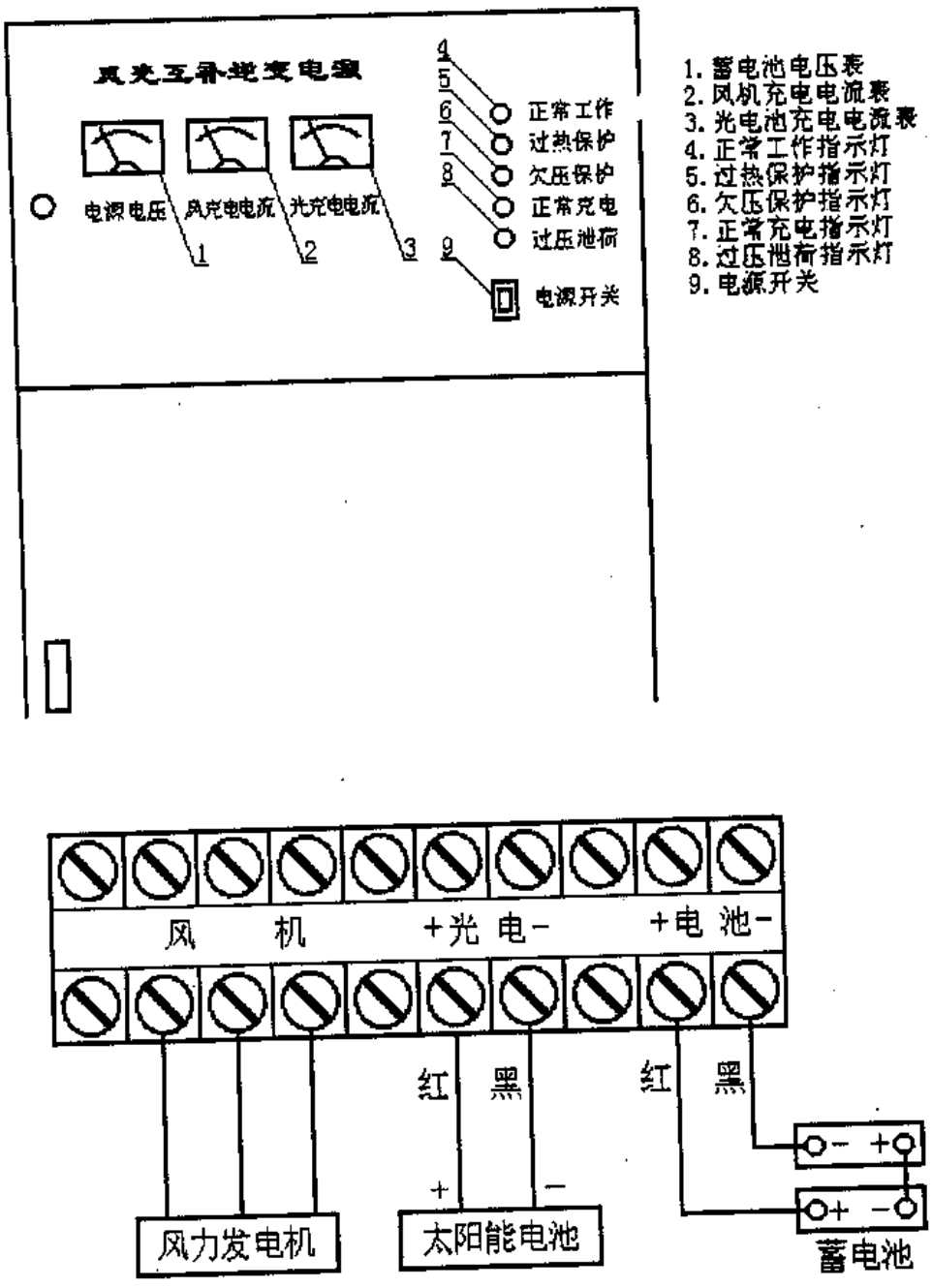


\section{APPENDIX C. User manual-English translation}

\section{Inner Mongolia Household PV/Wind Hybrid Power System}

1. Components of household PV/wind hybrid power system:

- FD2.5-300W wind machine (produced by Livestock Machinery Factory, Shangdu, Inner Mongolia)

- $150 \mathrm{~W}$ PV array (produced by Siemens or Solarex, USA)

- 150Ah, 36V battery bank (Haerbin Battery Factory's special products)

- $500 \mathrm{~W}$ DC/AC inverter (TV set Device Factory, Hohhot)

2. Appliances supported by system:

- Color TV (14-21-inch), power range 60-70W

- 80 liter refrigerator (energy-saving model is recommended; 600-700Wh/day)

- $7 \mathrm{~W}$ light bulbs (energy-saving) (up to three)

- Satellite TV antenna

- Washing machine

3. Wind machine

3.1 FD 2.5-300W wind machine technical parameters:

Rotor diameter

Number of blades

Rated wind speed

$2.5 \mathrm{~m}$

Working speed range

3

Maximum wind speed

$8 \mathrm{~m} / \mathrm{s}$

$3-25 \mathrm{~m} / \mathrm{s}$

Rated power

$40 \mathrm{~m} / \mathrm{s}$

Maximal output power

$300 \mathrm{~W}$

Rated working condition efficiency

$500 \mathrm{~W}$

Energy capturing efficiency

Total efficiency

$\geq 0.77$ wind

$\geq 0.42$

$\geq 0.3$

Overspeed control

horizontal furling

Generator

permanent magnetic inductive alternator

\subsection{Installation of FD2.5-300W wind machine (see Figure 4)}

1) Siting:

The wind machine should always be located far away from trees and/or buildings, in order to maximize its exposure to wind. It should also be erected as near to the battery bank as possible (no further than 40 meters); otherwise the line loss will deteriorate its charging condition.

2) Foundations:

Dimensions are described in Figure 4; cement, sand and gravel should be mixed in a $1: 2: 3$ ratio. The top surface of the base tower should be kept horizontal while pouring concrete. Bolts should be exposed $25-30 \mathrm{~mm}$ above the upper surface, and all bolts accompanied with nuts. The concrete should set for at least 48 hours.

3) Anchors: 
Position the 3 anchors according to Figure 4, excavating 3 holes, and make sure all guy cable hooks are $50-70 \mathrm{~mm}$ above ground. All anchors should be fixed by concrete or big stones.

4) Installation of blades:

First, the $15 \mathrm{M} 10 \mathrm{X} 80$ bolts are put into screws located in the hub, then the hub is put on the ground with its flange upwards. The three blades are installed with their upwind side upward. If the blades are not located in their proper position, you can correct this with a hammer, the billet used as a bumper. Remember a washer is needed when screwing in the nuts, and uniform torque is appreciated.

5) Tail vane (see Figure 3)

To erect the tail vane, first affix the M8X65 and M8X20 bolts from the side which contains writing. Then the tail vane can be fixed upon the tail tube. Remember both washers and spring washers are needed when screwing every nut. Attention: when the tail vane is erected the bumper is opposite to the side with printings.

6) Base:

Make the upper base plate level by adjusting the height of the long bolts. The mast is hinged by a pin, both ends of the pin are affixed with a washer, and the open end of the pin is fixed by a cotter pin.

7) Guy cables:

Connect the three parts of the mast through the joint flange, insert the bottom end of the lower mast into the seat on the upper base plate and fix them with a positioning screw. One end of the guy cable connects to the mast, the other end connects to the tension regulator, then connects to the anchor hook. First the bolts of the tension regulator are screwed to its longest position, then screw the bolts to strain guy cables. Finally fasten all the hooks with lead wire. Erect the mast to check whether it is located at the center of the anchors, whether it is perpendicular to the ground, and that it is adjusted to the right position.

8) Connecting nacelle to the mast:

For ease of installation the mast should be raised to its proper height (Figure 4); six M12X40 bolts are needed to accomplish the connection of the nacelle and mast. Spring washers and uniform torque are necessary. The cap of the bearing is connected to the upper end of the revolution cannula by M8X25 bolts with a spring washer.

9) Wiring:

The leads from the generator are connected to the wires that run down the mast tube through the hollow bolt on top of the nacelle.

10) Installation of hub, diversion cap and tail vane:

- Hub is connected to the output shaft through M16 bolts, washers, and spring washers.

- Diversion cap is connected to the hub using M10X10 bolts, washers and spring washers.

- Tail vane is connected to the nacelle through hinge, hinge shaft, nylon bush and M16 nuts.

11) Checking the installation:

- Check the tightness of all the bolts and nuts.

- Check the smoothness of revolution parts and the blades when working.

- Check the accuracy of wire connections and their reliabilities.

- The wind machine can be erected after finishing all of the check items. Short-circuit 
the output of the wind machine while erecting to avoid an accident.

\subsection{Maintenance}

1) Always examine whether the anchors or mast base become loose, whether guy cable is damaged, and especially whether the earth becomes loose after storms or the winter.

2) Pay attention to the operating state of the wind machine, stop it whenever any unusual phenomena occurs including abnormal noise or swaying.

3) Wind machines with a brake system should often be checked for reliability.

4) The wind machine has grease fittings on its bearings; they should all be greased semiannually, including the generator shaft and nacelle revolution part.

\subsection{Troubleshooting}

The wind machine is a matured product, so problems should be infrequent. However, mastering some ability for troubleshooting is still helpful.

Table 1. Troubleshooting guide

\begin{tabular}{|c|c|c|}
\hline Problem & Cause & Corrective action \\
\hline \multirow{5}{*}{$\begin{array}{l}\text { Acute } \\
\text { shaking of } \\
\text { the wind } \\
\text { machine }\end{array}$} & Loose guy cable & Tighten the guy cable \\
\hline & Loose securing bolts in tail vane & Tighten the loose parts \\
\hline & Distortion of blades & Rectify the blades \\
\hline & Hub cannot turn smoothly & Disassemble and reassemble \\
\hline & Securing bolts of generator become loose & Tighten bolts with spring washer \\
\hline \multirow{2}{*}{$\begin{array}{l}\text { Trouble in } \\
\text { changing } \\
\text { direction }\end{array}$} & $\begin{array}{l}\text { Revolution part is dirty or is full of sand } \\
\text { or gravel }\end{array}$ & Clean and grease \\
\hline & $\begin{array}{l}\text { The upper end of the mast was distorted } \\
\text { by accident }\end{array}$ & Correct the distortion \\
\hline \multirow{5}{*}{$\begin{array}{l}\text { Abnormal } \\
\text { noise }\end{array}$} & The fastened part has become loose & $\begin{array}{l}\text { Take down the wind machine and } \\
\text { tighten the loose part }\end{array}$ \\
\hline & The generator's bearing is loose & Add copper cushion, reassemble \\
\hline & Damage to generator's bearing & Replace bearing \\
\hline & Hub is rubbing the other part & Check and rectify \\
\hline & Friction between rotor and stator & $\begin{array}{l}\text { Replace or repair pertinent } \\
\text { bearings }\end{array}$ \\
\hline \multirow{2}{*}{$\begin{array}{l}\text { Failure of } \\
\text { brake } \\
\text { system }\end{array}$} & Brake bracket is worn out & Replace the brake bracket \\
\hline & Loose or lost joint of brake & Check and rectify \\
\hline \multirow{5}{*}{$\begin{array}{l}\text { Blades' } \\
\text { rotating } \\
\text { speed drops } \\
\text { dramatically }\end{array}$} & Failure to restore the blades & Check and grease \\
\hline & Generator not greased for a long time & Grease \\
\hline & Generator's bearing is damaged & Replace bearing \\
\hline & Brake system does not work properly & Readjust the brake system \\
\hline & Distortion of blades & Repair or replace the blades \\
\hline \multirow{3}{*}{$\begin{array}{l}\text { Generated } \\
\text { voltage is }\end{array}$} & Short circuit & Check and correct \\
\hline & Open circuit & Check and correct \\
\hline & Failure of rectifying tube & Replace rectifying tube \\
\hline
\end{tabular}




\begin{tabular}{|c|c|c|}
\hline \multirow{4}{*}{$\begin{array}{l}\text { too low or } \\
\text { without } \\
\text { output } \\
\text { voltage }\end{array}$} & Fuse error & $\begin{array}{l}\text { Check for short circuit load or } \\
\text { overload; replace fuse }\end{array}$ \\
\hline & Bad connection to the lead & Check and rectify \\
\hline & $\begin{array}{l}\text { Connection between rotator and shaft (of } \\
\text { generator) is loose }\end{array}$ & Replace generator \\
\hline & Generator overheat & Grease or replace generator \\
\hline \multirow{3}{*}{$\begin{array}{l}\text { Fail to } \\
\text { charge } \\
\text { batteries }\end{array}$} & $\begin{array}{l}\text { Generated voltage is too low or is without } \\
\text { output voltage }\end{array}$ & Refer to the above \\
\hline & Corrosion of lead batteries & $\begin{array}{l}\text { Clean corrosion and cover it with } \\
\text { Vaseline }\end{array}$ \\
\hline & Damage to battery & Replace battery \\
\hline $\begin{array}{l}\text { Insufficient } \\
\text { or no power } \\
\text { supply }\end{array}$ & $\begin{array}{l}\text { Refer to 'Generated voltage is too low or } \\
\text { without output voltage' \& 'Fail to charge } \\
\text { batteries,' above }\end{array}$ & See above \\
\hline
\end{tabular}

\section{PV array}

\subsection{Technical specification of PV modules}

Model:

Type:

Number of cell in series

SM55/50

Rated maximal power (Pmax)

Mono-crystalline silicon

Open circuit voltage

36

Rated voltage

$55 \mathrm{Wp}$

$21.7 \mathrm{~V}$

$17.4 \mathrm{~V}$

Short circuit current

$3.45 \mathrm{~A}$

Rated Current

$3.15 \mathrm{~A}$

\subsection{Installation of PV array}

1) The PV array is made up of one or more PV modules. In case of more than one component, they must be assembled in a parallel series by components with uniform parameters.

2) The connection between the PV array and rack must be reliable.

3) Adjust the tilt angle of the PV array every month to capture as much solar energy as possible.

4) The rack of the PV array must be fastened on a concrete foundation.

5) The PV array can be mounted on the roof, but the distance between the PV array and the roof must be greater than $5 \mathrm{~cm}$. The installation rack must connect to the main construction of the buildings, not just the roof.

\subsection{Maintenance of PV array}

Always keep the surface of the PV array clean. If there is dust accumulation, wash it with fresh water, and then dry it with gauze. Never use caustic solvent or hard ware in cleaning. Clean after sand or snow storms. The array should be cleaned monthly.

Avoid locating the PV array in the shadow of trees or buildings, which will significantly reduce its capture of solar energy. 
The rack of the PV array should maintain a constant tilt angle or be changed with the seasons; the latter will guarantee the PV array's best performance. Below is the recommended procedure for adjusting the tilt angles:

1) The tilt angle should be equal to local latitude minus $11^{\circ} 48^{\prime}$ after vernal equinox.

2) The tilt angle should be equal to local latitude plus $11^{\circ} 48^{\prime}$ after autumnal equinox.

3) The average tilt angle is $5^{\circ}$ greater than local latitude.

4) The recommended constant tilt angle can be chosen from Table 2.

Table 2. Optimized PV array tilt angles.

\begin{tabular}{l|l}
\hline Local latitude $(\Phi)$ & Optimized PV array tilt angle \\
$0-10$ & $\Phi+0-5^{\circ}$ \\
$10-20$ & $\Phi+5-10^{\circ}$ \\
$20-30$ & $\Phi+5-15^{\circ}$ \\
$30-40$ & $\Phi+10-15^{\circ}$ \\
$40-50$ & $\Phi+15-20^{\circ}$ \\
\hline
\end{tabular}

\section{Lead acid battery}

\subsection{Technical specifications of lead acid battery:}

Model

Parameters

Rated capacity for $30 \mathrm{~h}$

Rated Capacity for $20 \mathrm{~h}$

Rated capacity for $10 \mathrm{~h}$

Size
$6 \mathrm{UW}-150$

$12 \mathrm{~V} / 150 \mathrm{Ah}$

$150 \mathrm{Ah}$

$134.5 \mathrm{Ah}$

$124.5 \mathrm{Ah}$

499 X 193 X 252

\subsection{Maintenance of Battery}

1) Always check the connection between the lead and wire, and determine whether the battery lead is rusted. The lead and clamp are always anointed with a Vaseline film.

2) Check the electrolyte level every 3 months. Make sure the surface of the electrolyte is 20$25 \mathrm{~mm}$ beyond the lead plate, or you'll have to refill with distilled water.

3) Check the specific gravity of the electrolyte annually. Charge the battery to its maximal capacity and keep it undisturbed for several hours, then the specific gravity of the electrolyte is measured. If the electrolyte specific gravity of a certain cell of battery is below $1.24 \mathrm{~kg} /$ liter, refill with a thicker electrolyte to keep its normal value of 1.265 $\left(25^{\circ} \mathrm{C}\right)$; if the electrolyte specific gravity of a certain cell is past 1.30 , refill with distilled water to adjust to the normal value.

4) Give the battery a protective charge monthly or bi-monthly. Reduce power consumption, or stop output power entirely to charge the battery fully. When the voltage and electrolyte of the battery reach their normal value and bubbles escape from the refill opening rapidly, then the battery can resume normal power supply.

5) Always keep the surface of the battery clean, make sure the refill opening is sealed, and maintain good ventilation and dry conditions in storage area. The environment temperature should be kept in the range of $5-35^{\circ} \mathrm{C}$

6) Never place metal on top of the battery to avoid short circuit. 


\subsection{Preparation and refilling of electrolyte}

1) Specific gravity of the electrolyte should be 1.265 (Inner Mongolia, $25^{\circ} \mathrm{C}$ )

2) Since the specific gravity varies with temperature, it must be adjusted according to the temperature. If the temperature of the electrolyte is not $25^{\circ} \mathrm{C}$, specific gravity must be converted given $25^{\circ} \mathrm{C}$ using the following formula:

$D_{25}=D_{t}+a(t-25)$

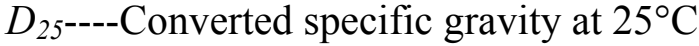

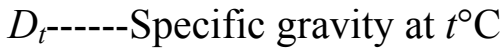

$t$--------Environment temperature when measuring

$\mathrm{a}=0.00075$--------Temperature coefficient

3) In preparing the electrolyte, the proper amount of distilled water must be poured into a vessel, and then a corresponding amount of oil of vitriol is poured slowly into the water. Stir while pouring; never pour water into oil of vitriol.

\subsection{Refilling the electrolyte}

1) When the temperature of the electrolyte drops below $30^{\circ} \mathrm{C}$, it can be poured into the battery. The level of electrolyte should be kept between the highest and lowest position.

2) In preparing the new battery, it must remain undisturbed after pouring the electrolyte for 4-6 hours. The first time of charge begins when the electrolyte temperature drops below $30^{\circ} \mathrm{C}$. The procedure of pouring electrolyte and first time of charge must be finished within 12 hours. For a dry battery, 30 minutes after pouring the electrolyte its polarity can be tested by a DC voltmeter. If there is no error, the battery is ready to be used.

\section{Inverter controller in $\mathrm{PV} /$ wind hybrid power system}

The inverter controller can be used in a system where the power of the wind machine ranges from $100 \mathrm{~W}$ to $300 \mathrm{~W}$ and the power of the PV array ranges from $50 \mathrm{~W}$ to $200 \mathrm{~W}$. The controller includes the wind machine controller, wind machine dump load controller, PV controller and $\mathrm{DC} / \mathrm{AC}$ transformer.

\subsection{Technical specification of inverter controller:}

1) Inverter:

- Rated input voltage

- Output voltage

- Output wave form

- Output frequency

- Output power

- Efficiency

- Noise level

- Continuous work with rated load (500W)

- Continuous work with $150 \%$ rated load $(750 \mathrm{~W})$ at least 1 hour

- Continuous work with $200 \%$ rated load (1000W)at least 2 seconds

- Protects against under-voltage, over-current, output short-circuit and input polarity misconnection.

2) Charge controller:

- Charging current

DC $36 \mathrm{~V}$

AC $220 \mathrm{~V} \pm 10 \%$ (input voltage ranges $90-120 \%$ of rated input

rectangular wave

$50 \mathrm{HZ} \pm 1 \mathrm{HZ}$

$500 \mathrm{~W}$

$\geq 85 \%$ ( $75 \%$ resistive load)

$\leq 50$ decibels (A)

at least 4 hours 
3) PV Controller:

- Auto switch off PV charger when certain battery cell voltage is higher than $2.4 \mathrm{~V}$; turn it on when voltage is below $2.1 \mathrm{~V}$.

- Capable of enduring at least 1 hour of $125 \%$ open circuit voltage of PV module (82V)

- Capable of enduring at least 1 hour of $125 \%$ short circuit current of PV module (13A)

- Capable of preventing discharge of battery through PV module

- Protects against misconnection in polarities and short circuit

4) Wind machine controller

- Capable of enduring 2 times the wind machine's rated voltage (72V) for at least 1 hour

- Capable of enduring 2 times the wind machine's rated current (20A) for at least 1 hour

- Protects against misconnection in polarities and short circuit

5) Power of dump load: $\leq 600 \mathrm{~W}$

\subsection{Installation of inverter controller}

Please examine the installation diagram carefully, and then operate as follows:

1) Turn off the inverter controller

2) Connect the battery bank to the corresponding terminals on the inverter controller

3) Connect the PV array to the corresponding terminals on the inverter controller with a special cable

4) Connect the three wires of the wind machine to the corresponding terminals on the inverter controller

5) Check wiring. Make sure there are no errors; turn on the inverter controller. The normal working indicator lights show that the inverter controller is ready to output power

\subsection{Operating condition:}

1) Environment temperature: $-10-40^{\circ} \mathrm{C}$

2) Maintain good ventilation; keep away from caustic gas, flammable and explosive materials.

3) Never store flammable and explosive materials near the inverter controller; never dry clothes on it

\subsection{Attention:}

1) Since the inverter controller cannot automatically regulate its power factor, it is recommended that the total power of electric appliances used daily not exceed $65 \%$ of its rated output $(325 \mathrm{~W})$ for daily use.

2) Never use a nearly destroyed battery or battery of different type or model to form the battery bank of the power system.

3) Always pay attention to the variation of the indicator. If the overheat indicator light is on, turn off some electrical equipment that was being used. The inverter controller will resume normal power supply automatically.

4) If the under-voltage indicator light is on, this indicates that only $20 \%$ capacity remains in the battery. The system will resume supply of power after the battery capacity exceeds $20 \%$. 


\section{REPORT DOCUMENTATION PAGE}

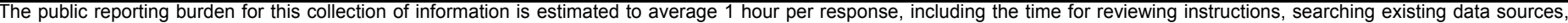

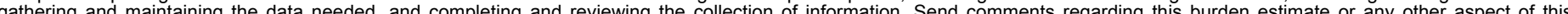

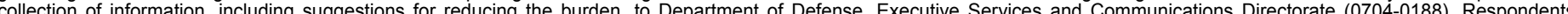

chould be aware that notwithstanding any other provision of law, no person shall be subject to any penally

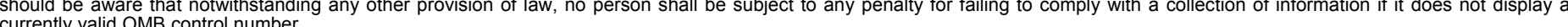

PLEASE DO NOT RETURN YOUR FORM TO THE ABOVE ORGANIZATION.

\begin{tabular}{l|l|l|l} 
1. REPORT DATE $(D D-M M-Y Y Y Y)$ & 2. REPORT TYPE & 3. DATES COVERED (FrOm - TO)
\end{tabular}

February 2005

4. TITLE AND SUBTITLE

DOE/NREL Inner Mongolia PV/Wind Hybrid Systems Pilot Project:

A Post Installation Assessment

5a. CONTRACT NUMBER

DE-AC36-99-G010337

5b. GRANT NUMBER

5c. PROGRAM ELEMENT NUMBER

6. AUTHOR(S)

K.K. Stroup

5d. PROJECT NUMBER

NREL/TP 710-37678

5e. TASK NUMBER

IGIN.5300

5f. WORK UNIT NUMBER
7. PERFORMING ORGANIZATION NAME(S) AND ADDRESS(ES)

National Renewable Energy Laboratory

1617 Cole Blvd.

Golden, CO 80401-3393
8. PERFORMING ORGANIZATION REPORT NUMBER

NREL/

9. SPONSORING/MONITORING AGENCY NAME(S) AND ADDRESS(ES)

10. SPONSOR/MONITOR'S ACRONYM(S) NREL

11. SPONSORING/MONITORING AGENCY REPORT NUMBER

12. DISTRIBUTION AVAILABILITY STATEMENT

National Technical Information Service

U.S. Department of Commerce

5285 Port Royal Road

Springfield, VA 22161

13. SUPPLEMENTARY NOTES

14. ABSTRACT (Maximum 200 Words)

This report assesses the Inner Mongolia Pilot Project, which disseminates wind-solar hybrid systems to a rural and remote population.

15. SUBJECT TERMS

Mongolia; rural electrification; wind-solar hybrid systems; rural energy; China; diesel-powered generator and battery sets (gen-sets)

\begin{tabular}{l|l|l|}
\hline \multicolumn{3}{|l|}{ 16. SECURITY CLASSIFICATION OF: } \\
\hline \begin{tabular}{l|l|l} 
a. REPORT \\
Unclassified
\end{tabular} & $\begin{array}{l}\text { b. ABSTRACT } \\
\text { Unclassified }\end{array}$ & $\begin{array}{l}\text { c. THIS PAGE } \\
\text { Unclassified }\end{array}$ \\
\hline
\end{tabular}

\begin{tabular}{l|l} 
17. LIMITATION & 18. \\
OF ABSTRACT & OF PAGES \\
UL &
\end{tabular}

19a. NAME OF RESPONSIBLE PERSON

19b. TELEPHONE NUMBER (Include area code) 